FEDERAL RESERVE BANK OF SAN FRANCISCO

WORKING PAPER SERIES

\title{
Taking the Fed at its Word: A New Approach to Estimating Central Bank Objectives using Text Analysis
}

\author{
Adam Hale Shapiro and Daniel Wilson \\ Federal Reserve Bank of San Francisco \\ January 2021 \\ Working Paper 2019-02 \\ https://www.frbsf.org/economic-research/publications/working-papers/2019/02/
}

\section{Suggested citation:}

Shapiro, Adam Hale, Daniel Wilson. 2021. "Taking the Fed at its Word: A New Approach to Estimating Central Bank Objectives using Text Analysis," Federal Reserve Bank of San Francisco Working Paper 2019-02. https://doi.org/10.24148/wp2019-02

The views in this paper are solely the responsibility of the authors and should not be interpreted as reflecting the views of the Federal Reserve Bank of San Francisco or the Board of Governors of the Federal Reserve System. 


\title{
Taking the Fed at its Word: A New Approach to Estimating Central Bank Objectives using Text Analysis*
}

\author{
Adam H. Shapiro ${ }^{\dagger}$ and Daniel J. Wilson ${ }^{\ddagger}$ \\ $1 / 30 / 21$
}

\begin{abstract}
We propose a new approach to estimating central bank preferences, including the implicit inflation target, that requires no priors on the underlying macroeconomic structure nor observation of monetary policy actions. Our approach entails directly estimating the central bank's objective function from the sentiment expressed by policymakers in their internal meetings. We apply the approach to the objective function of the U.S. Federal Open Market Committee (FOMC). The results challenge two key aspects of conventional wisdom regarding FOMC preferences. First, the FOMC had an implicit inflation target of approximately $1 \frac{1}{2}$ percent on average over our baseline 2000 - 2011 sample period, significantly below the commonly-assumed value of 2. Second, the FOMC's loss depends strongly on output growth and stock market performance and less so on their perception of current economic slack.
\end{abstract}

${ }^{*}$ We thank Shelby Buckman, Lily Huang, and Ben Shapiro for superb research assistance and we thank the team of FRBSF research assistants who participated in the human audit study for this paper. We are indebted to Moritz Sudhof for his help with parsing the FOMC text data by speaker and general advice on text analysis. We thank Regis Barnichon, Vasco Curdia, Richard Dennis, John Fernald, Christopher Gibbs, Matthew Gentzkow, Ben Johannsen, Michael McMahon, Victoria Nuguer, Glenn Rudebusch, John Williams, and four anonymous referees for invaluable feedback on the project. The paper benefitted from comments and suggestions by seminar participants at the Federal Reserve Board, Federal Reserve Bank of San Francisco, National Association of Business Economists, the Central Bank of Brazil Annual Inflation Targeting Conference, and the Quantitative Macroeconomics Workshop at Reserve Bank of Australia. The views expressed in this paper are solely those of the authors and do not necessarily reflect the views of the Federal Reserve Bank of San Francisco, or the Board of Governors of the Federal Reserve System.

${ }^{\dagger}$ Federal Reserve Bank of San Francisco, adam.shapiro@sf.frb.org

${ }_{\ddagger}^{\ddagger}$ Federal Reserve Bank of San Francisco, daniel.wilson@sf.frb.org 
I'm bemused by the de facto inflation targeters that we have become here [laughter] with the 1.5 percent goal.

- Ben Bernanke, Chairman of the Federal Reserve

September 2006 FOMC Meeting

\section{Introduction}

What is the central bank's objective function? This is a core question of monetary macroeconomics. The canonical model assumes that the central bank has quadratic preferences over inflation, relative to a known target, and economic slack (Walsh (2017)). Although there is broad consensus on what the central bank objective function should look like based on the large literature on optimal monetary policy, there has been very little study of what the central bank objective function actually is in practice. The dearth of positive analysis of the central bank objective function is surprising considering it is implicitly the foundation underlying monetary policy choices. Moreover, the sparsity is certainly not due to a belief that the objective function is well understood. For example, even the functional form, much less the parameters, is not widely agreed upon. As Blinder (1997) argued, "academic macroeconomists tend to use quadratic loss functions for reasons of mathematical convenience, without thinking much about their substantive implications. The assumption is not innocuous...practical central bankers and academics would benefit from more serious thinking about the functional form of the loss function."

In this paper, we propose a new approach to estimating central bank objectives. Our approach relies on the assumption that the central bank's preferences regarding desired levels of inflation and economic activity are embedded in the words spoken by central bank policymakers at internal meetings. Specifically, we demonstrate that the sentiment expressed by policymakers can be used to directly estimate the central bank's loss function, including the implicit inflation target. This approach could be used internally and externally to study the preferences of any central bank that has transcripts or detailed summaries of their policymaking deliberations. We apply the approach here to estimating the U.S. Federal Open Market Committee's (FOMC) objective function. We construct a proxy for loss using a measure of the negative sentiment expressed in the FOMC's internal discussions. We then estimate how the FOMC's negativity is affected by macroeconomic and financial variables potentially entering the FOMC's loss function, using real-time data on the Federal Reserve staff (Greenbook) forecasts of core PCE inflation and real economic variables along with contemporaneous stock market variables.

The results from this exercise challenge two key aspects of the conventional wisdom 
on FOMC preferences, the first relating to the inflation target and the second relating to preferences regarding economic slack. Beginning with the first aspect, the analysis indicates that the FOMC had an implicit inflation target of approximately $1 \frac{1}{2}$ percent on average over the 2000 to 2011 sample period. The 2000-2011 period is when the FOMC both had an agreed-upon preferred inflation measure (core PCE inflation) and had not yet announced an official inflation target 1 This finding is robust along several dimensions: using alternative measures of negativity, filtering out FOMC discussion unrelated to inflation, conditioning or not on macroeconomic forecasts and/or financial variables, and allowing for asymmetric preferences.

Our $1 \frac{1}{2}$ percent estimated target over 2000-2011 stands in contrast to the commonly held view, both at the time and currently, that the FOMC's inflation target was 2 percent over this period. Svensson (2015), for example, points to the "widely held perception of an unofficial Federal Reserve inflation target of about 2 percent" over the 2000-2011 period of his study. In addition, many macroeconomic models assume the Federal Reserve had a 2 percent target over this period $L^{2}$ Since both average realized inflation and survey measures of longer-run inflation expectations hovered close to 2 percent over that period, this perception would imply that the Federal Reserve was keeping inflation at desired levels. By contrast, our results suggest that not only did the FOMC miss hitting its inflation target, but inflation expectations became anchored at a level well above what the FOMC intended $S^{3}$ In fact, we see in the internal meeting transcripts that this discrepancy between the FOMC's desired target and the public's perception of the target drew the concern of several committee members, including by St. Louis Federal Reserve President William Poole in the September 2006 meeting:

I had several conversations at Jackson Hole with Wall Street economists and journalists, and they said, quite frankly, that they really do not believe that our effective inflation target is 1 to 2 percent. They believe we have morphed into $1 \frac{1}{2}$ to $2 \frac{1}{2}$ percent, and no one thought that we were really going to do

\footnotetext{
${ }^{1}$ The Greenbook began forecasting PCE inflation in January 2000. The FOMC officially announced an inflation target of 2.0 percent based on PCE inflation in January 2012. As discussed below, we also use our sentiment approach to separately estimate the inflation target from 2012 to 2019 based on data from FOMC minutes.

${ }^{2}$ The Federal Reserve Board's FRB/US model and the New York Fed's DSGE model (Del Negro et al. (2013)) set a prior on the inflation target centered at 2 percent over this time period. The perceived inflation target rate (PTR) variable used in the Federal Reserve Board's FRB/US model and academic papers (e.g., Fuhrer et al. (2012) and Bauer and Rudebusch (2017)) is based on long-run inflation expectations from the Survey of Professional Forecasters, which was slightly above 2 percent over our sample period. The 2 percent target over this period is also assumed in a number of academic papers (e.g., Bianchi et al. (2019)).

${ }^{3}$ An official target was not publicly announced by the FOMC until January 2012.
} 
anything over time to bring it down to 1 to 2 .

This concern of appearing incapable of keeping inflation at its desired levels - or in other words, not seeming credible — was echoed by a multitude of FOMC participants.4 In fact, Chairman Ben Bernanke expressed concern at the March 2006 meeting that even a 20 or 30 basis point miss of the inflation target could be potentially damaging to the Fed's credibility:

Like most of you, I am not at all alarmist about inflation. I think the worst that is likely to happen would be 20 or 30 basis points over the next year. But even that amount is a little disconcerting for me. I think it is very important for us to maintain our credibility on inflation and it would be somewhat expensive to bring that additional inflation back down.

The FOMC's strong emphasis on credibility suggests that the central bank would have behaved quite differently had the consensus inflation target been 2 percent instead of $1 \frac{1}{2}$ percent. The FOMC raised the federal funds rate 17 times in the mid-2000s, in part, from concerns about inflation moving out of the $1 \frac{1}{2}$ percent comfort zone. For instance, at the January 2006 meeting, when the Greenbook Core PCE inflation nowcast sat at 2.0 percent, Chicago Federal Reserve President Michael Moskow stated:

With inflation remaining at such rates, we could begin to lose credibility if markets mistakenly inferred that our comfort zone had drifted higher. When we stop raising rates, we ought to be reasonably confident that policy is restrictive enough to bring inflation back toward the center of our comfort zone, which I believe is $1 \frac{1}{2}$ percent...So for today, we should move forward with an increase of 25 basis points...

Similar comments in favor of raising rates because inflation was moving away from this comfort zone were made by other FOMC participants.5 In fact, the data corroborate this interest-rate setting behaviour. As we show in Section 5.3, the estimates from a simple Taylor rule with an inflation target of $1 \frac{1}{2}$ percent resemble the "balanced-approach" rule of Taylor (1999). By contrast, a target of 2 percent produces a worse fit and the wrong sign on the inflation-gap term. Thus, a reaction function where the FOMC tended to raise

\footnotetext{
${ }^{4}$ In Appendix D.3, we list similar quotes regarding missing the inflation target and the bank's credibility concerns. Survey evidence shows that this high regard for credibility is ubiquitous across almost all central banks (Blinder (2000)). Numerous papers in the literature have shown that not maintaining central bank credibility can have important welfare implications (for example, Bomfim and Rudebusch (2000), Faust and Svensson (2001), and Erceg and Levin (2003)).

${ }^{5}$ Additional statements are provided in Appendix D.4.
} 
(lower) interest rates when inflation was above (below) $1 \frac{1}{2}$ percent fits the data better than a 2 percent target. ${ }^{6}$

Given the discrepancy between our estimate of an implicit inflation target of $1 \frac{1}{2}$ and the conventional prior of 2 , we complement our regression analysis with a narrative analysis that identifies and tabulates instances in which FOMC participants explicitly stated their inflation target preferences. Though stated target preferences are conceptually distinct from the implicit target consistent with the overall tone of the committee's discussion, we do find that the consensus target preference was $1 \frac{1}{2}$ percent for most of our baseline sample period. However, the narrative analysis also reveals that some participants shifted their preference up to 2 percent during the Great Recession. As a validation exercise using our sentiment analysis approach, we split our speaker-meeting observations into three subsamples: those observations where the narrative evidence suggests the speaker had a preference for $1 \frac{1}{2}$ percent, those with a preference for 2 percent, and those with no explicit evidence of an inflation target preference. The loss function estimated using the $1 \frac{1}{2}$ percent narrative-preference subsample yields an implied inflation target close to $1 \frac{1}{2}$ percent, while the loss function estimated using the 2 percent narrative-preference subsample yields an implied inflation target close to 2 percent (and the other group is estimated to have a target in between), thus validating the performance of the sentiment analysis approach.

These results suggest that the majority of participants preferred an inflation target of $1 \frac{1}{2}$ percent over the 2000-2011 period, despite some FOMC participants shifting to a preference for 2 percent towards the end of the sample period. It is plausible that these individuals represented the vanguard of a broader shift in inflation preferences among FOMC participants, leading to the announcement of an explicit 2 percent inflation target in 2012. Indeed, we find corroborating evidence for this broader shift in preferences. Specifically, in an extension in which we apply the sentiment analysis approach using data from FOMC minutes separately for the 2000-2011 period and post-2011 (2012-2019), we find evidence that the inflation target did indeed shift up to 2.0 percent after 2011.

The second key aspect of our findings from the sentiment analysis approach is that, in contrast to typical formulations of the central bank loss function, the FOMC's loss

\footnotetext{
${ }^{6}$ In addition to impacting central bank behavior, an inflation target of $1 \frac{1}{2}$ may have inherently different welfare consequences than the commonly held view of 2 percent. Indeed, some FOMC participants stated they were in favor of an inflation target of $1 \frac{1}{2}$ percent as opposed to something higher, such as 2 percent, precisely because the lower rate is assumed to substantially improve welfare (see appendix for participants' statements). While there is disagreement in the economics literature regarding the precise welfare costs of inflation, a number of influential papers have shown that relatively small changes in steady-state inflation can have substantial welfare implications (for example, Dotsey and Ireland (1996), Lucas (2001), Di Tella et al. (2001), Erosa and Ventura (2002), Coibion et al. (2012)).
} 
was little affected by contemporaneous economic slack. Instead, we find that loss was strongly affected by output growth and financial variables, most prominently recent stock market returns. There are two potential interpretations for this result. The most direct interpretation is that output growth and financial conditions are part of the central bank's objective function. 7 There is, in fact, considerable external support for this interpretation. Thornton (2011) documents that from 1991 until 2009 the FOMC's policy directive, announced to the public after each FOMC meeting, stated "The Federal Open Market Committee seeks monetary and financial conditions that will foster price stability and promote sustainable growth in output" [italics added]. Thornton further notes that neither "maximum sustainable employment nor the unemployment rate" is mentioned in these directives. The finding that stock market performance affects the FOMC's loss is consistent with work by Peek et al. (2015) and Wischnewsky et al. (2019) who argue that the FOMC responds to financial variables. 8

An alternative, and not mutually exclusive, interpretation is that current financial indicators and near-term forecasts of output growth are signals of future (longer-run) levels of slack. That is, perhaps policymakers do not care about output growth and financial markets per se, but do care about future slack, which may be predicted by these variables. We do not take a strong stand on which of these two interpretations is more likely, though we do find some empirical evidence supporting direct inclusion. Specifically, growth has a stronger effect than slack on current loss even when these two variables are measured by longer-horizon Greenbook forecasts.

Direct estimation using text analysis offers a new approach to studying central bank preferences, complementing prior indirect approaches. Prior analyses have relied on indirect inference, deriving central bankers' preferences from either observed interest rate votes $9^{9}$ or statements about desired interest rates viewed through the lens of an estimated interest-rate rule 10

Inferring the objective function from estimated interest-rate rules has two main drawbacks. First, inferring the parameters of the objective function, or even what variables are in it, requires precise knowledge of the structure of the macroeconomic model implicitly underlying the central bank's actions.11 For instance, if the central bank believes the

\footnotetext{
${ }^{7}$ Such an objective function has been formulated previously in the literature (e.g., Barro and Gordon (1983) and Walsh (2017).

${ }^{8} \mathrm{It}$ is also consistent with Cieslak and Vissing-Jorgensen (2018) who find that negative mentions of the stock market in FOMC minutes and transcripts have high explanatory power for interest rate policy changes.

${ }^{9}$ See Favero and Rovelli (2003), Dennis (2006), Surico (2007), Ilbas (2012), and Givens (2012)

${ }^{10}$ See Chappell Jr et al. (1997) and Meade and Stasavage (2008).

${ }^{11}$ We demonstrate this point with a simple three-equation New Keynesian model in Appendix Section
} 
economy behaves according to the New Keynesian framework, backing out the structural parameters of the objective function requires knowledge of the slopes and persistence parameters of the Phillips and IS curves - parameters for which there is very little consensus in the literature. More broadly, the actual structure of the economy is undoubtedly more complex than any available theoretical model (Blanchard $(2018))$. Second, identification of the objective function in these analyses must be limited to periods in which there are changes to the federal funds rate target. There are plausibly many instances when the FOMC is in some way constrained in its ability to change its policy target to perfectly align with its preferences. The zero lower bound, which was in effect between 2008 and 2015 and from March 2020 to the time of this writing, is the most obvious such constraint. Another is the convention of only moving the fed funds target by quarter-point increments.

In the remainder of the paper, we first derive in Section 2 the regression specifications we use to estimate the loss function and discuss identification issues. In Section 3, we describe the textual source data we compiled on FOMC meeting transcripts, minutes, and speeches and how we measured the negativity therein. We also show how the negativity in each of these sources has varied over time. Section 4 presents the main results of the paper. Based on the FOMC's private meeting transcripts, we first estimate a standard symmetric loss function for the 2000-2011 period and identify the implied inflation target. We then consider asymmetry and robustness to alternative sentiment measures. In Section 5, we provide four types of external validation related to our estimate of the inflation target. Specifically, we provide corroborating evidence from narrative analysis, heterogeneity across different types of FOMC participants, Taylor rule estimation, and estimates based on FOMC minutes. In Section 6, we use our sentiment analysis approach to investigate the inflation target before and after our baseline sample period. We offer concluding remarks in Section 7 .

\section{Deriving an Estimable Loss Function}

\subsection{Standard Quadratic Loss Function}

The canonical model of central bank preferences and optimal policy is based on an assumed central bank loss function within a standard New Keynesian (NK) model of the macroeconomy (see, for example, Clarida et al. (1999), Giannoni and Woodford (2003), Walsh (2004), and Surico (2007)). In Appendix A.1, we present a simple version of the A.1. The point is demonstrated in more general models in Rudebusch and Svensson (1999), Dennis (2006), and Surico (2007) 
model that conveys the role of the loss function in determining interest rate policy and illustrates the difficulty of identifying the structural parameters of the loss function from estimates of the interest rate rule alone. And, of course, more complicated loss functions or economic environments will only introduce more structural parameters into the interest rate rule coefficients. ${ }^{12}$ In addition, any instability over time in the structural parameters of the IS or Phillips curves would further complicate efforts to infer the loss function parameters from estimated Taylor rule coefficients. For instance, there has been evidence in recent years that the slope of the Phillips curve has flattened over the past couple of decades (e.g., Leduc and Wilson (2017).

Therefore, we propose an approach to directly estimate the central bank's loss function. To fix ideas, consider the standard short-run loss function:

$$
L_{t}=\tilde{\pi}_{t}^{2}+\phi \tilde{u}_{t}^{2}
$$

where $\tilde{\pi}=\pi-\pi^{*}$ is the inflation gap, defined as inflation minus the central bank's inflation target, and $\tilde{u}=u-u^{*}$ represents the unemployment gap and is meant to capture current economic activity or "slack."

Conceptually, there are other variables that could enter the loss function. As discussed in the introduction, previous studies have suggested that monetary policymakers may be concerned with output growth as well as financial conditions. Furthermore, economists have also put forth different functional forms for how economic activity enters the loss function. For instance, Barro and Gordon (1983) and Walsh (2017) formulate a loss function where economic activity is proxied with a linear term in addition to the squared term. For this reason, we consider a more general loss function that nests equation (1):

$$
L_{t}=\tilde{\pi}_{t}^{2}+\mathbf{X}_{t} \Lambda
$$

where $\mathbf{X}$ is a vector of non-inflation variables potentially entering the loss function such as the unemployment gap, output growth, and financial variables.

We proxy for loss using a measure of the negativity, denoted $N$, expressed by FOMC members in their meetings: $N=\delta L$. We measure negativity for individual members of the FOMC, $N_{i t}$, and hence we allow for speaker-specific fixed effects. These fixed effects allow for heterogeneity across speakers in their general (time-invariant) style/tone of speaking.

\footnotetext{
${ }^{12}$ For instance, a recent paper by Nakamura and Steinsson $(2018)$ argues that Fed interest rate shocks may have an additional channel beyond the conventional IS curve. Interest rate shocks, because they reflect the Fed's economic forecasts, convey information to private agents about future (potential) output growth which can create actual output growth through investment decisions. This additional Fed information channel introduces even more structural parameters into the economic environment, further complicating the ability to infer the Fed's loss function from estimates of their interest rate rule.
} 
Allowing for this heterogeneity could be potentially important because it ensures that changes in the composition of the FOMC over time do not lead one to misinterpret changes in negativity over time. Applying these changes to equation (2), and adding an i.i.d. error term to capture measurement error in loss, yields the following regression specification:

$$
N_{i t}=\alpha_{i}+\delta \tilde{\pi}_{t}^{2}+\sum_{j} \omega_{j} x_{j, t}+\varepsilon_{i t},
$$

where $\alpha_{i}$ is a speaker fixed effect, $x_{j, t}$ is the $j^{\text {th }}$ element of the vector $\mathbf{X}_{t}, \omega_{j} \equiv \delta \lambda_{j}$, and $\lambda_{j}$ is the $j^{\text {th }}$ element of the parameter vector $\Lambda$.

The implicit target, $\pi^{*}$, is a latent variable that is of wide general interest to the public, economists, and other policymakers. The value of the true $\pi^{*}$ guiding monetary policy is unknown, especially prior to the FOMC's formal adoption of a 2.0 percent inflation target (as measured by PCE price index) in January 2012. Hence, rather than imposing an assumed $\pi^{*}$ to measure $\tilde{\pi}_{t}$, we directly estimate it.

The inflation gap term in equation (3) can be expanded as follows:

$$
N_{i t}=f_{i}+\delta \pi_{t}^{2}+\theta \pi_{t}+\sum_{j} \omega_{j} x_{j, t}+\varepsilon_{i t}
$$

where $\theta \equiv-2 \delta \pi^{*}$ and $f_{i} \equiv \alpha_{i}+\delta \pi^{* 2}$. Thus, the implied $\pi^{*}$ can be backed out from the

estimated coefficients on inflation and inflation squared: $\hat{\pi}^{*}=-\hat{\theta} / 2 \hat{\delta}$. The coefficients of equation (4) can be estimated via OLS. We calculate standard errors that are robust to heteroskedasticity and two-way clustering by time (meeting) and speaker. Clustering by time accounts for potential correlation of errors across speakers at a given meeting, while clustering by speaker allows for potential correlation over time within speaker. The standard error for $\hat{\pi}^{*}$ is calculated using the delta method from the estimated variancecovariance matrix (allowing for heteroskedasticity and two-way clustering).

\subsection{Identification}

Note that the right-hand side of equation (4) should be the FOMC's real-time perceptions of the current and future values of those variables. To measure these real-time perceptions, we use the real-time "Greenbook" forecasts prepared by the Federal Reserve's economic staff in advance of each FOMC meeting. Greenbook forecasts have the appeal that they are the actual numbers discussed by FOMC members at the meetings. Moreover, they incorporate all of the higher-frequency information available between any contemporaneous data releases and the actual meeting. Importantly, because the Greenbook 
forecasts are prepared prior to when the FOMC meets, they can be considered exogenous with respect to the committee's dialogue.

Following Romer and Romer (2004), Coibion and Gorodnichenko (2011), and others, our baseline regression specifications use short-run Greenbook forecasts of these variables and omit longer-run forecasts. Specifically, we use an average of the Greenbook's currentquarter and one-quarter-ahead forecasts. Conceptually, "short-run" forecasts here should be thought of as the time horizon over which the central bank takes current and forecasted inflation and real economic activity as exogenous or outside of their control. As Romer and Romer emphasize, over the longer-run the central bank endogenously determines these variables via interest rate policy in order to minimize its lifetime loss. Hence, longer-run forecasts "are contaminated by assumptions or inside information [on the part of Federal Reserve staff] about the course of monetary policy." Put differently, the FOMC's loss is a function of their perception of economic states over the short-run as well as their perception of states over the longer-run in the hypothetical scenario where the central bank did not change monetary policy. However, this latter perception-sometimes referred to as a constant-interest-rate (CIR) forecast (e.g., Rudebusch and Svensson (1999)) — is not observed and thus could be considered an omitted variable(s) in our regressions 13

We assess the potential for a resulting omitted-variable bias in two ways. First, in Appendix A.2 we discuss how the interpretation of the regression coefficients changes if these short-run forecasts also reflect information about longer-run CIR forecasts due to persistence. As Romer and Romer (2004) note, short-run Greenbook forecasts will capture the central bank's perceived (exogenous) persistence of current variables: "both output growth and inflation are serially correlated enough that forecasts one and two quarters ahead provide a good indication of the likely forecasted path of the economy over longer horizons." We show that such persistence is unlikely to affect our estimate of the estimated inflation target. Second, we show empirically (in Section 4.3) that the results are robust to including farther-ahead Greenbook forecasts in measuring short-run expectations. Specifically, while our baseline uses averages of current and one-quarter-ahead forecasts, we produce alternative results using averages encompassing forecasts as far as four quarters ahead. Forecasts for horizons beyond four quarters are not consistently provided in the Greenbook and, in any case, would increasingly violate the CIR assumption.

Finally, it should be noted that we do not directly consider an interest-rate smoothing term in the objective function (for example, as specified by Woodford (2003)) because the interest rate target is chosen by the FOMC at the close of the meeting and is therefore

\footnotetext{
${ }^{13}$ Greenbooks occasionally include CIR forecasts as "alternative simulations," but these are not consistently available for our full sample period.
} 
endogenous 14 However, we do include a measure of short-term yield volatility as way to control for the FOMC potentially disliking large interest rate movements 15

\subsection{Asymmetric Inflation Preferences}

Allowing for asymmetry in the relationship between the inflation gap and loss is potentially important both generally for understanding the central bank's preferences but also specifically for estimating the inflation target. Allowing for asymmetry, however, requires a non-linear estimation approach because the ability to solve for $\pi^{*}$ as a function of linear least squares coefficients, as we did in Table 1, relied on the symmetric, quadratic specification for the inflation gap. To relax the symmetry constraint in a parsimonious way, we alter the loss function specification to be linear (rather than quadratic) in the inflation gap but with potentially different slopes above and below zero:

$$
N_{i t}=\delta_{1}\left(\pi_{t}-\pi^{*}\right) * \mathbb{1}\left[\pi_{t}>\pi^{*}\right]+\delta_{2}\left(\pi_{t}-\pi^{*}\right) * \mathbb{1}\left[\pi_{t} \leq \pi^{*}\right]+\mathbf{X}_{t} \Lambda+\varepsilon_{i t},
$$

where $\mathbf{X}_{t}$ is a vector of non-inflation variables entering the loss function and $\mathbb{1}[]$ denotes an indicator variable equal to one if the condition in the brackets is true and zero otherwise.

We estimate $\pi^{*}$ along with the coefficients $\delta_{1}, \delta_{2}$, and $\Lambda$ using a grid search over all possible values of $\pi^{*}$ from 0 to 3.0 , with step size of 0.01 . At each iteration, we plug in the corresponding $\pi^{*}$ into equation (5) and then estimate the equation via linear OLS. The final estimates of $\hat{\pi}^{*}, \hat{\delta}_{1}, \hat{\delta}_{2}$, and $\hat{\Lambda}$ are those resulting from the iteration yielding the minimum sum of squared residuals (SSR). The standard errors of $\hat{\delta}_{1}, \hat{\delta}_{2}$, and $\hat{\Lambda}$ are also obtained from that minimum-SSR regression and allow for two-way clustering by time (sample-month) and speaker (as in the symmetric case above). To obtain the standard error for $\hat{\pi}^{*}$, we use a block bootstrap procedure that allows for the same two-way clustering 16

\footnotetext{
${ }^{14}$ That is, the federal funds rate is potentially correlated with unobserved factors that also affect the members' language.

${ }^{15}$ Appendix Tables G4 and G5 show the results are similar across all specifications and are also robust to an alternative proxy for interest-rate volatility, the squared first-difference of the 3 -month fed funds futures rate.

${ }^{16}$ The block bootstrap procedure loops over 100 draws, where each draw pulls all observations from a random sample of $T-1$ months (with replacement) and estimates $\hat{\pi}^{*}$ using the grid search method described above. The standard error of $\pi^{*}$ is calculated as $\left[\operatorname{var}\left(\hat{\pi}^{*}\right)^{(t)}+\operatorname{var}\left(\hat{\pi}^{*}\right)^{(i)}-\operatorname{var}\left(\hat{\pi}^{*}\right)^{(t, i)}\right]^{\frac{1}{2}}$ where $\operatorname{var}\left(\hat{\pi}^{*}\right)^{(j)}$ is the variance of the $\hat{\pi}^{*}$ distribution when sampling with replacement by $(j)$ and the $95 \%$ confidence interval is given by plus or minus 1.96 times the standard error (see Cameron and Miller $(2015)$ ).
} 


\section{Measuring Central Bank Sentiment}

We extract a direct measure of the FOMC's loss from publicly available transcripts. Below we outline the data sources used and describe how we quantified the negativity expressed in FOMC meetings, minutes, and speeches. We then show how our negativity measures have varied over time.

\subsection{Data Sources}

Our main textual data source is the public archive of FOMC transcripts that can be downloaded directly from the Federal Reserve Board of Governors website: https: //www.federalreserve.gov/monetarypolicy/fomc_historical.htm. These include all regular FOMC meetings from 1976 to 2015 (as of the time of this writing), though we make no use of pre-1986 transcripts in this paper given other data constraints. We converted these pdf files to text files and then parsed the text to generate separate text files for every utterance (sentence) in the transcript which is tagged with a speaker. There were 704,499 total utterances. We then apply three filters to remove utterances likely to be especially noisy. First, we drop utterances with less than five words. Second, we drop stand-alone utterances, defined as an utterance that is preceded and followed by utterances from different speakers. Third, we used the Oxford Dictionary of Economics (ODE) to filter out remarks that did not contain at least one economics-related term. We define a remark as a set of consecutive utterances by a single speaker (i.e., comments made by a speaker before discussion turned to another speaker). Because the ODE is quite expansive, containing 3,229 terms, and very little of the discussions at FOMC meetings is unrelated to economics, this filter removed just 3.0 percent of the 566,696 utterances remaining after the first two filters, leaving 549,649. As we show in Section 4, our results are very similar whether or not we apply the economic-terms filter. We also provide results based on two alternative filters, one that keeps only remarks containing terms related to inflation and one that keeps only remarks related to slack. ${ }^{17}$

Most speakers will make many remarks during a given meeting/transcript. Using historical lists of Federal Reserve governors and bank presidents, and which presidents were voters versus non-voters at any given meeting, we are also able to perform analyses on particular subsets of remarks, such as those by Fed chairs, governors, presidents, and voters. We exclude remarks from non-FOMC members (mostly Fed research staff members) given

\footnotetext{
${ }^{17}$ The inflation terms are: price, prices, pricing, inflation, inflationary, cpi, pcepi, core, deflation, deflationary, disinflation, disinflationary. The slack terms are: output gap, unemployment, unemployed, jobless, joblessness, nonemployment, U3, U4, U5, U6, nairu, natural rate, potential output, potential GDP, potential GNP, slack, utilization.
} 
that our goal is to estimate the collective loss function of the FOMC. This exclusion also has the benefit of, in effect, filtering out the portion(s) of each FOMC meeting in which the staff presents its assessment of economic and financial conditions to the committee, leaving primarily only the portion of the meeting in which committee members discuss their economic outlooks and policy views.

Using the methodology described below, we calculate a unique negativity score for each speaker-meeting, pooling all remarks by a given speaker at that meeting. This yields 4,223 speaker*meeting observations over all meetings between 1986 and 2015, and 1,676 for our primary sample period of 2000 to 2011.

For additional analyses, we also collected the minutes of the FOMC meetings, which are released to the public three weeks after the corresponding meeting. The minutes are a summary of the discussion that took place at the meeting, with no attribution of any specific comments or opinions to individual FOMC members 18

\subsection{Quantifying Negativity in FOMC Text}

There is a large and growing literature aimed at quantifying sentiment from text. We use a method known as the "Bag of Words" or "lexical" approach, which relies on predefined dictionaries of words that are associated with particular sentiments ${ }^{19}$ We employ an updated version of the dictionaries from Loughran and McDonald (2011) (hereafter, LM), who construct lists of negative and positive words curated to be appropriate for financial text. They show that their dictionaries are superior for classifying economic and financial texts to other dictionaries, for example the Harvard Psychosociological Dictionary, which tend to miscategorize words that are neutral in a financial/economic context (e.g., tax, costs, capital, expense, liability, risk, excess, and depreciation) 20 There are 2,355 negative words and 354 positive words in the LM dictionaries. We ignore posi-

\footnotetext{
${ }^{18} \mathrm{PDF}$ files for minutes from 1993 onward are available at: https://www.federalreserve.gov/ monetarypolicy/fomc_historical.htm.

${ }^{19}$ The other approach uses machine learning (ML) techniques. See Liu (2010) for a detailed description of the ML approach to sentiment analysis and Shapiro et al. (2018) for an application of both lexical and ML approaches to measuring news sentiment.

${ }^{20}$ Heston and Sinha (2015) measure negativity in news articles about companies and estimate their impact on those companies' stock returns. They use the Harvard Psychosociological Dictionary along with Loughran and McDonald's dictionary. More closely related to our paper, Jegadeesh and Wu (2017) use a combination of these same two dictionaries to measure the tone (net positivity) of FOMC meeting minutes, with sentences in the minutes separated by topic. Apel et al. (2019) and Picault and Renault (2017) use the lexical approach to classify the hawkishness vs dovishness of central bank communications for the FOMC and the ECB, respectively. Lastly, the study of economic policy uncertainty by Baker et al. (2016) also uses a lexical-based measure as part of its uncertainty index. That measure is a simple count of news articles containing terms such as "uncertain" and "not certain" along with terms related to economic policy.
} 
tive and negative words preceded by "not" or "n't," as recommended by Loughran and McDonald (2016) We show an example of scored text from an FOMC transcript in Appendix B.

The net negativity scores, $N_{i t}$, are calculated as the fraction of negative words by speaker $i$ at a given FOMC meeting in month $t$ minus the fraction of positive words by speaker $i$ at the same meeting (subsequent to any text filtering as described in the previous subsection). Using the difference between the negative and positive fractions - as opposed to one or the other - ensures that our measure is independent of overall emotivity (i.e., use of both negative and positive words). Nonetheless, we show later that the results are similar using either the negative or positive fractions alone.22

To help validate our sentiment measure, we performed a "human audit" as follows. We randomly selected $10 \%$ of the roughly 1,900 speaker-by-meeting observations of FOMC meeting text from 2000 to 2013. We then asked a group of 14 research assistants to read and evaluate the tone of a given observation's text on a 5-point scale (from least to most negative) 23

The audit results are shown in the scatterplot in Figure 1. Each dot represents a speaker-meeting observation. The negativity score assigned by a research assistant is shown on the $\mathrm{x}$-axis while the LM net negativity fraction is shown on the $\mathrm{y}$-axis. The mean LM fraction, by human score category, is indicated by the red circles. A linear regression fit line also is provided. While there is a good deal of variation in the LM net negativity measure within a category, we find a strong correlation between the human scores and LM net negativity. Specifically, the Spearman's rank correlation is 0.40, which is statistically significant below the $0.01 \%$ level. ${ }^{24}$

\footnotetext{
${ }^{21}$ We first removed stop words and intensifiers, and then searched for positive and negative words preceded by "not" and "n't." For example, "not a very bad reading" would be reduced to "not bad reading." We also ran specifications where we removed the words "unemployed" and "unemployment" from the LM negativity dictionary since higher unemployment can be a positive or a negative event depending on the current unemployment gap. We found no change in our results. We reviewed the LM dictionaries for other such terms and did not find any.

${ }^{22}$ See Appendix Table G1.

${ }^{23}$ Specifically, they were instructed to: "Assign a score from 1 [very positive] to 5 [very negative] of the sentiment/negativity expressed by the speaker at that meeting. This score should be thought of as your best guess of the score that speaker would give if they were asked, "how negative are you today?" at that meeting. That is, this score should be your assessment of how you think the speaker felt (about economic conditions) as of that meeting date, without imposing how you think he or she should have felt. That is, you should ignore factual statements (e.g., "revenue growth is low", "unemployment rose last month", "inflation has been trending higher") and focus on the speaker's sentimental language (e.g., "I'm not happy about that", "This concerns me", ... "which is a troubling development")." The resulting data set consists of 182 human audit scores.

${ }^{24}$ We also performed the same analysis on two other common computational sentiment analysis measures. The first is a lexical measure analogous to the LM net negativity but using the Harvard Psychosociological Dictionary to define negative and positive words. The rank correlation between this measure and
} 
Figure 2 plots the estimated time (meeting-month) fixed effects from a simple regression of the negativity scores on time and speaker fixed effects, using data from January 1986 through December 2015. The dotted line shows the actual time series of coefficients on the time dummies, while the solid line shows a smoothed version calculated as an 11-month centered moving average. FOMC meeting negativity has a clear countercyclical pattern, rising in recessions and falling in expansions. Negativity rises especially sharply during the 2007-2009 Great Recession. It gradually fell after the Great Recession but was still relatively high by the end of 2015 , consistent with the weakness of the recovery during the 2010-2015 period 25

It also is interesting that negativity was not relatively higher during the late 1980s, when inflation and unemployment were relatively higher, than in later years, in contrast to the picture one gets from the so-called "misery index" which sums inflation and the unemployment rate. Our results in section 6.2 suggest this difference can be explained by the late 1980s having a combination of a higher natural rate of unemployment, a higher inflation target, and lower sensitivity to inflation in the FOMC's loss function.

\section{Main Results}

\subsection{Symmetric Loss Function}

We start with estimating versions of a U-shaped (i.e., quadratic) loss function, as shown in equation (4). The estimation uses 1,676 speaker-meeting observations over the period January 2000 through December 2011. We use January 2000 as the sample start

the human scores is just 0.14. The comparatively worse performance of the Harvard Psychosociological Dictionary based lexical measure relative to LM illustrates the importance of domain (economics/finance) specificity in constructing a sentiment measure. The second alternative measure we considered is the widely-used, open-source python package, Vader. Vader is a predictive model that provides estimated probabilities that a given set of text is negative, neutral, and positive. The Vader model is based on a machine learning algorithm trained on a combination of general english language words and social media data. Relative to LM, Vader has the advantage of taking into account parts-of-speech, context (to some extent), and other advanced features of current natural language processing tools. However, it is not domain-specific to economics and finance. We find a rank correlation between the Vader net negativity measure (probability negative minus probability positive) and the human scores of 0.41 , very similar to that of LM net negativity. As noted later in the paper, using Vader to measure net negativity also yields similar results to our baseline LM measure in the loss function regressions.

${ }^{25} \mathrm{We}$ similarly plot the net negativity for the minutes from each FOMC meetings and speeches of FOMC members in Appendix Figure G1. Net negativity in the minutes moves quite similarly to that in the transcripts through 2015. After 2015, net negativity in the minutes remained relatively low until 2020; it spiked around the time of the onset of the COVID-19 pandemic. Also, it is worth noting that the time series pattern of our FOMC negativity measure appears to be quite consistent with the patterns of the topic-specific time series of net positivity in FOMC minutes constructed by Jegadeesh and Wu (2017), plotted in their Figure 2. 
date for our baseline analysis for two reasons. First, the Greenbook does not contain forecasts prior to 2000 for PCE inflation, which is the measure that the FOMC publicly stated in 2012 was its preferred measure of inflation $($ FOMC $(2012)) \cdot{ }^{26}$ Second, it is widely believed that the inflation target was different (and likely time-varying) prior to the Great Moderation starting in the late 1990s (see Ireland (2007), Cogley et al. (2010), and Coibion and Gorodnichenko (2011)). In Section 6.2, we expand the sample period to 1986-2011 (which entails splicing in a "PCE-adjusted" core CPI inflation Greenbook forecast) and estimate a version of the loss-function with a time-varying $\pi_{t}^{*}$ and also allowing for the time of the regime change to a constant target period to float freely. The results from this exercise indicate that the constant-target period begins in 2000, consistent with our baseline sample period. We use December 2011 as the final month of the baseline sample period because the FOMC first officially announced an inflation target (of 2 percent) in January 2012. We use our sentiment approach to separately estimate the post-2011 target on the FOMC minutes in Section 6.1.

The results of estimating a U-shaped loss function are shown in Table 1. Note that standard errors (shown in parentheses) are robust to heteroskedasticity and two-way clustering by time (meeting) and speaker. The first column shows the results of a simple specification that includes only $\pi_{t}$ and $\pi_{t}^{2}$. This estimated quadratic relationship also is plotted visually in panel (a) of Figure 3, overlaid on a bin-scatter plot of negativity against short-run inflation. ${ }^{27}$ In the scatter plot, both inflation and negativity have been residualized with respect to speaker fixed effects. The negative sign on $\pi_{t}$ and the positive sign on $\pi_{t}^{2}$ implies that loss has a convex relationship with inflation and that there exists a loss-minimizing inflation rate, $\pi^{*}$.

As indicated in column (1) of the table, the estimated quadratic loss function implies a $\hat{\pi}^{*}$ of approximately 1.25 percent, with a $95 \%$ confidence interval of 0.8 to 1.7 . How we arrive at this value of $\hat{\pi}^{*}$ is clear from panel (a) of Figure 3 . Negativity tends to be lowest when inflation is around 1.3 to 1.5 percent and rises as inflation moves outside that range in either direction.

\footnotetext{
${ }^{26}$ While it is clear from the Greenbook and from the FOMC transcripts that the FOMC shifted from focusing on the CPI to the PCEPI measure in the years around 2000, the exact timing and extent of the shift is somewhat ambiguous. As a robustness exercise, we estimate the loss function using Greenbook CPI forecasts and, as shown in Appendix Table G3, found very similar results but for a higher estimated inflation target. Specifically, comparing Table G3 to the corresponding columns in Table 2 , we see that the estimated inflation target based on the CPI is 20 to 50 basis points higher than that based on the PCE, consistent with the fact that CPI inflation averaged around 30 basis points higher than PCE inflation over 2000 to 2011.

${ }^{27} \mathrm{~A}$ bin-scatter plot divides observations into equal bins - 100 in this case - and then plots the mean of $\mathrm{x}$ against the mean of $\mathrm{y}$ for each bin. Bin-scatter plots are frequently used to visualize data when there are a very large number of underlying data points.
} 
This estimate is considerably lower than both the 2.0 percent inflation target officially announced by the FOMC in January 2012 and survey measures of longer-run inflation expectations, as seen in Figure $4{ }^{28}$ Moreover, as noted in the introduction, the transcripts reveal that at least some committee members were well aware of the discrepancy between the FOMC's target and market participants' perception of the target.29 The estimate is also below the 2000-2011 average of actual year-over-year core PCE inflation, which is 1.8 (measured using either current vintage or real-time data) ${ }^{30}$

We next add non-inflation variables, linear and squared, to in the remaining columns of Table 1. In column (2), we estimate the standard loss function including the unemployment gap, with both a linear and squared term. The unemployment gap is measured using the Greenbook's forecast of the unemployment rate minus its estimate of the natural rate of unemployment (as of that meeting). As with other Greenbook forecasts, we average the current-quarter and one-quarter ahead forecasts. The coefficients on both the linear and squared unemployment gaps are found to be statistically insignificant.

In column (3), we replace the unemployment gap with output growth, again measured by the Greenbook short-run forecast. As noted earlier, some prior studies have found a role for output growth in central bank preferences and interest rate policy (e.g., Walsh (2003), Coibion and Gorodnichenko (2011), Orphanides and Williams (2006)). We find that negativity falls significantly with both output growth and its squared term-implying loss falls monotonically with output growth. This result is consistent with the prior studies finding a role for output growth in interest rate rules. It is also consistent with the fact, documented in (Thornton (2011)), that the FOMC explicitly stated its policy objectives in terms of "economic growth" or "growth in output" from 1991 through 2008, when it changed its policy directive to refer to "maximum employment." 31

Some FOMC participants and outside observers have suggested that financial variables may also enter the central bank's loss function (Bernanke and Gertler (2001), Kohn

\footnotetext{
${ }^{28}$ Market-based measures of inflation expectations were also above this value. For example, the TIPSbased 5-year-ahead, 5-year-forward break-even inflation rate (based on CPI) averaged 2.4 between 20032012.

${ }^{29}$ In addition to William Poole, Timothy Geithner and Eric Rosengren made similar comments at the September 2006 and January 2009 meetings, respectively. The result is also reminiscent of Afrouzi et al. (2015)'s finding that inflation expectations of firms in New Zealand have been persistently higher than the central bank's announced target over the past 25 years.

${ }^{30}$ The average excluding the zero lower bound period (Dec. 2008 through the end of our sample period), which arguably hampered the Fed's ability to boost inflation, is even higher at 1.9.

${ }^{31}$ In an additional regression, we interacted a post-2008 dummy with output growth to test the hypothesis that the FOMC's language in the transcripts coincided with the change in the language of its stated objectives. The coefficient on the interaction was positive and significant, indicating that movements in output growth changed the FOMC's loss by a smaller amount in the post 2008 period, corroborating the change in the stated objectives.
} 
(2006), and Peek et al. (2015)). We examine this hypothesis by adding a number of common financial measures to our specification. Specifically, in column (4) we include the trailing 90-day change (preceding the meeting) in the S\&P 500 index, the previous month's Shiller P/E ratio (a measure of the recent level of stock market prices), the stock market volatility index (VIX) and real-time short-term yield volatility taken from Christensen and Rudebusch (2012) ${ }^{32}$ The short-term yield volatility measure is included to control for a possible interest-rate smoothing motive ${ }^{33}$ Negativity moves strongly in the opposite direction with recent stock market returns and in the same direction as financial volatility ${ }^{34}$ but statistically insignificant ${ }^{35}$ These results are consistent with Peek et al. (2015), who argue that financial variables do enter the FOMC's loss function based on their evidence that references to financial instability in the FOMC transcripts significantly improve the fit of an estimated Taylor Rule. They are also consistent with Cieslak and Vissing-Jorgensen (2018) who find that negative mentions of the stock market in FOMC minutes and transcripts have high explanatory power for interest rate policy changes.

We next estimate a loss function specification that replaces the quadratic functional form for inflation with a constrained/symmetric piecewise-linear form. This is equivalent to estimating the piecewise-linear specification shown in equation (5) while constraining $\delta_{1}=-\delta_{2}$. In other words, we estimate a $\mathrm{V}$-shaped instead of a U-shaped loss function (in terms of inflation) while still maintaining symmetry. The results are shown in columns (1), (2), and (3) of Table 2. The specification underlying column (1) includes only the inflation gap terms (i.e., restricting $\omega$ and $\kappa$ to equal 0 ). We obtain a $\hat{\pi}^{*}$ of 1.4 , which is slightly higher than that obtained using the quadratic specification. The results in column (1) are shown visually in panel (b) of Figure 3. As with panel (a) of Figure 3, we overlay this fitted relationship on a bin-scatter plot of negativity against inflation. We see that the V-shape appears to fit the data slightly better than the U-shape (as verified by the

\footnotetext{
${ }^{32}$ Both volatility measures are measured as the average value over the 3 days preceding the meeting.

${ }^{33}$ We obtain similar results when using the squared values of the first-difference in real-time short-rate projections (see Appendix Tables G4 and G5). The short-rate projection is measured as the implied 3-months-ahead fed future rate from Christensen and Rudebusch (2012) at the time right before the meeting (i.e., the average value of the projection over the 3 days preceding the meeting). The Shiller PE ratio is only available monthly, so we can only include the preceding month's value as opposed to the value immediately preceding the meeting. We assume that financial variables enter the FOMC's loss in a linear fashion.

${ }^{34}$ We also ran specifications that included forecast uncertainty as control (measured by the SPF dispersion variables) which we report in tables $\mathrm{G} 6$ and $\mathrm{G} 7$.

${ }^{35}$ Note that when financial variables are added, the coefficient on linear output growth becomes approximately zero while squared output growth remains negative and significant. Taken literally, this implies that loss falls as growth deviates from zero, even in the negative direction. However, we note that the coefficient on the linear term is imprecisely estimated because negative growth is rarely observed in our sample (10 percent of the sample) and occurs contemporaneously with strong movements in the financial variables.
} 
higher $R^{2}$ in the regression). Column (2) adds output growth and output growth squared. Both are found to reduce the FOMC's net negativity and their inclusion has no effect on the estimated inflation target, which remains at 1.4. Finally, the specification underlying column (3) includes all additional factors which results in a modestly higher estimate of $\pi^{*}$ of 1.55 . The coefficients for the other variables are similar to the analogous quadratic specification (column (4) of Table 1), with a negative effect on loss from output growth squared and recent stock market returns and a positive effect on loss from the Shiller $\mathrm{P} / \mathrm{E}$ ratio.

\subsection{Asymmetric Loss Function}

The results above are based on the assumption of a symmetric loss function. We now relax that assumption by estimating the piecewise-linear specification shown in equation (5). The results when we allow for asymmetry are very similar and shown in column (4) with only inflation terms included, column (5) with output growth included, and column (6) with all additional factors included. The results in column (4) are shown visually in panel (c) of Figure 3. The slope by which loss increases away from target is about the same (in absolute value) above and below the target. The coefficients on the inflation gap above and below zero indicate that negativity rises faster as inflation moves further below target than it does when inflation moves further above target. That is, the absolute value of the slope coefficient for the inflation gap below zero is larger than the slope coefficient for the inflation gap above zero. The "Symmetry p-val" row at the bottom of Table 2

shows the p-value on the null hypothesis that $\hat{\delta}_{1}=-\hat{\delta}_{2}$ based on a t-test using the two-way clustered variance-covariance matrix. In the full specification, the difference in slopes is found to be significant, with a p-value of 0.001. We performed a number of robustness checks in terms of including additional controls, which we report in Appendix Tables G6 to G9. This includes specifications with the squares of financial variables, a lagged dependent variable, lagged inflation, 10-year inflation expectations, and the dispersion in SPF nowcasts and forecasts of inflation, GDP growth, and unemployment. Overall, the estimates remain stable and the inflation target hovers around 1.5 in all of these additional specifications.

One caution in interpreting these results deserves mention. The asymmetry of the loss function in terms of inflation relative to target can, of course, only be estimated over the range of observed inflation rates during the sample period. Greenbook near-term forecasts of core PCE inflation between 2000 and 2011 rarely fell much below 1 percent and never got very close to zero. FOMC policymakers have frequently spoken about the particular 
dangers of deflation (especially given the zero lower bound on interest rate policy). It is entirely possible that FOMC preferences are much more asymmetric in the range of inflation close to zero. That is, the loss function slope could sharply steepen (in absolute value) as inflation rates get close to or below zero, which we haven't observed in the data.

\subsection{Loss Function Implied by Alternative Forecast Horizons}

As discussed in Section 2.2, the Greenbook forecasts of inflation, the unemployment gap, and real GDP growth are short-run forecasts and so, by omitting the FOMC's longerrun expectations of these variables, our results could potentially suffer from omitted variable bias. To assess the potential for such bias, we investigate how the results - especially the estimated inflation target - change as one includes farther-ahead forecasts in these macroeconomic variables. Table 3 shows the results of this exercise. The first column simply redisplays the results of estimating our baseline specification, in which inflation, the unemployment gap, and real GDP growth are measured as averages of the Greenbook's current-quarter and one-quarter-ahead forecasts. In column (2), these variables are measured as averages of current-quarter through two-quarter-ahead forecasts; column (3) uses averages of current-quarter through three-quarter ahead forecasts; and column (4) uses averages of current-quarter through four-quarter-ahead forecasts. ${ }^{36}$

We see that the estimated loss function is quite similar across these alternative specifications. In particular, the estimated inflation target is little affected by including fartherahead forecasts in the measures of the macroeconomic variables. For example, both the baseline specification, using averages of current-quarter and one-quarter-ahead forecasts, and the specification using averages of current-quarter through four-quarter-ahead forecasts, yield $\hat{\pi}^{*} \approx 1.5 .37$

\subsection{Loss Function Implied by Filtered Transcripts}

We next investigate the loss function using the net negativity measures from particular subsets of the full corpus of meeting transcript text. As described in Section 3, our baseline

\footnotetext{
${ }^{36}$ This sensitivity check mimics that of Orphanides (2004), who estimated forward-looking interest rate rules using Greenbook inflation forecast averages encompassing horizons ranging from 1 to 4 quarters ahead. He found the results were insensitive to the alternative forecast horizons.

${ }^{37}$ We also ran specifications including median inflation expectations from the SPF (10-year-ahead CPI) as an additional regressor (see Appendix Tables G8 and G9). Of course, it is possible that the FOMC's loss function contains constant-interest-rate forecasts beyond four quarters ahead, which are unobserved to us, that could create an omitted variable bias. We show in Appendix A.2 that under this assumption the estimated coefficients on the short-run forecasts reflect both their direct impact on short-run loss plus their effect on longer-run loss given their degree of persistence.
} 
negativity measure is constructed from transcripts text that filtered out speaker remarks that did not contain at least one word from the Oxford Dictionary of Economics (ODE). This filter was intended to remove remarks in the FOMC meetings that are unrelated to economic discussions. Using similar methodology, we also explored (1) not filtering at all (keeping all remarks), (2) keeping only remarks associated with inflation, and (3) keeping only remarks associated with slack. For inflation and slack, we constructed our own lists as subsets of ODE words and phrases. From these alternative sets of text, we computed the LM net negativity score by speaker-meeting as before (fraction of negative words minus fraction of positive words). Time series plots of the monthly median values of these three alternative measures are provided in Appendix Figure E2. Loss function estimates using these alternative negativity measures are provided in Table 4 . The loss function estimates using negativity calculated from the unfiltered text (column (2)) are very similar to the baseline estimates. This is not surprising given that nearly $90 \%$ of the transcript remarks contain economic terms. When we filter to include only remarks related to inflation (column (3)) or slack terms (column (4)) the estimates are generally consistent with the baseline estimates but with less precise estimates of the inflation target. Interestingly, the estimated inflation target is somewhat higher when we focus on remarks related to slack, consistent with slack remarks being more negative in low-inflation/high-slack periods and more positive in high-inflation/low-slack periods.

Lastly, we consider two potential concerns one might have with our baseline measure of net negativity. The first concern is the lexical sentiment analysis could mistakenly categorize a purely factual statement as positive or negative if that statement happens to contain a word in the LM positive or negative dictionaries. We address this concern in two ways. First, we construct an alternative net negativity measure that excludes/ignores statements that do not include a personal pronoun (I, I'm, I'll, I've, I'd, W/we, W/we're, $\mathrm{W} /$ we've, W/e'd, M/my, M/mine, O/our, us) based on the logic that utterances containing personal pronouns are more likely to express an opinion and not be a purely factual statement. The loss function regression using this measure are shown in column (5) of Table 4. The coefficients are very similar to the baseline results (in column (1)), and the estimated inflation target is unchanged at 1.55. Second, we construct a measure after manually removing factual phrases that would be scored positive or negative according to the LM lexicons. For example, the statement, "inflation declined last month," is scored as negative using the LM lexicons because "declined" is in the LM negative dictionary. To filter out such phrases, we first searched for directional words like "declined" in the LM positive and negative dictionaries. We identified 73 directional words (including variations such as "gain", "gained", "gaining"). We then identified all economic variables within the 
1500 most frequently occurring words (unigrams) in the transcripts - words such as "inflation," "price," "output," etc ${ }^{38}$ Finally, to construct this alternative "no fact phrase" measure of net negatively, we filter out (i.e., treat as neutral) any bigram represented by the pairing of a directional word and an economic variable. The regression results based on this alternative measure are shown in column (6) of Table 4 . The baseline results are virtually unchanged by filtering out such fact phrases.

The second concern is that some LM terms classified as positive or negative could plausibly be construed as neutral in central bank parlance. For example, the words "easing" and "stability," which are classified as positive by LM, might be mentioned in regard to neutral economic terms such as "quantitative easing" or "price stability." 39 More generally, the LM dictionary does not consider the word's context - the simplest example would be bigrams and trigams that contain positive or negative LM unigrams. We went through the 50 most common bigrams and trigrams that contain either a positive or negative LM word in the transcripts, and flagged those that have plausibly neutral sentiment (see Appendix Table G11). We then filtered out these flagged bigrams and trigrams.40 The results using this filtered subset of text are shown in column (7) of Table 4 of the paper (labeled "Adjusted LM"). The results are almost identical to the baseline 41

\subsection{Alternative Sentiment Measures}

Our baseline results are based on measuring sentiment using the difference between the fraction of negative words and the fraction of positive words (net negativity). In this subsection, we provide results based on alternative, independently-constructed sentiment measures. First, we estimate the FOMC loss function using the negative and positive fractions separately. Second, we generate a net negativity measure using a popular opensource python tool called VADER (Valence Aware Dictionary and Sentiment Reasoner) (Hutto and Gilbert (2014)). VADER is also a lexical sentiment classifier, based on a combination of available general-english and social media lexicons, but it also applies a number of heuristic rules to take account of certain contextual characteristics of how each word is used in a given sentence. The rules relate to negation (e.g., a word being preceded by "not" reverses its valence), punctuation (e.g., exclamation points), capitalization, degree modification (e.g., being preceded by "very" or "slightly"), and coming before or after the word "but." Such rules can improve the accuracy of a sentiment classifier. However, an

\footnotetext{
${ }^{38}$ See Appendix Table G12 for the full list of directional words and economic variables.

${ }^{39}$ Note, our baseline measure removes the words "unemployed" and "unemployment" for a similar reason.

${ }^{40}$ We also removed the unigrams "volatile," "volatility," "ease," and "easing."

${ }^{41}$ We report cross-correlations for these negativity measures in Appendix Table G13.
} 
important downside of VADER for our application is that the sentiment scores associated with its lexicon and rules are constructed from social media text/language which often will have very different word meanings than those in the economics and finance domain (as shown in Shapiro et al. (2018)).

The results of using these alternative measures are shown in Appendix Table G1 and are remarkably consistent across all of the sentiment measures. In particular, like the baseline measure, all three of the alternative measures point to an inflation target - that is, the inflation rate minimizing negativity and maximizing positivity - of approximately $1 \frac{1}{2}$. With regards to the other potential factors in the loss function, the results are generally qualitatively similar across the measures, though the statistical significance varies. One notable difference is that the financial variables appear to affect negativity more strongly than positivity.

\section{Corroborating Evidence on the Inflation Target}

\subsection{Narrative Analysis}

The analysis in the prior two sections estimated, among other things, the implicit inflation target most consistent with the FOMC's preferences, as revealed by the tone of their discussions. Here we complement that analysis with a narrative approach, aiming to identify explicit statements of a preferred inflation target. Specifically, we perform an automated regular expression (regex) search over all FOMC meeting transcripts (including conference calls) from 1986 through 2013 for terms or phrases related to inflation objectives ${ }^{42}$ We then reviewed and analyzed the sections of text corresponding to those matches.

Discussion of explicit inflation targeting did not begin to appear in the FOMC meetings until around 1994. Prior to then, FOMC participants occasionally mentioned an objective of "price stability" but without relating that to an explicit inflation target. One illuminating exception we found was a statement made by Federal Reserve Board Governor David Mullins in the November 1993 meeting that suggests an implicit target moving below 3 percent by that time: "I think there's a real payoff not just from stabilizing inflation in

\footnotetext{
${ }^{42}$ We performed two separate searches and collected the union of the two results. The first search looked for text containing any of the following strings: inflation target | inflation objective | long-run inflation | long run inflation | longer-run inflation | longer run inflation | inflation goal | objective for inflation | target for inflation | goal for inflation | PCE objective | PCE goal | PCE target | target for PCE inflation | goal for PCE inflation | objective for PCE inflation | objective for core | goal for core | target for core. The second was a regex search that looked for lines of text containing: (inflation | PCE) AND (percent) AND (objective|target|long-run|longer-run|long run|longer run), where "|" represents "or."
} 
the 3 to 4 percent range but in moving lower".

The first serious consideration of an explicit inflation target, that we could find, comes from St. Louis Fed President Thomas Meltzer in 1994. At the July meeting that year, he said "If we don't make an explicit statement in this FOMC testimony with respect to our long-run expectations on inflation that goes beyond 'we think price stability is good,' and get more specific in terms of a target range, then at the very least I think we have to make it clear that we consider 3 percent inflation to be unacceptable..." A few meetings later, in November 1994, he stated: "...I feel that it may be time for us to consider setting a specific inflation target that looks out into the future. I think, and this point was made as well, that it could make our job considerably easier in circumstances like the present-with upward cyclical inflationary pressures-if people were willing to look out to a longer-range target and that added to credibility."

There was much debate over the following couple years about whether the FOMC should have an inflation target, even internally. For instance, Atlanta Fed President Robert Forrestal during the Jan. 31/Feb. 11995 meeting said “...I would be against an inflation target and I would associate myself entirely with the views of Governor [Janet] Yellen" (who had noted some potential risks to having a target) while other participants expressed being in favor of a target. The question remained unsettled into the late 1990s, as exemplified by this statement from President Melzer at the November 1997 meeting: "What are the FOMC's intentions? Do we like seeing inflation below 2 percent? Does the public know it? I think, as I have said before, that we ought to be more explicit about our longer-term objective. In that event, it would be much less likely that our actions would be misinterpreted as being anti-jobs or anti-growth."

Starting in the early 2000s, however, explicit statements by FOMC participants of their inflation preferences became much more common. Indeed, while the automated regularexpression search described above found only 50 matches over 1986 to 1999 - and only 2 of those mentioned a specific inflation target - the search yielded several hundred matches over the 2000 to 2013 period. Reading through the sections of text corresponding to those matches, we identified and tabulated each instance in which a participant expressed their own preference for a specific numerical inflation target (or range such as between 1.5 and 2). Figure 7 plots the results of this narrative analysis. Each circle represents a stated preference, from the indicated speaker (y-axis) at the indicated FOMC meeting (x-axis), for a specific inflation target. The value of the preferred target is shown within the circle and also indicated by the circle's color. Values go from 1.0 (light blue) to 1.5 (dark blue) to 1.75 (purple) to 2.0 (red).

In total, we identified 58 statements of an inflation target preference. 20 of these 
expressed a preference for $1 \frac{1}{2}$ percent; 9 for either exactly $1 \frac{3}{4}$ or between $1 \frac{1}{2}$ and 2 percent; 27 for 2 percent; and just two for 1 percent. However, these aggregate counts mask a clear and important pattern over time. Statements in favor of a 2 percent target were non-existent before 2007 and did not become widespread until 2009, late in the Great Recession. In fact, a single participant, Governor Frederic Mishkin accounted for all but one of the pre-2009 2 percent statements 43 Prior to the Great Recession, $1 \frac{1}{2}$ percent was the overwhelming favorite among participants.

Although the consensus target preference was $1 \frac{1}{2}$ percent for most of our baseline sample period this analysis also reveals that some participants shifted their preference up to 2 percent during the Great Recession. Specifically. the transition of the consensus favorite over the course of the Great Recession is book-ended by the March 20-21, 2007 regular meeting and a conference call meeting on January 16, 2009. In the March 2007 meeting, FOMC participants were explicitly asked by the Chair if they thought the Fed should have an explicit numerical inflation target and, if so, what that target should be. Four members expressed a preference for $1 \frac{1}{2}$ percent, three for between $1 \frac{1}{2}$ and 2 percent, two for 1 percent, and just one (Mishkin) for 2 percent. In the January 2009 meeting, seven out of the ten members that voiced a specific preference desired 2 percent. In fact, most of those seven had themselves previously expressed a lower preferred target.

We next use this narrative evidence as a way to validate our sentiment-based approach of estimating the inflation target. Here we split our speaker-meeting observations into three subsamples: (1) observations in which the speaker's most recent explicit statement of an inflation target preference was for 2.0, (2) observations in which the speaker's most recent explicit statement of an inflation target was for below 2.0 (typically 1.5), and observations from speakers who do not explicitly state a preference 44 The results are shown in Table 5. We estimate an inflation target of 2.25 for doves ("narrative 2.0"), 1.36 for hawks ("narrative 1.5"), and in between at 1.55 for others. These results not only provide some external validation of the sentiment-based approach of measuring the inflation target, but also suggest that the majority of participants preferred an inflation target of $1 \frac{1}{2}$ percent over the 2000 to 2011 period, despite some FOMC participants shifting to a preference for 2 percent towards the end of the sample period. Of course, in January 2012, the 2 percent explicit target was codified officially by the FOMC in their public

\footnotetext{
${ }^{43}$ Governor Mishkin alluded to the fact that most other participants preferred $1 \frac{1}{2}$ percent at the October 2007 meeting: "People know that I am a 2 percent kind of guy, and I know good people here who are $1 \frac{1}{2}$ percent kinds of guys."

${ }^{44}$ Specifically, the "narrative 2.0" subsample consists of Cumming, Evans, Lockhart, Mishkin, Rosengren, and Kohn for all meetings, and Yellen and Pianalto for January 2009 onwards. The "narrative 1.5" subsample consists of Bullard, Plosser, Fisher, Lacker, Geithner, Poole, Meyer, Moskow, Broaddus, and Hoenig for all meetings, and Yellen and Pianalto prior to January 2009.
} 
announcement of the target. One plausible explanation for this shift was that, at this time, nominal interest rates had hit the zero lower bound, hampering the Fed's ability to raise inflation. In such a low interest rate environment, raising the inflation target can provide a hedge against hitting the zero lower bound in future episodes (see Ball (2014) and Andrade et al. (2018)).

\section{$5.2 \quad$ Heterogeneous Preferences}

An appealing feature of the sentiment analysis approach to studying central bank preferences is that it allows one to investigate heterogeneity in the loss function across different types of FOMC participants. In this subsection, we first investigate heterogeneity in preferences of Fed governors (including the chair) vs. regional presidents and of FOMC voters vs. non-voters. We then consider heterogeneity across hawks and doves, using several different hawk/dove measures. This latter analysis also serves to provide additional external validation of our key result that the FOMC had an implicit inflation target of 1.5 percent on average over 2000 to 2011.

Columns (1)-(4) of Table 6 report results where observations are split across particular types of speakers (defined by their status at the time of their remarks): (1) FOMC voting participants, (2) FOMC non-voting participants, (3) Governors, and (4) Regional Fed Presidents. Comparing voting and non-voting participants (columns (1) and (2), respectively), we find that voters have a somewhat higher implicit inflation target than non-voters, 1.75 versus 1.51, though the difference is not statistically significant. Comparing the results for governors (including the chair) versus regional Fed presidents, in columns (3) and (4), we find governors had a target close to 2 while presidents had a target of about 1.5. Moreover, the inflation target estimated from presidents' negativity is more precisely estimated than that from governors 45 It also appears that non-voters and regional presidents have stronger preferences in favor of higher output growth.

Next, we investigate how the implicit inflation target differs between hawks and doves on the FOMC based on external information signaling speakers' hawkishness/dovishness. We consider three different measures of hawkishness/dovishness. First, we split speakermeeting observations into hawkish and dovish following the lexical hawkish/dovish sentiment scoring approach of Malmendier et al. (2020) and Apel and Blix Grimadi (2014) (see Appendix F for details). We then code a speaker-meeting observation as hawkish (dovish) if its text contains more such hawkish (dovish) phrases than dovish (hawkish) phrases. Ties are considered neutral and dropped for the purposes of this exercise. Finally, we esti-

\footnotetext{
${ }^{45}$ We also tried estimating a separate loss function for FOMC chairs, however we found there were too few observations to obtain precise estimates.
} 
mate our baseline loss function regression separately for hawkish and dovish observations. The results are shown in columns (5) and (6) of Table 6. Consistent with the notion that hawks have a lower inflation target (i.e., are less tolerant of higher inflation), we estimate an inflation target of 1.45 for the hawkish subsample and 1.86 for the dovish subsample.

Second, and closely related, we classify speakers as either hawkish or dovish - restricting these classifications to be fixed over time - based on whether they had more or less hawkish phrases than dovish phrases over all of their utterances in the transcripts. We then estimate the baseline loss function regressions separately for hawkish and dovish speakers. The results are shown in columns (7) and (8) of Table 6. We find an inflation target of 1.35 for hawkish speakers and 1.73 for dovish speakers, consistent with hawkish speakers having a lower target.

Third, we classify speakers as hawkish or dovish based on observed dissents to FOMC interest rate decisions (i.e., statements) by participants. We used the data set of FOMC dissents from Thornton et al. (2014) which, in addition to listing which FOMC participants dissented in each meeting, notes whether the dissent was in a hawkish or dovish direction (i.e., favoring tighter or looser interest rate policy than the rest of the committee). Of course, many speakers/participants never dissented over our sample period; these speakers' observations are dropped for this exercise. We estimate our baseline regression separately for hawkish and dovish dissenters. The results are shown in columns (9) and (10) of Table 6. Based on dissents, we again find that hawkish participants preferred a lower inflation target than dovish participants, though the results here are less precise (likely due to the smaller number of observations because of the rarity of dissents) and the difference in the inflation target point estimates is smaller than in the prior analysis of hawks versus doves. These three separate analyses, in addition to the narrative analysis, not only reveal interesting heterogeneity in preferences across speaker types, but also provide strong evidence of external validity for our general sentiment analysis approach 46

\subsection{Taylor Rule Estimations of $\pi^{*}$}

As another way to corroborate the text-based estimate of $\pi^{*}$, we assess whether it is consistent with the FOMC's interest rate setting behavior. Specifically, we compare how well a simple Taylor rule fits with the 1.5 estimate versus two alternative measures of $\pi^{*}$ - the commonly held view of 2 percent and the perceived target variable (PTR) from

\footnotetext{
${ }^{46}$ As far as the coefficients on the other variables are concerned, there is no clear consistent pattern regarding the coefficients on the unemployment gap and output growth. However, it does appear that doves have a stronger preference in favor of higher stock market returns while hawks have a stronger dislike of higher stock $\mathrm{P} / \mathrm{E}$ ratios. These results may suggest that hawks have greater concern about potential overheating in financial markets.
} 
the FRB/US model used in many macroeconomic analyses. We estimate the following Taylor rule:

$$
f f r_{t}=\pi_{t}+r_{t}^{*}+\alpha\left(\pi_{t}-\pi_{t}^{*}\right)+\beta\left(u_{t}-u_{t}^{*}\right)+\varepsilon_{t}
$$

under three different measures of $\pi^{*}$ : a constant equal to 1.5 , a constant equal to 2 , and PTR (which is time varying). The variable $f f r_{t}$ is the nominal federal funds rate, $\pi_{t}$ is the average of the Greenbook nowcast and 1-quarter ahead measure of Core PCE inflation, and $\left(u_{t}-u_{t}^{*}\right)$ is the analogous measure of the Greenbook unemployment gap. We use two alternative measures of the natural rate of interest $\left(r_{t}^{*}\right)$ : Christensen and Rudebusch (2019) and Lubik and Matthes (2015) ${ }^{47}$

The results for the 2000-2008 period are shown in columns (1) through (6) of Table $7{ }^{48}$ We do not include the zero-lower-bound (ZLB) period because there is no time variation in the federal funds rate. The 1.5 measure of $\pi^{*}$ performs better in terms of $R^{2}$ across all three measures of $\pi^{*}$ in terms of R-squared as well as well the expected sign on the coefficients. Specifically, coefficients using $\pi^{*}=1.5$ appear to resemble the "balancedapproach" rule of Taylor (1999), where $\alpha=0.5$ and $\beta=-2$. Not only do the other two measures of $\pi^{*}$ have a worse fit, but they produce measures of $\alpha$ (the coefficient on inflation relative to its target) that are either insignificant or the wrong sign. This analysis gives evidence that the FOMC tended to raise (lower) interest rates when inflation was above (below) 1.5 percent, as opposed to the commonly held view of doing so around 2 percent or the PTR variable used in many macroeconomic models.

\subsection{FOMC Meeting Minutes}

A fourth piece of corroborating evidence on our baseline loss function estimates comes from applying our sentiment analysis approach to the FOMC meeting minutes. Three weeks after each FOMC meeting, the Federal Reserve releases a summary, known as the minutes, of the discussion at the meeting. The minutes are a general overview of the topics discussed and opinions expressed at the meeting, with no attribution of any comments or opinions to individual FOMC members. While the tone of the minutes is much less emotive than that of the actual spoken remarks made at the meeting, it is nonetheless

\footnotetext{
${ }^{47}$ Both measures are advantageous because they are "macroeconomic model-free" - meaning they are less prone to bias from any misspecification of output and inflation dynamics. Christensen and Rudebusch (2019) is based on a dynamic term-structure model and Lubik and Matthes (2015) is based on time-varying parameter vector auto-regressive model.

${ }^{48}$ In Section 6.2, we test the reaction function using a time-varying $\pi_{t}^{*}$ generated from FOMC transcripts going back to 1986 shown in columns (7) and (8) of Table 7.
} 
interesting to see whether the expressed negativity in the minutes relates to inflation, slack, and output growth in a similar fashion to that in the transcripts.

We therefore repeat the same loss function estimations done in subsections 4.1 and 4.2 above but using the net negativity from the minutes ${ }^{49}$ Though minutes are available for meetings up to the present, we restrict the sample period here to 2000-2011 to facilitate comparison to the transcripts' results above. We discuss results based on post-2011 minutes in the next section.

The results are shown in columns (1) and (2) of Table 8,50 Whether controls are omitted (column 1) or included (column 2), we obtain an estimated $\hat{\pi}^{*}$ close to 1.5. Indeed, in our preferred specification (column 2), we get exactly the same $\hat{\pi}^{*}$, at 1.55 , using the minutes as we did using the transcripts, though the standard error is larger. Thus, the language used in the public minutes of the FOMC meetings appears to point to a similar inflation target as that implied by the verbatim language actually used the meetings. We also find output growth has an even stronger effect on negativity in the minutes than in the transcripts, while stock market returns have a smaller (and statistically insignificant) effect.

\section{The Inflation Target in Other Periods}

Our baseline results in Section 4 are based on the January 2000 to December 2011 sample period. January 2000 is when the Greenbook first began routinely providing PCE inflation nowcasts and forecasts. December 2011 is the last month before the FOMC officially announced an inflation target. In January 2012, the FOMC announced an intended target of 2.0 percent based on the PCE inflation measure. In this section, we apply our sentiment analysis approach to estimating the implicit inflation target before and after the baseline 2000-2011 period.

\footnotetext{
${ }^{49} \mathrm{We}$ also estimate the loss function using sentiment from the public speeches of FOMC participants. The results are shown in Appendix Table G2. The estimated inflation target based on the speeches is higher (a little above 2) than that based on the FOMC meetings (either transcripts or minutes). A potential explanation is that policymakers may express less concern about inflation in public than in private.

${ }^{50}$ We follow the same non-linear gridsearch estimation procedure described and used in subsection 4.2 . Recall the procedure searches over potential inflation targets from 0.00 to 3.00 , with step sizes of 0.01 , for the estimated loss function yielding the minimum sum of squared residuals.
} 


\subsection{The Post-2011 Inflation Target}

We begin by considering the post-2011 period. As of the time of this writing, the latest available FOMC transcripts and Greenbook forecasts are for December 2015 (due to the Federal Reserve's five-year publication lag for these historical documents). In principal, one could use this short 2012 to 2015 period to estimate the loss function and test whether the inflation target shifted up to 2.0. However, aside from concerns related to relying on such a short time series dimension, a major complication comes from the fact than both actual inflation and Greenbook forecasts of inflation were well below 2 throughout the 2012-2015 period. In particular, our measure of Greenbook inflation (average of current quarter and one-quarter ahead forecasts) fluctuated within a narrow range from 1.05 to 1.75 (averaging a little under 1.5) during these four years 51 Any revealed preference approach, such as our sentiment analysis approach or a Taylor Rule approach, is unable to estimate a preferred inflation rate if that rate is outside of the range of observed values in the data. Thus, to examine the post-2011 period, we turn to the FOMC minutes, which are available up to the present. We demonstrated above that the minutes yield very similar results to those based on the transcripts.

Using the minutes net negativity, we estimate our baseline (symmetric V) loss function for the period from January 2012 through December 2019. We end the sample with 2019 to avoid the large volatility in economic and financial variables associated with the COVID19 pandemic, though the results (including $\hat{\pi}^{*}$ ) are very similar if we include data through 2020. Because Greenbook forecasts are not available through 2015 (as of the time of this writing), we fill in the time series data for those variables (inflation, unemployment gap, and output growth) using forecasts from IHS Markit/Macroeconomic Advisers (MA) 52 As we show in Appendix Figure G3, these near-term forecasts from MA track those from the Greenbook very closely.

The results are shown in columns (3) and (4) of Table 8. We find that the estimated inflation target did indeed shift up to 2.0 in the post-2011 period, consistent with the FOMC's establishment of an official 2 percent target in January 2012 [53

\footnotetext{
${ }^{51}$ See Appendix Figure G3

${ }^{52}$ As we did with the Greenbook data, we measure these variables using an average of current quarter and one-quarter ahead forecasts.

${ }^{53}$ Results based on the asymmetric V specification are very similar and are provided in Appendix Table G10.
} 


\subsection{The Pre-2000 Inflation Target}

Our baseline analysis is run during a period when inflation was relatively low and steady. Prior to the 1990s, however, inflation was higher and less stable. Indeed, numerous studies have shown that both trend inflation and inflation persistence dramatically declined (see Stock and Watson (2007), Stock and Watson (2016)) from the high inflation period of the 1970s and 80s to the late 1990s and 2000s. Other studies (for example, Ireland (2007)) have more explicitly linked this decline in trend inflation to a decline in the Federal Reserve's target. Committee members also noted that the implicit inflation target was likely declining over this period. For example in the January 2003 FOMC meeting, Governor Donald Kohn stated "...I do believe that, from 1987 at least into the second part of the 1990s, the Committee surely did not have a constant inflation target." Indeed, a close reading of the transcripts from the mid-1980s and the 1990s suggests that the FOMC was far from agreement on whether they should even have an explicit inflation target, much less what that target should be. An analysis that includes this period should therefore allow for the possibility that the implicit target - that is, the target consistent with the central bank's preferences - was time-varying and different than it was over the 2000-2011 period. Thus, we relax the assumption that $\pi^{*}$ is a constant, and estimate the FOMC's symmetric loss function allowing $\pi_{t}^{*}$ to be time varying.

For tractability, we make two assumptions about the path of $\pi_{t}^{*}$. First, $\pi_{t}^{*}$ is assumed to fit a constant over a "constant-target period" - defined as a time period between $s$ and $2011 \mathrm{~m} 12$. Second, $\pi_{t}^{*}$ is assumed to fit a quadratic polynomial function of time during a "time-varying-target period" - defined as a period between $1986 \mathrm{~m} 2$ and $s .54$ We imputed the core PCE forecasts back to $1986 \mathrm{~m} 1$ by splicing adjusted Greenbook forecasts of core CPI - adjusted using the average difference between core CPI and core PCE over pre-2000 period. We let the regime change, $s$, float freely which allows for the possibility that $\pi_{t}^{*}$ is time-varying or constant for the entire sample period, 1986m1-2011m12.

We perform a grid search over four parameters that govern the path of $\pi_{t}^{*}$ : a constant in the constant-target period, a slope and curvature in the time-varying-target period, and a date, $s$, of the regime switch between the time-varying and constant-target period. For aid in identification, we estimate $\pi_{t}^{*}$ assuming a symmetric V-shaped loss function, however, we allow the slope of the $\mathrm{V}$-shape to differ in the time-varying- and constanttarget periods. Technical details are available in Appendix C.

The results in Figures 5 (without controls) and 6 (with controls) 55 show that the

\footnotetext{
${ }^{54} 1986 \mathrm{~m} 2$ is the first month when core CPI inflation forecasts were published in the Greenbook.

${ }^{55}$ Controls include the full set included in column (2) of Table 2. We also include the difference between GB headline and core inflation to control for energy price fluctuations, which were volatile during this
} 
FOMC's implied inflation target did in fact decline over time. Specifically, $\pi_{t}^{*}$ is slightly above 3 percent in $1986 \mathrm{~m} 1$ and declines to approximately $1 \frac{1}{2}$ beginning in 2000 , where it remains until the end of the sample period $(2011 \mathrm{~m} 12)$. This decline is consistent with Ireland (2007), Cogley et al. (2010), and Coibion and Gorodnichenko (2011), which also found declines in $\pi^{*}$ over a similar time period, despite the very different approach 56 While the level of $\pi_{t}^{*}$ declined, the loss function became steeper (results not depicted in Figure) ${ }^{57}$ That is, the FOMC's language showed a stronger dislike of inflation deviations in the later period when inflation was in fact more stable and less persistent.

As an external validity check of this time-varying of measure of $\pi_{t}^{*}$, we use it in estimating the Federal Reserve's interest rate reaction function, equation (6) discussed in Section 5.3. The results of estimating this interest rate rule over the 1986-2008 period using this measure of $\pi_{t}^{*}$ are shown in column (7) of Table 7[58 The results are quite sensible, showing coefficients similar in magnitude and significance to those using the 1.5 measure over the 2000-2008 period. For comparison purposes, we repeat this exercise using the inflation target measure from the FRB/US model (PTR). The results based on the PTR show a much lower $R^{2}$ and the wrong sign on the inflation gap term. In sum, the time-varying $\hat{\pi}_{t}^{*}$ obtained using our sentiment analysis approach yields a more reasonable and better-fitting interest rate rule than one based on conventional measures.

\section{Conclusion}

We proposed and applied an approach to directly estimating central bank preferences using sentiment text analysis of internal policy-making deliberations. This approach could be applied to the estimation of the objective function for any central bank that provides transcripts or detailed summaries of their internal meetings. In this paper, we applied the approach to estimate the objectives of the U.S. Federal Open Market Committee, based on their internal meeting transcripts. Our baseline analysis, estimated on the period between 2000 and 2011, found that the FOMC's implicit inflation target was roughly $1 \frac{1}{2}$ percent. This result is robust to alternative functional forms for the loss function and

period.

${ }^{56}$ The finding that the FOMC's preferred inflation target fell from the mid-1980s to around 2000 contrasts somewhat with Ball and Mazumder (2018) who argue that the inflation target itself was flat during that period but that the public's inflation expectations shifted from being backward-looking to anchored at the Fed's target.

${ }^{57}$ The coefficient increased from 0.2 in the time-varying period to 0.45 in the stable period.

${ }^{58}$ We use the measure of $\pi_{t}^{*}$ constructed using controls, shown in Figure 6. For this extended analysis of the reaction function, we cannot use the Christensen-Rudebusch measure of $r^{*}$ since its only available back to 1999 . 
is also obtained when we separately analyze the negativity expressed in the minutes of the FOMC meetings. This estimate of the inflation target is significantly below survey measures of longer-run inflation expectations over this period. However, we document that FOMC members often explicitly stated their preferred inflation target and $1 \frac{1}{2}$ percent seemed to be the consensus choice at least up until 2009, when a shift up to 2 percent began to emerge. Indeed, we find corroborating evidence for this broader shift in preferences to 2 percent when we apply the sentiment analysis approach using data from FOMC minutes separately for the 2012-2019 period.

We also find that the FOMC's negativity was more strongly affected by output growth and financial conditions than by contemporaneous economic slack. The focus by central bankers' on output growth has been suggested in prior theoretical work (e.g., Walsh (2003)) and also found empirically in Taylor Rule estimations (e.g., Coibion and Gorodnichenko (2011)). It is also consistent with prior narrative analysis of FOMC communications by Thornton (2011), who showed that the FOMC routinely cited "growth in output," and not sustainable employment, the unemployment rate, or any concept of slack, as part of their policy directive from 1979 through 2008.

That financial variables may also enter the central bank's loss function is a much more contested issue. For example, Bernanke and Gertler (2001) argue that monetary policymakers should not respond to asset prices. Former vice chair Don Kohn Kohn (2006) and Kohn (2008)) went further, arguing that the Fed does not respond to asset prices. On the other side, Peek et al. (2015) augmented an empirical Taylor Rule with a variable measuring references to financial instability and found it to be significantly predictive of Fed interest rate changes. In a similar vein, Cieslak and Vissing-Jorgensen (2018) find that both actual negative stock market returns and references to stock market declines in the FOMC transcripts are predictive of target rate cuts. An interesting avenue of future research would be to better uncover why the FOMC appears to care about stock market returns, even after accounting for inflation, slack, and growth. One plausible reason is that FOMC members regard these variables as good indicators of the forward trajectory of the economy. That is, they serve as proxies for constant-interest-rate economic projections, measuring where the economy would be headed in the absence of any monetary policy actions. 


\section{References}

Afrouzi, H., Kumar, S., Coibion, O., and Gorodnichenko, Y. (2015). Inflation targeting does not anchor inflation expectations: Evidence from firms in new zealand. Brookings Papers on Economic Activity, (1):151-208.

Andrade, P., Galí, J., Bihan, H. L., and Matheron, J. (2018). The optimal inflation target and the natural rate of interest. Technical report, National Bureau of Economic Research.

Apel, M. and Blix Grimadi, M. (2014). How informative are central bank minutes? Review of Economics/Jahrbuch für Wirtschaftswissenschaften, 65(1).

Apel, M., Grimaldi, M., and Hull, I. (2019). How much information do monetary policy committees disclose? evidence from the fomc's minutes and transcripts. Technical report, Sveriges Riksbank Working Paper Series.

Baker, S. R., Bloom, N., and Davis, S. J. (2016). Measuring economic policy uncertainty*. The Quarterly Journal of Economics, 131(4):1593-1636.

Ball, L. and Mazumder, S. (2018). A phillips curve with anchored expectations and short-term unemployment. Journal of Money, Credit and Banking.

Ball, L. M. (2014). The case for a long-run inflation target of four percent. Number 14-92. International Monetary Fund.

Barro, R. J. and Gordon, D. B. (1983). Rules, discretion and reputation in a model of monetary policy. Journal of monetary economics, 12(1):101-121.

Bauer, M. D. and Rudebusch, G. D. (2017). Interest rates under falling stars. FRBSF Working Paper.

Bernanke, B. S. and Gertler, M. (2001). Should central banks respond to movements in asset prices? American Economic Review, 91(2):253-257.

Bianchi, F., Melosi, L., and Rottner, M. (2019). Hitting the elusive inflation target. Technical report, National Bureau of Economic Research.

Blanchard, O. (2018). On the future of macroeconomic models. Oxford Review of Economic Policy, 34(1-2):43-54. 
Blinder, A. S. (1997). Distinguished lecture on economics in government: What central bankers could learn from academics-and vice versa. The Journal of Economic Perspectives, 11(2):3-19.

Blinder, A. S. (2000). Central-bank credibility: why do we care? how do we build it? American economic review, 90(5):1421-1431.

Bomfim, A. N. and Rudebusch, G. D. (2000). Opportunistic and deliberate disinflation under imperfect credibility. Journal of Money, Credit and Banking, pages 707-721.

Cameron, A. C. and Miller, D. L. (2015). A practitioner's guide to cluster-robust inference. Journal of Human Resources, 50(2):317-372.

Chappell Jr, H. W., Havrilesky, T. M., and McGregor, R. R. (1997). Monetary policy preferences of individual fomc members: a content analysis of the memoranda of discussion. Review of Economics and Statistics, 79(3):454-460.

Christensen, J. H. and Rudebusch, G. D. (2012). The response of interest rates to us and uk quantitative easing. The Economic Journal, 122(564):F385-F414.

Christensen, J. H. and Rudebusch, G. D. (2019). A new normal for interest rates? evidence from inflation-indexed debt. Review of Economics and Statistics, 101(5):933-949.

Cieslak, A. and Vissing-Jorgensen, A. (2018). The economics of the fed put. working paper.

Clarida, R., Gali, J., and Gertler, M. (1999). The science of monetary policy: a new keynesian perspective. Journal of economic literature, 37(4):1661-1707.

Cogley, T., Primiceri, G. E., and Sargent, T. J. (2010). Inflation-gap persistence in the us. American Economic Journal: Macroeconomics, 2(1):43-69.

Coibion, O. and Gorodnichenko, Y. (2011). Monetary policy, trend inflation, and the great moderation: An alternative interpretation. American Economic Review, 101(1):341-70.

Coibion, O., Gorodnichenko, Y., and Wieland, J. (2012). The optimal inflation rate in new keynesian models: should central banks raise their inflation targets in light of the zero lower bound? Review of Economic Studies, 79(4):1371-1406.

Del Negro, M., Eusepi, S., Giannoni, M. P., Sbordone, A. M., Tambalotti, A., Cocci, M., Hasegawa, R., and Linder, M. (2013). The frbny dsge model. FRB of New York Staff Report, (647). 
Dennis, R. (2006). The policy preferences of the us federal reserve. Journal of Applied Econometrics, 21(1):55-77.

Di Tella, R., MacCulloch, R. J., and Oswald, A. J. (2001). Preferences over inflation and unemployment: Evidence from surveys of happiness. American economic review, 91(1):335-341.

Dotsey, M. and Ireland, P. (1996). The welfare cost of inflation in general equilibrium. Journal of Monetary Economics, 37(1):29-47.

Erceg, C. J. and Levin, A. T. (2003). Imperfect credibility and inflation persistence. Journal of monetary economics, 50(4):915-944.

Erosa, A. and Ventura, G. (2002). On inflation as a regressive consumption tax. Journal of Monetary Economics, 49(4):761-795.

Faust, J. and Svensson, L. E. (2001). Transparency and credibility: Monetary policy with unobservable goals. International Economic Review, 42(2):369-397.

Favero, C. A. and Rovelli, R. (2003). Macroeconomic stability and the preferences of the fed: A formal analysis, 1961-98. Journal of Money, Credit and Banking, pages 545-556.

FOMC (2012). Statement on longer-run goals and monetary policy strategy. [Online; posted 25-January-2012],

Fuhrer, J. C., Olivei, G. P., and Tootell, G. M. (2012). Inflation dynamics when inflation is near zero. Journal of Money, Credit and Banking, 44:83-122.

Giannoni, M. P. and Woodford, M. (2003). Optimal Interest-Rate Rules: I. General Theory. NBER Working Papers 9419, National Bureau of Economic Research, Inc.

Givens, G. E. (2012). Estimating central bank preferences under commitment and discretion. Journal of Money, credit and Banking, 44(6):1033-1061.

Heston, S. L. and Sinha, N. R. (2015). News versus sentiment: Predicting stock returns from news stories. Robert H. Smith School Research Paper.

Hutto, C. and Gilbert, E. (2014). Vader: A parsimonious rule-based model for sentiment analysis of social media text. Eighth International Conference on Weblogs and Social Media (ICWSM-14).

Ilbas, P. (2012). Revealing the preferences of the us federal reserve. Journal of Applied Econometrics, 27(3):440-473. 
Ireland, P. N. (2007). Changes in the federal reserve's inflation target: Causes and consequences. Journal of Money, credit and Banking, 39(8):1851-1882.

Jegadeesh, N. and Wu, D. A. (2017). Deciphering fedspeak: The information content of fomc meetings.

Kohn, D. L. (2006). Monetary policy and asset prices. European Central Bank.

Kohn, D. L. (2008). Monetary policy and asset prices revisited. Cato Institute.

Leduc, S. and Wilson, D. J. (2017). Has the Wage Phillips Curve Gone Dormant? FRBSF Economic Letter.

Liu, B. (2010). Sentiment analysis and subjectivity. Handbook of natural language processing, 2:627-666.

Loughran, T. and McDonald, B. (2011). When is a liability not a liability? textual analysis, dictionaries, and 10-ks. The Journal of Finance, 66(1):35-65.

Loughran, T. and McDonald, B. (2016). Textual analysis in accounting and finance: A survey. Journal of Accounting Research, 54(4):1187-1230.

Lubik, T. A. and Matthes, C. (2015). Calculating the natural rate of interest: A comparison of two alternative approaches. Richmond Fed Economic Brief, (Oct):1-6.

Lucas, R. E. (2001). Inflation and welfare. In Monetary Theory as a Basis for Monetary Policy, pages 96-142. Springer.

Malmendier, U., Nagel, S., and Yan, Z. (2020). The making of hawks and doves. Journal of Monetary Economics.

Meade, E. E. and Stasavage, D. (2008). Publicity of debate and the incentive to dissent: evidence from the us federal reserve. The Economic Journal, 118(528):695-717.

Nakamura, E. and Steinsson, J. (2018). High-frequency identification of monetary nonneutrality: The information effect*. The Quarterly Journal of Economics, 133(3):12831330.

Orphanides, A. (2004). Monetary policy rules, macroeconomic stability, and inflation: A view from the trenches. Journal of Money, Credit and Banking, pages 151-175.

Orphanides, A. and Williams, J. C. (2006). Monetary policy with imperfect knowledge. Journal of the European Economic Association, 4(2-3):366-375. 
Peek, J., Rosengren, E. S., and Tootell, G. M. (2015). Should us monetary policy have a ternary mandate? In Federal Reserve Bank of Boston 59 th Economic Conference: Macroprudential Monetary Policy.

Picault, M. and Renault, T. (2017). Words are not all created equal: A new measure of ecb communication. Journal of International Money and Finance, 79:136-156.

Romer, C. D. and Romer, D. H. (2004). A new measure of monetary shocks: Derivation and implications. American Economic Review, 94(4):1055-1084.

Rudebusch, G. and Svensson, L. E. (1999). Policy Rules for Inflation Targeting, pages 203-262. University of Chicago Press.

Shapiro, A. H., Sudhof, M., and Wilson, D. (2018). Measuring news sentiment. Working paper, Federal Reserve Bank of San Francisco.

Stock, J. H. and Watson, M. W. (2007). Why has us inflation become harder to forecast? Journal of Money, Credit and banking, 39:3-33.

Stock, J. H. and Watson, M. W. (2016). Core inflation and trend inflation. Review of Economics and Statistics, 98(4):770-784.

Surico, P. (2007). The fed's monetary policy rule and u.s. inflation: The case of asymmetric preferences. Journal of Economic Dynamics and Control, 31:305-324.

Svensson, L. E. (2015). The possible unemployment cost of average inflation below a credible target. American Economic Journal: Macroeconomics, 7(1):258-96.

Taylor, J. B. (1999). A historical analysis of monetary policy rules. In Monetary policy rules, pages 319-348. University of Chicago Press.

Thornton, D. L. (2011). What does the change in the fomc's statement of objectives mean? Economic Synopses, (1).

Thornton, D. L., Wheelock, D. C., et al. (2014). Making sense of dissents: a history of fomc dissents. Federal Reserve Bank of St. Louis Review, 96(3):213-227.

Walsh, C. (2003). Speed limit policies: the output gap and optimal monetary policy. American Economic Review, 93(1):265-278.

Walsh, C. E. (2004). Robustly optimal instrument rules and robust control: An equivalence result. Journal of Money, Credit and Banking, 36(6):1105-1113. 
Walsh, C. E. (2017). Monetary theory and policy. MIT press.

Wischnewsky, A., Jansen, D.-J., and Neuenkirch, M. (2019). Financial stability and the fed: Evidence from congressional hearings. De Nederlandsche Bank Working Paper.

Woodford, M. (2003). Optimal interest-rate smoothing. The Review of Economic Studies, $70(4): 861-886$. 
Table 1: Estimated U-shaped Loss Function

FOMC Meetings: $2000-2011$

\begin{tabular}{|c|c|c|c|c|}
\hline & 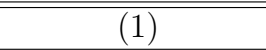 & $\overline{(2)}$ & $\overline{(3)}$ & 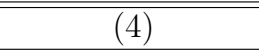 \\
\hline$\pi_{t}, \mathrm{~GB}$ & $\begin{array}{l}-1.145 \\
(0.716)\end{array}$ & $\begin{array}{l}-0.697 \\
(0.705)\end{array}$ & $\begin{array}{l}-1.066^{*} \\
(0.562)\end{array}$ & $\begin{array}{c}-1.720^{* * *} \\
(0.421)\end{array}$ \\
\hline$\pi_{t}^{2}, \mathrm{~GB}$ & $\begin{array}{l}0.458^{* *} \\
(0.203)\end{array}$ & $\begin{array}{l}0.384^{*} \\
(0.197)\end{array}$ & $\begin{array}{l}0.367^{* *} \\
(0.164)\end{array}$ & $\begin{array}{c}0.508^{* * *} \\
(0.126)\end{array}$ \\
\hline$\left(u_{t}-u_{t}^{*}\right), \mathrm{GB}$ & & $\begin{array}{c}0.154^{* *} \\
(0.0713)\end{array}$ & & $\begin{array}{c}-0.0482 \\
(0.0865)\end{array}$ \\
\hline$\left(u_{t}-u_{t}^{*}\right)^{2}, \mathrm{~GB}$ & & $\begin{array}{c}-0.0170 \\
(0.0143)\end{array}$ & & $\begin{array}{c}0.0130 \\
(0.0134)\end{array}$ \\
\hline$\Delta y_{t}, \mathrm{~GB}$ & & & $\begin{array}{c}-0.101^{* * *} \\
(0.0184)\end{array}$ & $\begin{array}{c}-0.0354 \\
(0.0263)\end{array}$ \\
\hline$\Delta y_{t}^{2}, \mathrm{~GB}$ & & & $\begin{array}{c}-0.0278^{* * *} \\
(0.00607)\end{array}$ & $\begin{array}{c}-0.0345^{* * *} \\
(0.00674)\end{array}$ \\
\hline S\&P Return, 3m & & & & $\begin{array}{c}-2.211^{* * *} \\
(0.597)\end{array}$ \\
\hline Shiller PE Ratio & & & & $\begin{array}{c}0.0186^{*} \\
(0.0107)\end{array}$ \\
\hline VIX Uncertainty & & & & $\begin{array}{c}0.00770 \\
(0.00578)\end{array}$ \\
\hline Short-Term Yield Volatility & & & & $\begin{array}{c}0.283 \\
(0.249)\end{array}$ \\
\hline Observations & 1676 & 1676 & 1676 & 1676 \\
\hline Adjusted $R^{2}$ & 0.043 & 0.053 & 0.169 & 0.227 \\
\hline Type & meeting & meeting & meeting & meeting \\
\hline Sample & $2000 \mathrm{~m} 1-2011 \mathrm{~m} 12$ & $2000 \mathrm{~m} 1-2011 \mathrm{~m} 12$ & 2000m1-2011m12 & 2000m1-2011m12 \\
\hline$\hat{\pi}^{*}$ & 1.249 & .908 & 1.451 & 1.691 \\
\hline $\mathrm{SE}$ & $(0.25)$ & $(0.471)$ & $(0.166)$ & $(0.102)$ \\
\hline 95\% C.I. & [.759-1.739] & {$[-.015-1.831]$} & {$[1.125-1.776]$} & [1.491 - 1.89] \\
\hline
\end{tabular}

The variables y and $\mathrm{y}^{*}$ denote $\log$ GDP and $\log$ potential GDP, respectively.

Standard errors (in parentheses) are robust to heteroskedasticity and two-way clustering by sample-month and speaker.

Regressions include speaker fixed effects.

${ }^{*} p<0.10,{ }^{* *} p<0.05,{ }^{* * *} p<0.01$ 
Table 2: Estimated V-shaped Loss Function

FOMC Meetings: $2000-2011$

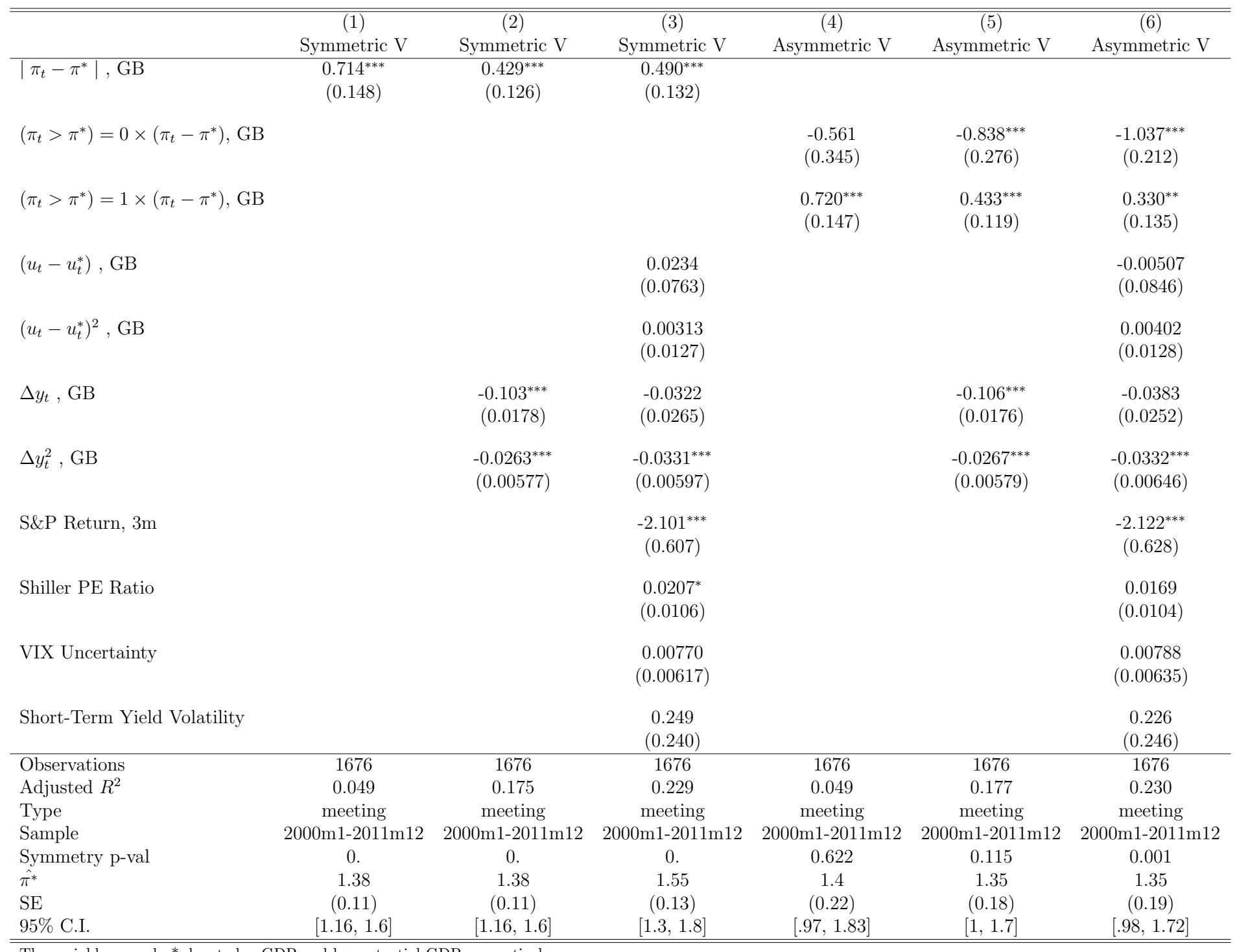

The variables y and $\mathrm{y}^{*}$ denote $\log$ GDP and log potential GDP, respectively.

Standard errors (in parentheses) are robust to heteroskedasticity and two-way clustering by sample-month and speaker.

Regressions include speaker fixed effects.

${ }^{*} p<0.10,{ }^{* *} p<0.05,{ }^{* * *} p<0.01$ 
Table 3: Estimated V-shaped Loss Function

Alternative Greenbook Forecast Horizons

FOMC Meetings: 2000 - 2011

\begin{tabular}{|c|c|c|c|c|}
\hline & $\begin{array}{c}\text { (1) } \\
0-1 \text { qtr ahead avg }\end{array}$ & $\begin{array}{c}\text { (2) } \\
0-2 \text { qtr ahead avg }\end{array}$ & $\begin{array}{c}\text { (3) } \\
0-3 \text { qtr ahead avg }\end{array}$ & $\begin{array}{c}(4) \\
0-4 \text { qtr ahead avg }\end{array}$ \\
\hline$\left|\pi_{t}-\pi^{*}\right|, \mathrm{GB}$ & $\begin{array}{c}0.489^{* * *} \\
(0.132)\end{array}$ & $\begin{array}{c}0.588^{* * *} \\
(0.153)\end{array}$ & $\begin{array}{c}0.649^{* * *} \\
(0.164)\end{array}$ & $\begin{array}{c}0.659^{* * *} \\
(0.172)\end{array}$ \\
\hline$\left(u_{t}-u_{t}^{*}\right), \mathrm{GB}$ & $\begin{array}{c}0.0226 \\
(0.0764)\end{array}$ & $\begin{array}{c}0.104 \\
(0.0777)\end{array}$ & $\begin{array}{c}0.179^{* *} \\
(0.0823)\end{array}$ & $\begin{array}{l}0.248^{* * *} \\
(0.0887)\end{array}$ \\
\hline$\left(u_{t}-u_{t}^{*}\right)^{2}, \mathrm{~GB}$ & $\begin{array}{l}0.00326 \\
(0.0127)\end{array}$ & $\begin{array}{l}-0.0141 \\
(0.0123)\end{array}$ & $\begin{array}{c}-0.0297^{* *} \\
(0.0131)\end{array}$ & $\begin{array}{c}-0.0430^{* * *} \\
(0.0144)\end{array}$ \\
\hline$\Delta y_{t}, \mathrm{~GB}$ & $\begin{array}{l}-0.0323 \\
(0.0265)\end{array}$ & $\begin{array}{c}0.0252 \\
(0.0383)\end{array}$ & $\begin{array}{c}0.0891 \\
(0.0594)\end{array}$ & $\begin{array}{c}0.169^{* *} \\
(0.0860)\end{array}$ \\
\hline$\Delta y_{t}^{2}, \mathrm{~GB}$ & $\begin{array}{l}-0.0331^{* * *} \\
(0.00597)\end{array}$ & $\begin{array}{l}-0.0436^{* * *} \\
(0.00762)\end{array}$ & $\begin{array}{l}-0.0562^{* * *} \\
(0.0106)\end{array}$ & $\begin{array}{l}-0.0703^{* * *} \\
(0.0145)\end{array}$ \\
\hline S\&P Return, 3m & $\begin{array}{c}-2.104^{* * *} \\
(0.606)\end{array}$ & $\begin{array}{c}-1.981^{* * *} \\
(0.589)\end{array}$ & $\begin{array}{c}-1.763^{* * *} \\
(0.594)\end{array}$ & $\begin{array}{c}-1.608^{* * *} \\
(0.609)\end{array}$ \\
\hline Shiller PE Ratio & $\begin{array}{l}0.0206^{*} \\
(0.0106)\end{array}$ & $\begin{array}{l}0.0253^{* *} \\
(0.0106)\end{array}$ & $\begin{array}{c}0.0293^{* * *} \\
(0.0108)\end{array}$ & $\begin{array}{c}0.0313^{* * *} \\
(0.0109)\end{array}$ \\
\hline VIX Uncertainty & $\begin{array}{c}0.00768 \\
(0.00616)\end{array}$ & $\begin{array}{c}0.0102^{*} \\
(0.00608)\end{array}$ & $\begin{array}{c}0.0122^{* *} \\
(0.00606)\end{array}$ & $\begin{array}{c}0.0136^{* *} \\
(0.00630)\end{array}$ \\
\hline Short-Term Yield Volatility & $\begin{array}{c}0.249 \\
(0.240)\end{array}$ & $\begin{array}{c}0.314 \\
(0.250)\end{array}$ & $\begin{array}{c}0.357 \\
(0.258)\end{array}$ & $\begin{array}{c}0.388 \\
(0.266)\end{array}$ \\
\hline Observations & 1676 & 1676 & 1676 & 1676 \\
\hline Adjusted $R^{2}$ & 0.229 & 0.223 & 0.218 & 0.213 \\
\hline Type & meeting & meeting & meeting & meeting \\
\hline Sample & 2000m1-2011m12 & 2000m1-2011m12 & 2000m1-2011m12 & $2000 \mathrm{~m} 1-2011 \mathrm{~m} 12$ \\
\hline$\hat{\pi}^{*}$ & 1.55 & 1.56 & 1.55 & 1.52 \\
\hline SE & $(0.13)$ & $(0.13)$ & $(0.12)$ & $(0.11)$ \\
\hline 95\% C.I. & {$[1.3,1.8]$} & {$[1.31,1.81]$} & {$[1.31,1.79]$} & {$[1.3,1.74]$} \\
\hline \multicolumn{5}{|c|}{$\begin{array}{l}\text { Columns differ in what horizons are included in the forecast average for each Greenbook (GB) variable. Column (1) is } \\
\text { our baseline specification and includes current-quarter (0-qtr ahead) and 1-quarter ahead forecasts. Column (2) includes } \\
0 \text { - through 2-quarter ahead forecasts; column (3) includes } 0 \text { - through } 3 \text {-quarter ahead forecast; and column (4) includes } \\
0 \text { - through 4-quarter ahead forecasts. Standard errors (in parentheses) are robust to heteroskedasticity and two-way } \\
\text { clustering by sample-month and speaker. Regressions include speaker fixed effects. } \\
{ }^{*} p<0.10,{ }^{* *} p<0.05,{ }^{* * *} p<0.01\end{array}$} \\
\hline
\end{tabular}


Table 4: Negativity using Filtered Subsets of Transcript Text

FOMC Meetings: 2000 - 2011

\begin{tabular}{|c|c|c|c|c|c|c|c|}
\hline & $\begin{array}{c}(1) \\
\text { Baseline }\end{array}$ & $\begin{array}{c}(2) \\
\text { All Text }\end{array}$ & $\begin{array}{c}(3) \\
\text { Inflation Text }\end{array}$ & $\begin{array}{c}(4) \\
\text { Slack Text }\end{array}$ & $\begin{array}{c}(5) \\
\text { Opinion Text }\end{array}$ & $\begin{array}{c}(6) \\
\text { No Fact Phrases }\end{array}$ & $\begin{array}{c}(7) \\
\text { Adjusted LM }\end{array}$ \\
\hline$\left|\pi_{t}-\pi^{*}\right|, \mathrm{GB}$ & $\begin{array}{c}0.489^{* * *} \\
(0.132)\end{array}$ & $\begin{array}{c}0.493^{* * *} \\
(0.133)\end{array}$ & $\begin{array}{c}0.411^{* * *} \\
(0.136)\end{array}$ & $\begin{array}{l}0.478^{* *} \\
(0.187)\end{array}$ & $\begin{array}{c}0.569^{* * *} \\
(0.131)\end{array}$ & $\begin{array}{c}0.446^{* * *} \\
(0.130)\end{array}$ & $\begin{array}{c}0.497^{* * *} \\
(0.126)\end{array}$ \\
\hline$\left(u_{t}-u_{t}^{*}\right), \mathrm{GB}$ & $\begin{array}{c}0.0226 \\
(0.0764)\end{array}$ & $\begin{array}{c}0.0177 \\
(0.0750)\end{array}$ & $\begin{array}{l}-0.0238 \\
(0.0901)\end{array}$ & $\begin{array}{l}-0.0477 \\
(0.107)\end{array}$ & $\begin{array}{c}0.0786 \\
(0.0611)\end{array}$ & $\begin{array}{r}-0.00912 \\
(0.0733)\end{array}$ & $\begin{array}{l}0.00471 \\
(0.0753)\end{array}$ \\
\hline$\left(u_{t}-u_{t}^{*}\right)^{2}, \mathrm{~GB}$ & $\begin{array}{c}0.00326 \\
(0.0127)\end{array}$ & $\begin{array}{c}0.00396 \\
(0.0124)\end{array}$ & $\begin{array}{c}0.0138 \\
(0.0153)\end{array}$ & $\begin{array}{c}0.0196 \\
(0.0185)\end{array}$ & $\begin{array}{r}-0.00945 \\
(0.0113)\end{array}$ & $\begin{array}{c}0.00962 \\
(0.0122)\end{array}$ & $\begin{array}{c}0.00675 \\
(0.0127)\end{array}$ \\
\hline$\Delta y_{t}, \mathrm{~GB}$ & $\begin{array}{l}-0.0323 \\
(0.0265)\end{array}$ & $\begin{array}{l}-0.0330 \\
(0.0262)\end{array}$ & $\begin{array}{l}-0.0528 \\
(0.0343)\end{array}$ & $\begin{array}{c}-0.0929^{*} \\
(0.0491)\end{array}$ & $\begin{array}{l}-0.0100 \\
(0.0286)\end{array}$ & $\begin{array}{l}-0.0323 \\
(0.0269)\end{array}$ & $\begin{array}{l}-0.0306 \\
(0.0258)\end{array}$ \\
\hline$\Delta y_{t}^{2}, \mathrm{~GB}$ & $\begin{array}{c}-0.0331^{* * *} \\
(0.00597)\end{array}$ & $\begin{array}{c}-0.0333^{* * *} \\
(0.00590)\end{array}$ & $\begin{array}{c}-0.0403^{* * *} \\
(0.00720)\end{array}$ & $\begin{array}{c}-0.0352^{* * *} \\
(0.00983)\end{array}$ & $\begin{array}{c}-0.0266^{* * *} \\
(0.00641)\end{array}$ & $\begin{array}{c}-0.0296^{* * *} \\
(0.00607)\end{array}$ & $\begin{array}{c}-0.0313^{* * *} \\
(0.00578)\end{array}$ \\
\hline S\&P Return, 3m & $\begin{array}{c}-2.104^{* * *} \\
(0.606)\end{array}$ & $\begin{array}{c}-2.090^{* * *} \\
(0.604)\end{array}$ & $\begin{array}{c}-2.276^{* * *} \\
(0.669)\end{array}$ & $\begin{array}{c}-3.039^{* * *} \\
(0.603)\end{array}$ & $\begin{array}{c}-2.035^{* * *} \\
(0.599)\end{array}$ & $\begin{array}{c}-2.124^{* * *} \\
(0.592)\end{array}$ & $\begin{array}{c}-2.173^{* * *} \\
(0.577)\end{array}$ \\
\hline Shiller PE Ratio & $\begin{array}{c}0.0206^{*} \\
(0.0106)\end{array}$ & $\begin{array}{l}0.0208^{* *} \\
(0.0104)\end{array}$ & $\begin{array}{c}0.0218^{*} \\
(0.0117)\end{array}$ & $\begin{array}{l}0.0313^{* *} \\
(0.0144)\end{array}$ & $\begin{array}{l}0.0236^{* * *} \\
(0.00902)\end{array}$ & $\begin{array}{c}0.0175^{*} \\
(0.00981)\end{array}$ & $\begin{array}{c}0.0181^{*} \\
(0.0103)\end{array}$ \\
\hline VIX Uncertainty & $\begin{array}{c}0.00768 \\
(0.00616)\end{array}$ & $\begin{array}{c}0.00757 \\
(0.00622)\end{array}$ & $\begin{array}{c}0.00686 \\
(0.00689)\end{array}$ & $\begin{array}{c}0.00360 \\
(0.00682)\end{array}$ & $\begin{array}{c}0.00885 \\
(0.00607)\end{array}$ & $\begin{array}{c}0.00590 \\
(0.00602)\end{array}$ & $\begin{array}{c}0.00641 \\
(0.00577)\end{array}$ \\
\hline Short-Term Yield Volatility & $\begin{array}{c}0.249 \\
(0.240)\end{array}$ & $\begin{array}{c}0.253 \\
(0.239)\end{array}$ & $\begin{array}{c}0.468 \\
(0.289)\end{array}$ & $\begin{array}{l}0.698^{* *} \\
(0.347)\end{array}$ & $\begin{array}{c}0.223 \\
(0.236)\end{array}$ & $\begin{array}{c}0.347 \\
(0.225)\end{array}$ & $\begin{array}{c}0.243 \\
(0.234)\end{array}$ \\
\hline Observations & 1676 & 1676 & 1609 & 1118 & 1676 & 1676 & 1676 \\
\hline Adjusted $R^{2}$ & 0.229 & 0.230 & 0.237 & 0.202 & 0.157 & 0.215 & 0.222 \\
\hline Type & meeting & meeting & meeting & meeting & meeting & meeting & meeting \\
\hline Sample & 2000m1-2011m12 & 2000m1-2011m12 & 2000m1-2011m12 & $2000 \mathrm{~m} 1-2011 \mathrm{~m} 12$ & 2000m1-2011m12 & 2000m1-2011m12 & 2000m1-2011m12 \\
\hline Speaker & ChairGovPres & ChairGovPres & ChairGovPres & ChairGovPres & ChairGovPres & ChairGovPres & ChairGovPres \\
\hline$\hat{\pi^{*}}$ & 1.55 & 1.56 & 1.55 & 1.79 & 1.55 & 1.55 & 1.57 \\
\hline SE & $(0.13)$ & $(0.12)$ & $(0.24)$ & $(0.2)$ & $(0.14)$ & $(0.12)$ & $(0.12)$ \\
\hline $95 \%$ C.I. & {$[1.3,1.8]$} & {$[1.32,1.8]$} & {$[1.08,2.02]$} & {$[1.4,2.18]$} & {$[1.28,1.82]$} & {$[1.31,1.79]$} & {$[1.33,1.81]$} \\
\hline
\end{tabular}

The variables y and $\mathrm{y}^{*}$ denote $\log$ GDP and $\log$ potential GDP, respectively.

Standard errors (in parentheses) are robust to heteroskedasticity and two-way clustering by sample-month and speaker. Regressions include speaker fixed effects.

${ }^{*} p<0.10,{ }^{* *} p<0.05,{ }^{* * *} p<0.01$ 
Table 5: Sample Splits Based on Narrative Evidence FOMC Meetings: $2000-2011$

\begin{tabular}{|c|c|c|c|c|}
\hline & $\begin{array}{c}(1) \\
\text { Baseline }\end{array}$ & $\begin{array}{c}(2) \\
\text { Narrative } 1.5\end{array}$ & $\begin{array}{c}(3) \\
\text { Narrative } 2.0\end{array}$ & $\begin{array}{c}(4) \\
\text { Other }\end{array}$ \\
\hline$\left|\pi_{t}-\pi^{*}\right|, \mathrm{GB}$ & $\begin{array}{c}0.489^{* * *} \\
(0.132)\end{array}$ & $\begin{array}{l}0.518^{* *} \\
(0.221)\end{array}$ & $\begin{array}{c}0.752^{* * *} \\
(0.208)\end{array}$ & $\begin{array}{c}0.398^{* * *} \\
(0.154)\end{array}$ \\
\hline$\left(u_{t}-u_{t}^{*}\right), \mathrm{GB}$ & $\begin{array}{c}0.0226 \\
(0.0764)\end{array}$ & $\begin{array}{c}0.119 \\
(0.116)\end{array}$ & $\begin{array}{c}-0.326^{* *} \\
(0.161)\end{array}$ & $\begin{array}{c}0.0453 \\
(0.0958)\end{array}$ \\
\hline$\left(u_{t}-u_{t}^{*}\right)^{2}, \mathrm{~GB}$ & $\begin{array}{l}0.00326 \\
(0.0127)\end{array}$ & $\begin{array}{l}-0.0106 \\
(0.0173)\end{array}$ & $\begin{array}{l}0.0522^{* *} \\
(0.0232)\end{array}$ & $\begin{array}{l}0.00182 \\
(0.0201)\end{array}$ \\
\hline$\Delta y_{t}, \mathrm{~GB}$ & $\begin{array}{l}-0.0323 \\
(0.0265)\end{array}$ & $\begin{array}{l}-0.0566 \\
(0.0417)\end{array}$ & $\begin{array}{c}-0.0324 \\
(0.0467)\end{array}$ & $\begin{array}{l}-0.0466^{*} \\
(0.0279)\end{array}$ \\
\hline$\Delta y_{t}^{2}, \mathrm{~GB}$ & $\begin{array}{c}-0.0331^{* * *} \\
(0.00597)\end{array}$ & $\begin{array}{c}-0.0310^{* * *} \\
(0.00764)\end{array}$ & $\begin{array}{c}-0.0669^{* * *} \\
(0.0145)\end{array}$ & $\begin{array}{c}-0.0266^{* * *} \\
(0.00666)\end{array}$ \\
\hline S\&P Return, 3m & $\begin{array}{c}-2.104^{* * *} \\
(0.606)\end{array}$ & $\begin{array}{l}-1.170 \\
(0.829)\end{array}$ & $\begin{array}{c}-4.674^{* * *} \\
(1.036)\end{array}$ & $\begin{array}{c}-2.270^{* * *} \\
(0.680)\end{array}$ \\
\hline Shiller PE Ratio & $\begin{array}{l}0.0206^{*} \\
(0.0106)\end{array}$ & $\begin{array}{c}0.0241 \\
(0.0165)\end{array}$ & $\begin{array}{c}0.0424 \\
(0.0474)\end{array}$ & $\begin{array}{l}0.0243^{*} \\
(0.0131)\end{array}$ \\
\hline VIX Uncertainty & $\begin{array}{c}0.00768 \\
(0.00616)\end{array}$ & $\begin{array}{c}0.0102 \\
(0.00885)\end{array}$ & $\begin{array}{c}-0.00339 \\
(0.0105)\end{array}$ & $\begin{array}{c}0.00552 \\
(0.00742)\end{array}$ \\
\hline Short-Term Yield Volatility & $\begin{array}{c}0.249 \\
(0.240)\end{array}$ & $\begin{array}{c}0.460 \\
(0.304)\end{array}$ & $\begin{array}{l}0.716^{*} \\
(0.413)\end{array}$ & $\begin{array}{l}-0.195 \\
(0.285)\end{array}$ \\
\hline Observations & 1676 & 587 & 240 & 849 \\
\hline Adjusted $R^{2}$ & 0.229 & 0.286 & 0.310 & 0.175 \\
\hline Type & meeting & meeting & meeting & meeting \\
\hline Sample & $2000 \mathrm{~m} 1-2011 \mathrm{~m} 12$ & $2000 \mathrm{~m} 1-2011 \mathrm{~m} 12$ & 2000m1-2011m12 & $2000 \mathrm{~m} 1-2011 \mathrm{~m} 12$ \\
\hline$\hat{\pi}^{*}$ & 1.55 & 1.36 & 2.25 & 1.55 \\
\hline $\mathrm{SE}$ & $(0.13)$ & $(0.2)$ & $(0.37)$ & $(0.13)$ \\
\hline 95\% C.I. & {$[1.3,1.8]$} & {$[.97,1.75]$} & {$[1.52,2.98]$} & {$[1.3,1.8]$} \\
\hline
\end{tabular}

The variables y and $\mathrm{y}^{*}$ denote $\log$ GDP and log potential GDP, respectively.

Standard errors (in parentheses) are robust to heteroskedasticity and two-way clustering by sample-month and speaker. Regressions include speaker fixed effects. ${ }^{*} p<0.10,{ }^{* *} p<0.05,{ }^{* * *} p<0.01$ 
Table 6: Allowing for Heterogeneity Across Speaker Types

FOMC Meetings: 2000 - 2011

\begin{tabular}{|c|c|c|c|c|c|c|c|c|c|c|}
\hline & $\begin{array}{c}(1) \\
\text { Voters }\end{array}$ & $\begin{array}{c}(2) \\
\text { Non-Voters }\end{array}$ & $\begin{array}{c}(3) \\
\text { Governors }\end{array}$ & $\begin{array}{c}(4) \\
\text { Presidents }\end{array}$ & $\begin{array}{c}\text { Hawkish Observations } \\
\text { Ho }\end{array}$ & $\begin{array}{c}(6) \\
\text { Dovish Observations }\end{array}$ & $\begin{array}{c}(7) \\
\text { Hawkish Speakers }\end{array}$ & $\begin{array}{c}(8) \\
\text { Dovish Speakers }\end{array}$ & $\begin{array}{c}\text { Hawkish Dissenters } \\
\text { Hal }\end{array}$ & $\begin{array}{c}(10) \\
\text { Dovish Dissenters }\end{array}$ \\
\hline$\left|\pi_{t}-\pi^{*}\right|, \mathrm{GB}$ & $\begin{array}{c}0.404^{* * *} \\
(0.146)\end{array}$ & $\begin{array}{c}0.713^{* * *} \\
(0.175)\end{array}$ & $\begin{array}{l}0.282^{*} \\
(0.161)\end{array}$ & $\begin{array}{c}0.651^{* * *} \\
(0.131)\end{array}$ & $\begin{array}{c}0.487^{* * *} \\
(0.144)\end{array}$ & $\begin{array}{c}0.654^{* * *} \\
(0.149)\end{array}$ & $\begin{array}{l}0.402^{* *} \\
(0.168)\end{array}$ & $\begin{array}{c}0.632^{* * *} \\
(0.170)\end{array}$ & $\begin{array}{l}0.668^{* *} \\
(0.324)\end{array}$ & $\begin{array}{c}0.665^{* * *} \\
(0.198)\end{array}$ \\
\hline$\left(u_{t}-u_{t}^{*}\right), \mathrm{GB}$ & $\begin{array}{l}0.00478 \\
(0.0997)\end{array}$ & $\begin{array}{c}0.0235 \\
(0.0879)\end{array}$ & $\begin{array}{c}0.0719 \\
(0.0774)\end{array}$ & $\begin{array}{r}-0.00129 \\
(0.0876)\end{array}$ & $\begin{array}{l}0.442^{* * *} \\
(0.0988)\end{array}$ & $\begin{array}{c}-0.331^{* * *} \\
(0.108)\end{array}$ & $\begin{array}{c}0.0954 \\
(0.0935)\end{array}$ & $\begin{array}{l}-0.102 \\
(0.107)\end{array}$ & $\begin{array}{c}0.181 \\
(0.118)\end{array}$ & $\begin{array}{c}-0.304^{* * *} \\
(0.116)\end{array}$ \\
\hline$\left(u_{t}-u_{t}^{*}\right)^{2}, \mathrm{~GB}$ & $\begin{array}{l}0.00377 \\
(0.0193)\end{array}$ & $\begin{array}{l}0.00524 \\
(0.0160)\end{array}$ & $\begin{array}{c}-0.00910 \\
(0.0156)\end{array}$ & $\begin{array}{l}0.00822 \\
(0.0133)\end{array}$ & $\begin{array}{c}-0.0791^{* * *} \\
(0.0203)\end{array}$ & $\begin{array}{c}0.0484^{* * *} \\
(0.0185)\end{array}$ & $\begin{array}{r}-0.00529 \\
(0.0168)\end{array}$ & $\begin{array}{c}0.0208 \\
(0.0164)\end{array}$ & $\begin{array}{c}-0.0129 \\
(0.0137)\end{array}$ & $\begin{array}{c}0.0221 \\
(0.0216)\end{array}$ \\
\hline$\Delta y_{t}, \mathrm{~GB}$ & $\begin{array}{c}-0.00351 \\
(0.0307)\end{array}$ & $\begin{array}{c}-0.0746^{* *} \\
(0.0328)\end{array}$ & $\begin{array}{c}0.0222 \\
(0.0385)\end{array}$ & $\begin{array}{c}-0.0542^{* *} \\
(0.0256)\end{array}$ & $\begin{array}{c}-0.112^{* * *} \\
(0.0422)\end{array}$ & $\begin{array}{l}0.0618^{* *} \\
(0.0291)\end{array}$ & $\begin{array}{c}-0.0619^{* *} \\
(0.0297)\end{array}$ & $\begin{array}{l}0.000388 \\
(0.0301)\end{array}$ & $\begin{array}{r}-0.107^{* * *} \\
(0.0347)\end{array}$ & $\begin{array}{c}-0.000740 \\
(0.0454)\end{array}$ \\
\hline$\Delta y_{t}^{2}, \mathrm{~GB}$ & $\begin{array}{c}-0.0335^{* * *} \\
(0.00626)\end{array}$ & $\begin{array}{c}-0.0375^{* * *} \\
(0.00941)\end{array}$ & $\begin{array}{c}-0.0296^{* * *} \\
(0.00901)\end{array}$ & $\begin{array}{c}-0.0366^{* * *} \\
(0.00664)\end{array}$ & $\begin{array}{c}-0.0312^{* * *} \\
(0.00894)\end{array}$ & $\begin{array}{c}-0.0401^{* * *} \\
(0.00646)\end{array}$ & $\begin{array}{c}-0.0294^{* * *} \\
(0.00689)\end{array}$ & $\begin{array}{c}-0.0394^{* * *} \\
(0.00816)\end{array}$ & $\begin{array}{c}-0.0149^{*} \\
(0.00800)\end{array}$ & $\begin{array}{c}-0.0526^{* * *} \\
(0.00989)\end{array}$ \\
\hline S\&P Return, $3 \mathrm{~m}$ & $\begin{array}{c}-2.762^{* * *} \\
(0.712)\end{array}$ & $\begin{array}{c}-1.429^{* *} \\
(0.631)\end{array}$ & $\begin{array}{c}-3.277^{* * *} \\
(0.793)\end{array}$ & $\begin{array}{c}-1.673^{* * *} \\
(0.618)\end{array}$ & $\begin{array}{c}-1.622^{*} \\
(0.880)\end{array}$ & $\begin{array}{c}-2.840^{* * *} \\
(0.549)\end{array}$ & $\begin{array}{c}-1.695^{* *} \\
(0.714)\end{array}$ & $\begin{array}{c}-2.674^{* * *} \\
(0.684)\end{array}$ & $\begin{array}{c}-1.569^{* *} \\
(0.680)\end{array}$ & $\begin{array}{c}-2.407^{* * *} \\
(0.204)\end{array}$ \\
\hline Shiller PE Ratio & $\begin{array}{c}0.0185 \\
(0.0129)\end{array}$ & $\begin{array}{l}0.0253^{* *} \\
(0.0111)\end{array}$ & $\begin{array}{l}0.0270^{* *} \\
(0.0113)\end{array}$ & $\begin{array}{c}0.0199 \\
(0.0122)\end{array}$ & $\begin{array}{c}0.0731^{* * *} \\
(0.0106)\end{array}$ & $\begin{array}{l}-0.00687 \\
(0.0141)\end{array}$ & $\begin{array}{l}0.0223^{*} \\
(0.0116)\end{array}$ & $\begin{array}{c}0.0193 \\
(0.0160)\end{array}$ & $\begin{array}{l}0.0309^{* *} \\
(0.0138)\end{array}$ & $\begin{array}{l}-0.0288^{*} \\
(0.0164)\end{array}$ \\
\hline VIX Uncertainty & $\begin{array}{c}0.00617 \\
(0.00756)\end{array}$ & $\begin{array}{c}0.00956 \\
(0.00591)\end{array}$ & $\begin{array}{l}0.000469 \\
(0.00714)\end{array}$ & $\begin{array}{c}0.0108 \\
(0.00697)\end{array}$ & $\begin{array}{c}0.00688 \\
(0.00919)\end{array}$ & $\begin{array}{c}0.0147^{* *} \\
(0.00641)\end{array}$ & $\begin{array}{c}0.00442 \\
(0.00854)\end{array}$ & $\begin{array}{c}0.0115 \\
(0.00729)\end{array}$ & $\begin{array}{c}-0.00205 \\
(0.00694)\end{array}$ & $\begin{array}{c}-0.00731 \\
(0.00820)\end{array}$ \\
\hline Short-Term Yield Volatility & $\begin{array}{l}0.0803 \\
(0.276) \\
\end{array}$ & $\begin{array}{l}0.449^{* *} \\
(0.228)\end{array}$ & $\begin{array}{c}-0.00399 \\
(0.348) \\
\end{array}$ & $\begin{array}{c}0.322 \\
(0.250) \\
\end{array}$ & $\begin{array}{l}-0.505 \\
(0.329) \\
\end{array}$ & $\begin{array}{c}0.309 \\
(0.355)\end{array}$ & $\begin{array}{l}-0.127 \\
(0.286) \\
\end{array}$ & $\begin{array}{l}0.548^{* *} \\
(0.277)\end{array}$ & $\begin{array}{r}-0.0198 \\
(0.275) \\
\end{array}$ & $\begin{array}{l}-0.378 \\
(0.436) \\
\end{array}$ \\
\hline Observations & 1015 & 661 & 542 & 1134 & 402 & 408 & 817 & 819 & 348 & 257 \\
\hline $\begin{array}{l}\text { Adjusted } R^{2} \\
\text { Type }\end{array}$ & $\begin{array}{l}0.164 \\
\text { meeting }\end{array}$ & $\begin{array}{l}0.319 \\
\text { meeting }\end{array}$ & $\begin{array}{l}0.107 \\
\text { meeting }\end{array}$ & $\begin{array}{l}0.304 \\
\text { meeting }\end{array}$ & $\begin{array}{c}0.242 \\
\text { meeting }\end{array}$ & $\begin{array}{l}0.202 \\
\text { meeting }\end{array}$ & $\begin{array}{l}0.221 \\
\text { meeting }\end{array}$ & $\begin{array}{l}0.245 \\
\text { meeting }\end{array}$ & $\begin{array}{c}0.254 \\
\text { meeting }\end{array}$ & $\begin{array}{c}0.283 \\
\text { meeting }\end{array}$ \\
\hline Sample & $2000 \mathrm{~m} 1-2011 \mathrm{~m} 12$ & $2000 \mathrm{~m} 1-2011 \mathrm{~m} 12$ & $2000 \mathrm{~m} 1-2011 \mathrm{~m} 12$ & $2000 \mathrm{~m} 1-2011 \mathrm{~m} 12$ & $2000 \mathrm{~m} 1-2011 \mathrm{~m} 12$ & $2000 \mathrm{~m} 1-2011 \mathrm{~m} 12$ & $2000 \mathrm{~m} 1-2011 \mathrm{~m} 12$ & $2000 \mathrm{~m} 1-2011 \mathrm{~m} 12$ & 2000m1-2011m12 & $2000 \mathrm{~m} 1-2011 \mathrm{~m} 12$ \\
\hline$\hat{\pi}^{*}$ & 1.75 & 1.51 & 2.05 & 1.54 & 1.45 & 1.86 & 1.35 & 1.73 & 1.3 & 1.52 \\
\hline SE & $(0.26)$ & $(0.14)$ & $(0.43)$ & $(0.16)$ & $(0.26)$ & $(0.24)$ & $(0.18)$ & $(0.17)$ & $(0.26)$ & $(0.25)$ \\
\hline $95 \%$ C.I. & {$[1.24,2.26]$} & {$[1.24,1.78]$} & {$[1.21,2.89]$} & {$[1.23,1.85]$} & {$[.9399,1.96]$} & {$[1.39,2.33]$} & {$[1,1.7]$} & {$[1.4,2.06]$} & {$[.79,1.81]$} & {$[1.03,2.01]$} \\
\hline
\end{tabular}

Standard errors (in parentheses) are robust to heteroskedasticity and two-way clustering by sample-month and speaker. Regressions include speaker fixed effects.

${ }^{*} p<0.10,{ }^{* *} p<0.05,{ }^{* * *} p<0.01$ 
Table 7: Estimated Taylor Rules under alternative measures of $\pi^{*}$

\begin{tabular}{|c|c|c|c|c|c|c|c|c|}
\hline & $\begin{array}{c}(1) \\
\pi^{*}=1.5\end{array}$ & $\begin{array}{c}(2) \\
\pi^{*}=1.5\end{array}$ & $\begin{array}{c}(3) \\
\pi^{*}=2\end{array}$ & $\begin{array}{c}(4) \\
\pi^{*}=2\end{array}$ & $\begin{array}{c}(5) \\
\pi^{*}=\mathrm{PTR}\end{array}$ & $\begin{array}{c}(6) \\
\pi^{*}=\mathrm{PTR}\end{array}$ & $\begin{array}{c}(7) \\
\pi^{*}=\mathrm{SW}\end{array}$ & $\begin{array}{c}(8) \\
\pi^{*}=\mathrm{PTR}\end{array}$ \\
\hline$\left(u_{t}-u_{t}^{*}\right), \mathrm{GB}$ & $\begin{array}{c}-1.718^{* * *} \\
(0.0976)\end{array}$ & $\begin{array}{c}-1.343^{* * *} \\
(0.112)\end{array}$ & $\begin{array}{c}-1.837^{* * *} \\
(0.108)\end{array}$ & $\begin{array}{c}-1.404^{* * *} \\
(0.149)\end{array}$ & $\begin{array}{c}-1.919^{* * *} \\
(0.116)\end{array}$ & $\begin{array}{c}-1.505^{* * *} \\
(0.162)\end{array}$ & $\begin{array}{c}-1.271^{* * *} \\
(0.0711)\end{array}$ & $\begin{array}{c}-1.251^{* * *} \\
(0.0686)\end{array}$ \\
\hline$\left(\pi_{t}-\pi_{t}^{*}\right), \mathrm{GB}$ & $\begin{array}{c}0.559^{* * *} \\
(0.143)\end{array}$ & $\begin{array}{c}0.795^{* * *} \\
(0.117)\end{array}$ & $\begin{array}{l}-0.166 \\
(0.157)\end{array}$ & $\begin{array}{c}0.110 \\
(0.177)\end{array}$ & $\begin{array}{c}-0.358^{* *} \\
(0.153)\end{array}$ & $\begin{array}{l}-0.179 \\
(0.184)\end{array}$ & $\begin{array}{l}0.898^{* * *} \\
(0.0616)\end{array}$ & $\begin{array}{c}-0.632^{* * *} \\
(0.0741)\end{array}$ \\
\hline Observations & 108 & 108 & 108 & 108 & 108 & 108 & 254 & 254 \\
\hline Adjusted $R^{2}$ & 0.787 & 0.740 & 0.754 & 0.647 & 0.760 & 0.649 & 0.675 & 0.475 \\
\hline$r^{*}$ & $\mathrm{CR}$ & LM & $\mathrm{CR}$ & LM & $\mathrm{CR}$ & LM & LM & LM \\
\hline Period & $2000 \mathrm{~m} 1-2008 \mathrm{~m} 12$ & 2000m1-2008m12 & 2000m1-2008m12 & $2000 \mathrm{~m} 1-2008 \mathrm{~m} 12$ & $2000 \mathrm{~m} 1-2008 \mathrm{~m} 12$ & $2000 \mathrm{~m} 1-2008 \mathrm{~m} 12$ & $1986 \mathrm{~m} 2-2008 \mathrm{~m} 12$ & $1986 \mathrm{~m} 2-2008 \mathrm{~m} 12$ \\
\hline
\end{tabular}

Columns (1) and (2) are estimated with $\pi^{*}$ equal to 1.5, columns (3) and (4) with $\pi^{*}$ equal to 2, column (7) with the time-varying $\pi^{*}$ estimated in Section 6 with controls (labeled SW),

and columns (5), (6), and (8) with $\pi^{*}$ equal to the time-varying variable FRB/US model variable PTR.

Columns (1), (3), and (5) are estimated with $\mathrm{r}^{*}$ taken from Christensen and Rudebusch 2019) (CR), and columns (2), (4), (6), (7), and (8) are estimated with $\mathrm{r}^{*}$ taken from Lubik and Matthes 2015) (LM)

${ }^{*} p<0.10,{ }^{* *} p<0.05,{ }^{* * *} p<0.01$ 
Table 8: Estimated Loss Function Based on FOMC Minutes

\begin{tabular}{|c|c|c|c|c|}
\hline & $\begin{array}{c}(1) \\
2000-2011\end{array}$ & $\begin{array}{c}(2) \\
2000-2011\end{array}$ & $\begin{array}{c}(3) \\
2012-2019\end{array}$ & $\begin{array}{c}(4) \\
2012-2019\end{array}$ \\
\hline$\left|\pi_{t}-\pi^{*}\right|$ & $\begin{array}{c}0.716^{* * *} \\
(0.240)\end{array}$ & $\begin{array}{l}0.428^{* *} \\
(0.180)\end{array}$ & $\begin{array}{c}0.204 \\
(0.165)\end{array}$ & $\begin{array}{l}0.301^{*} \\
(0.174)\end{array}$ \\
\hline$\left(u_{t}-u_{t}^{*}\right)$ & & $\begin{array}{c}0.161 \\
(0.109)\end{array}$ & & $\begin{array}{c}-0.485^{* * *} \\
(0.136)\end{array}$ \\
\hline$\left(u_{t}-u_{t}^{*}\right)^{2}$ & & $\begin{array}{l}-0.0228 \\
(0.0186)\end{array}$ & & $\begin{array}{c}0.0617 \\
(0.0403)\end{array}$ \\
\hline$\Delta y_{t}$ & & $\begin{array}{c}-0.198^{* * *} \\
(0.0317)\end{array}$ & & $\begin{array}{l}-0.276 \\
(0.478)\end{array}$ \\
\hline$\Delta y_{t}^{2}$ & & $\begin{array}{r}-0.0335^{* * *} \\
(0.00594)\end{array}$ & & $\begin{array}{c}0.0239 \\
(0.0847)\end{array}$ \\
\hline S\&P Return, 3m & & $\begin{array}{l}-1.043 \\
(0.718)\end{array}$ & & $\begin{array}{c}-0.399 \\
(1.005)\end{array}$ \\
\hline Shiller PE Ratio & & $\begin{array}{l}0.0348^{* *} \\
(0.0133)\end{array}$ & & $\begin{array}{c}-0.130^{* * *} \\
(0.0327)\end{array}$ \\
\hline VIX Uncertainty & & $\begin{array}{c}0.0112 \\
(0.00760)\end{array}$ & & $\begin{array}{c}-0.00505 \\
(0.0123)\end{array}$ \\
\hline Short-Term Yield Volatility & & $\begin{array}{l}0.0381 \\
(0.402)\end{array}$ & & $\begin{array}{c}0.157 \\
(0.607)\end{array}$ \\
\hline Constant & $\begin{array}{c}0.629^{* * *} \\
(0.122)\end{array}$ & $\begin{array}{c}0.300 \\
(0.407)\end{array}$ & $\begin{array}{l}0.436^{* * *} \\
(0.0796)\end{array}$ & $\begin{array}{c}4.576^{* * *} \\
(0.788)\end{array}$ \\
\hline Observations & 95 & 95 & 64 & 64 \\
\hline Adjusted $R^{2}$ & 0.088 & 0.765 & 0.005 & 0.354 \\
\hline Type & minutes & minutes & minutes & minutes \\
\hline Sample & $2000 \mathrm{~m} 1-2011 \mathrm{~m} 12$ & 2000m1-2011m12 & 2012m1-2019m12 & 2012m1-2019m12 \\
\hline$\hat{\pi}^{*}$ & 1.43 & 1.55 & 1.97 & 2.01 \\
\hline $\mathrm{SE}$ & $(0.27)$ & $(0.31)$ & $(0.38)$ & $(0.27)$ \\
\hline 95\% C.I. & {$[.95,1.55]$} & {$[1.2,2.15]$} & {$[1.42,2.58]$} & {$[1.43,2.43]$} \\
\hline
\end{tabular}

Because Greenbook forecasts are unavailable past 2015m12 we use IHS Markit/Macroeconomic Advisers forecasts for $2016 \mathrm{~m} 1$ onward. Standard errors (in parentheses) are robust to heteroskedasticity.

${ }^{*} p<0.10,{ }^{* *} p<0.05,{ }^{* * *} p<0.01$ 
Figure 1: LM Net Negativity vs. Human Scores

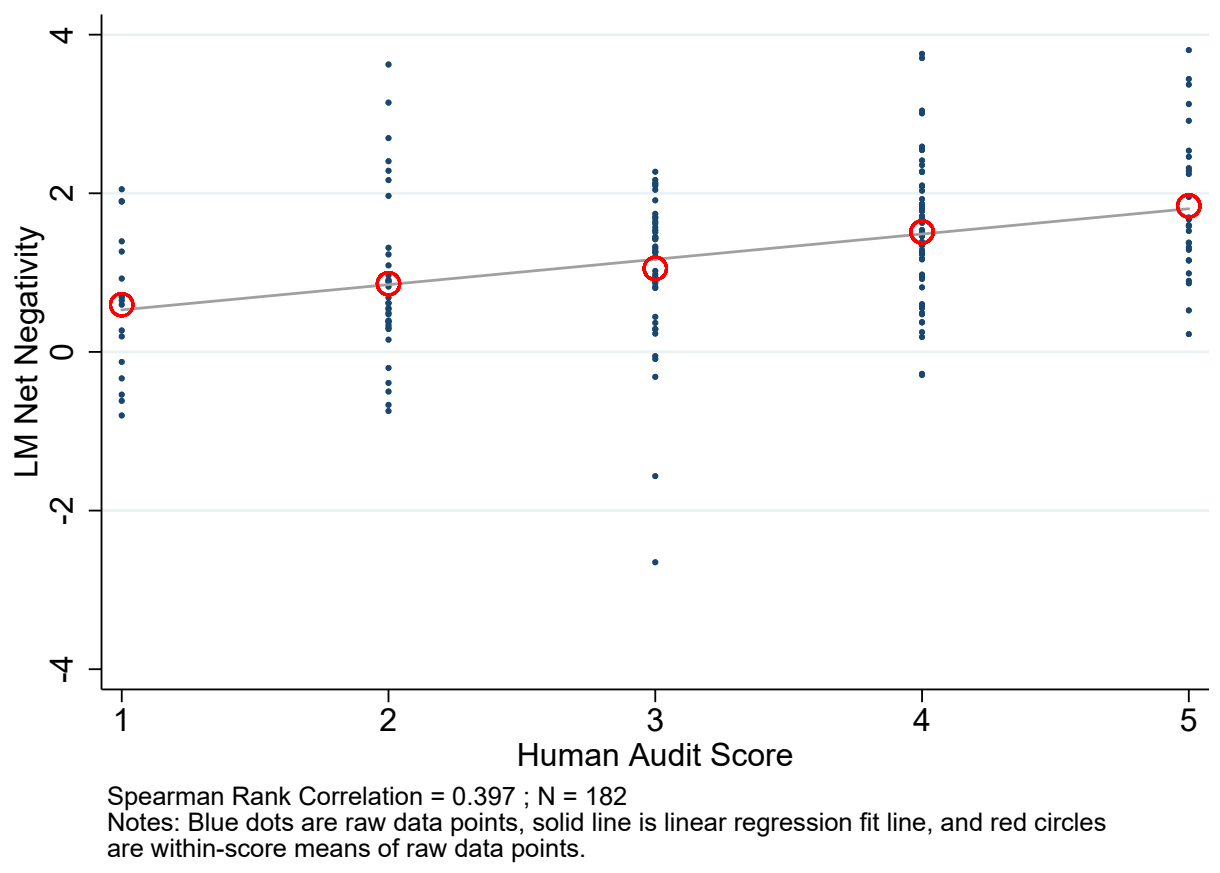

Figure 2: Transcripts of FOMC Meetings

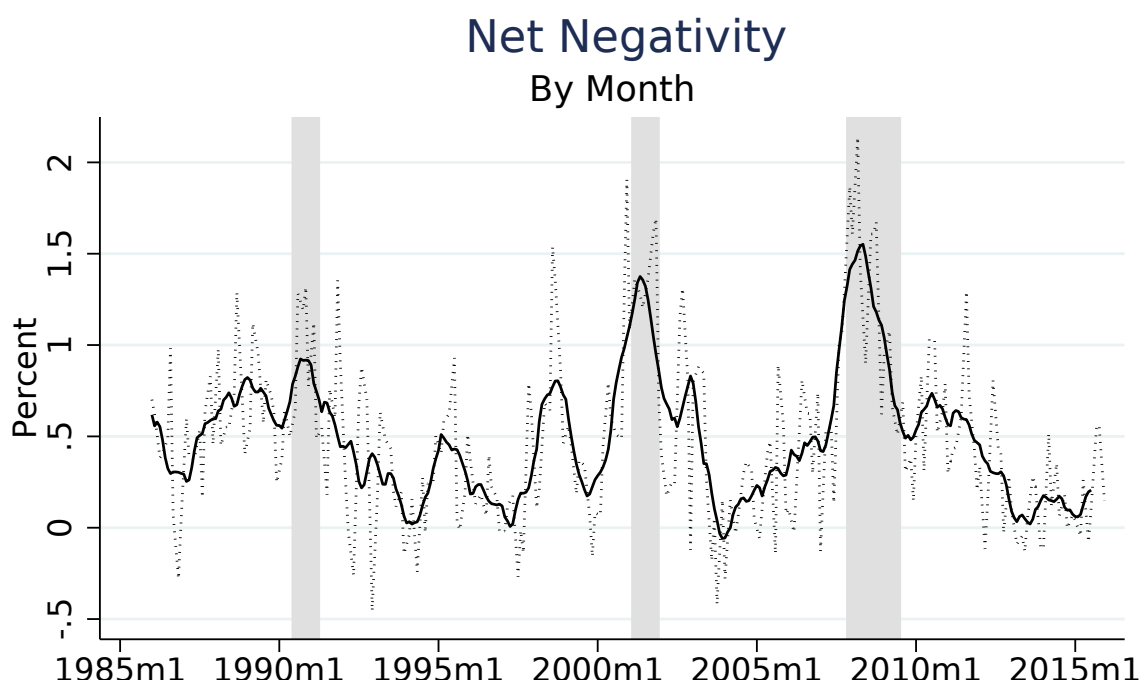

Dotted line plots coefficients on time dummies from regression with speaker fixed effects. Solid line is 11-month centered moving average.

Gray shaded areas indicate recessions. 
Figure 3: Estimated Loss Function for Inflation - Alternative Specifications

(a) Symmetric U (Quadratic)

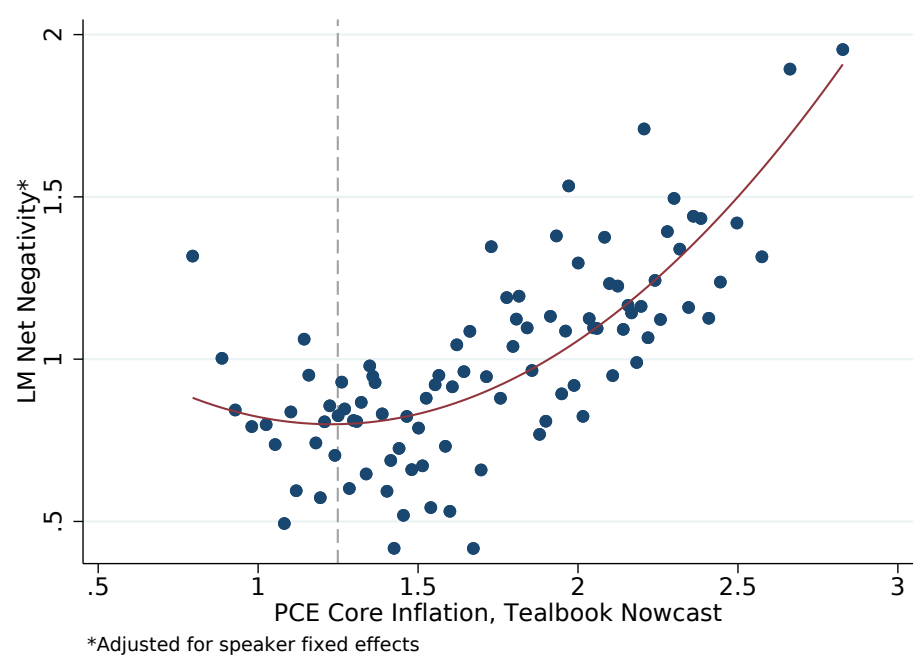

(b) Symmetric V (Constrained Piecewise-Linear)

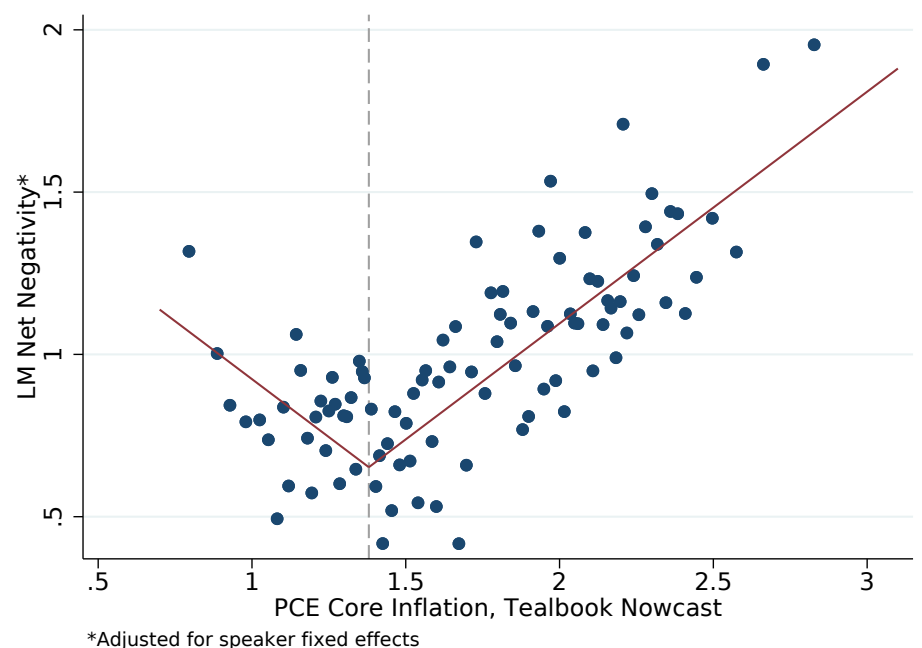

(c) Asymmetric V (Piecewise-Linear)

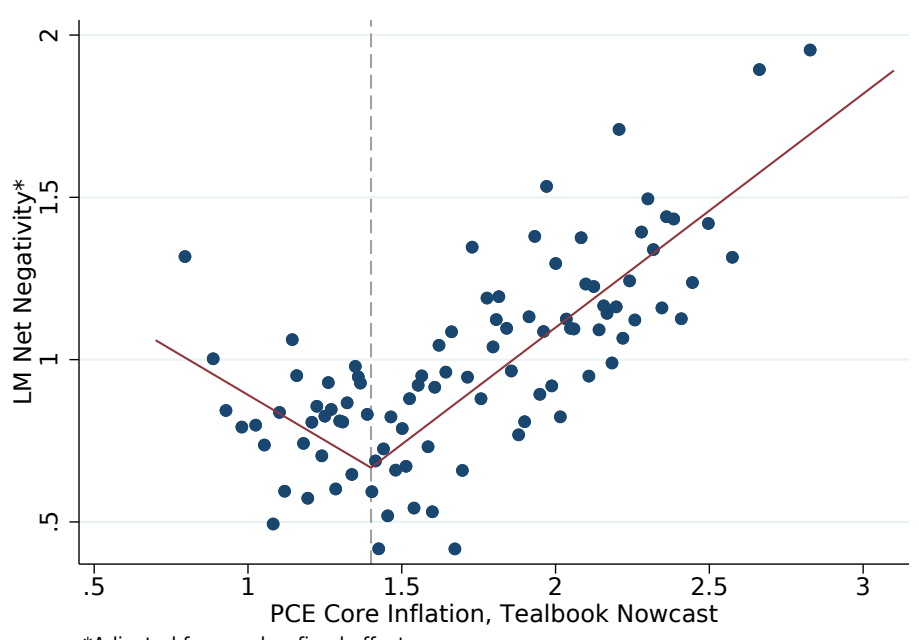

*Adjusted for speaker fixed effects 
Figure 4: $\hat{\pi}^{*}$ Compared with SPF Inflation Expectations

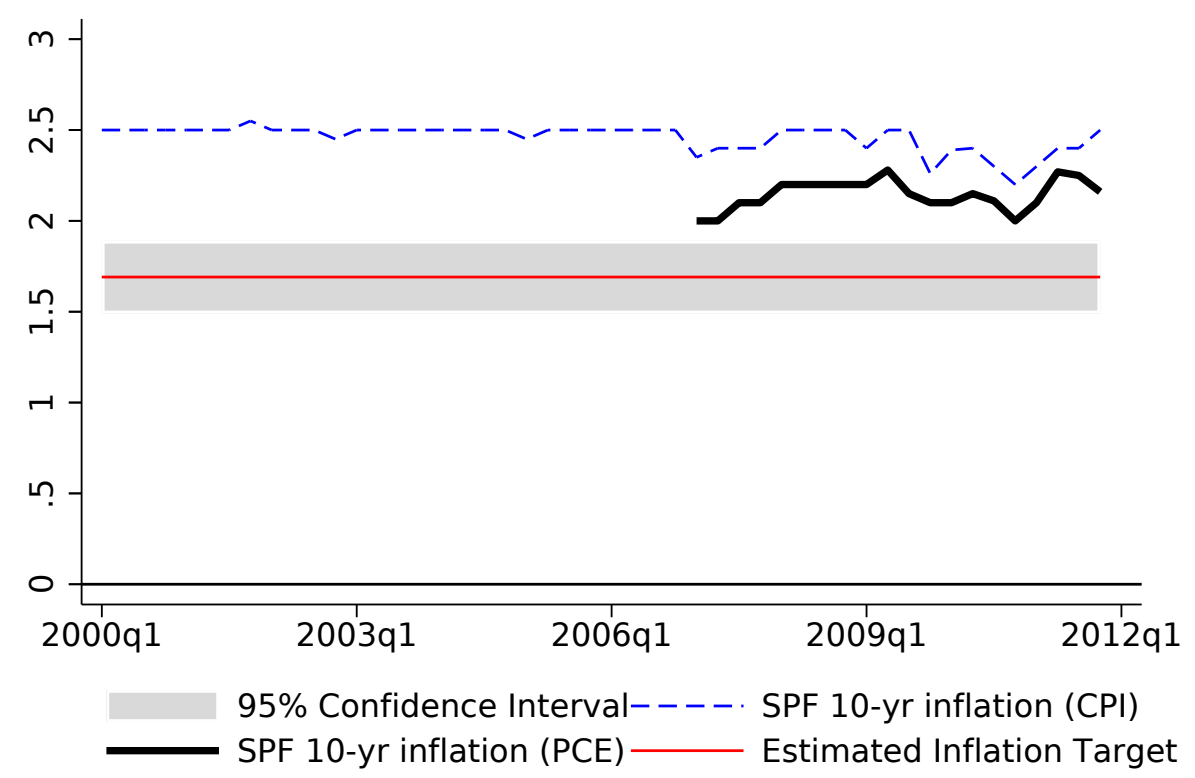


Figure 5: Estimated time-varying $\pi^{*}$

FOMC Meetings: 1986 - 2011

No Additional Factors

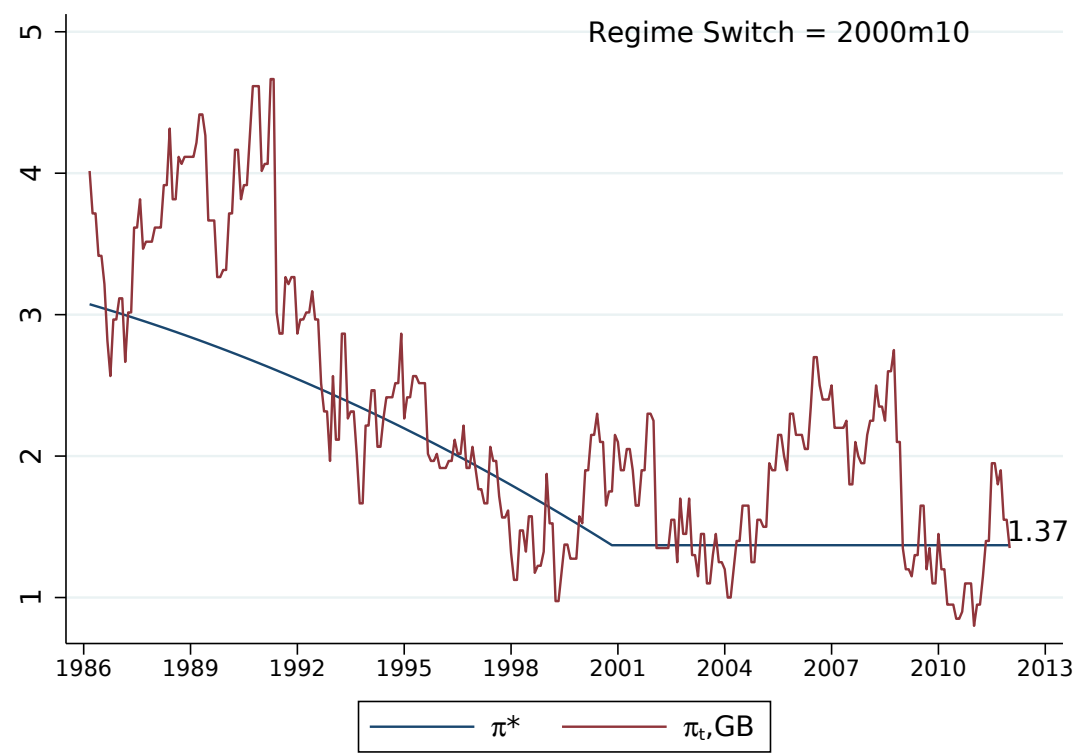

Figure 6: Estimated time-varying $\pi^{*}$

FOMC Meetings: 1986 - 2011

With Additional Factors

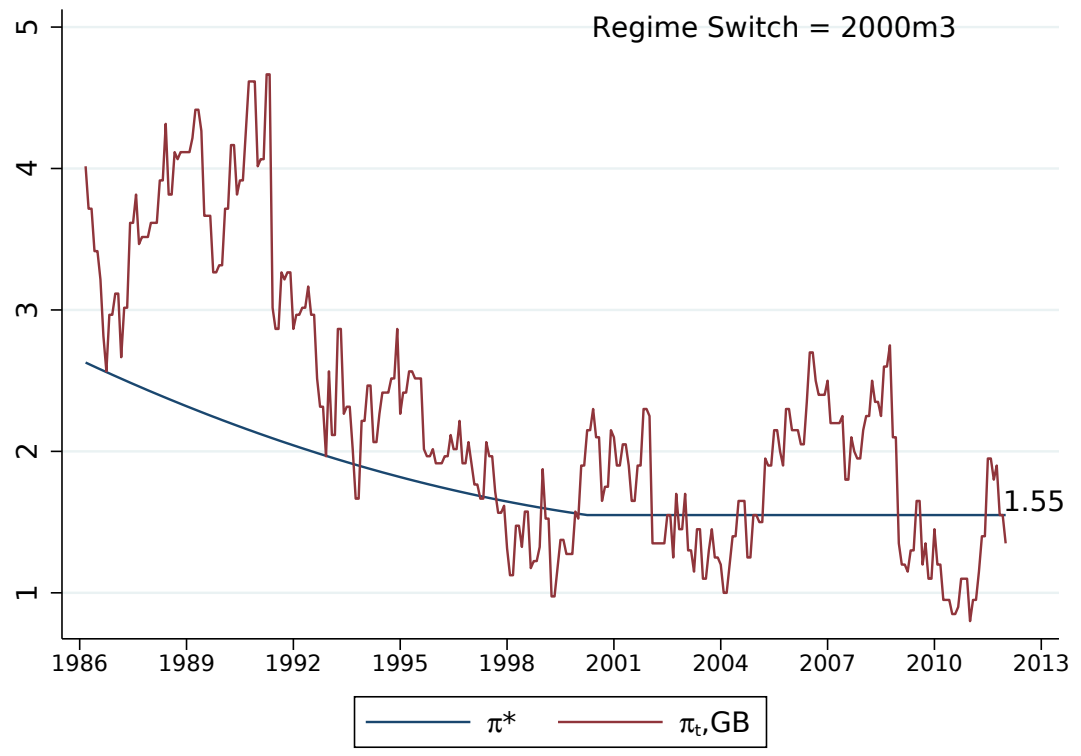


Figure 7: Explicit Statements of Inflation Target Preferences in FOMC Meetings By Speaker, Over Time

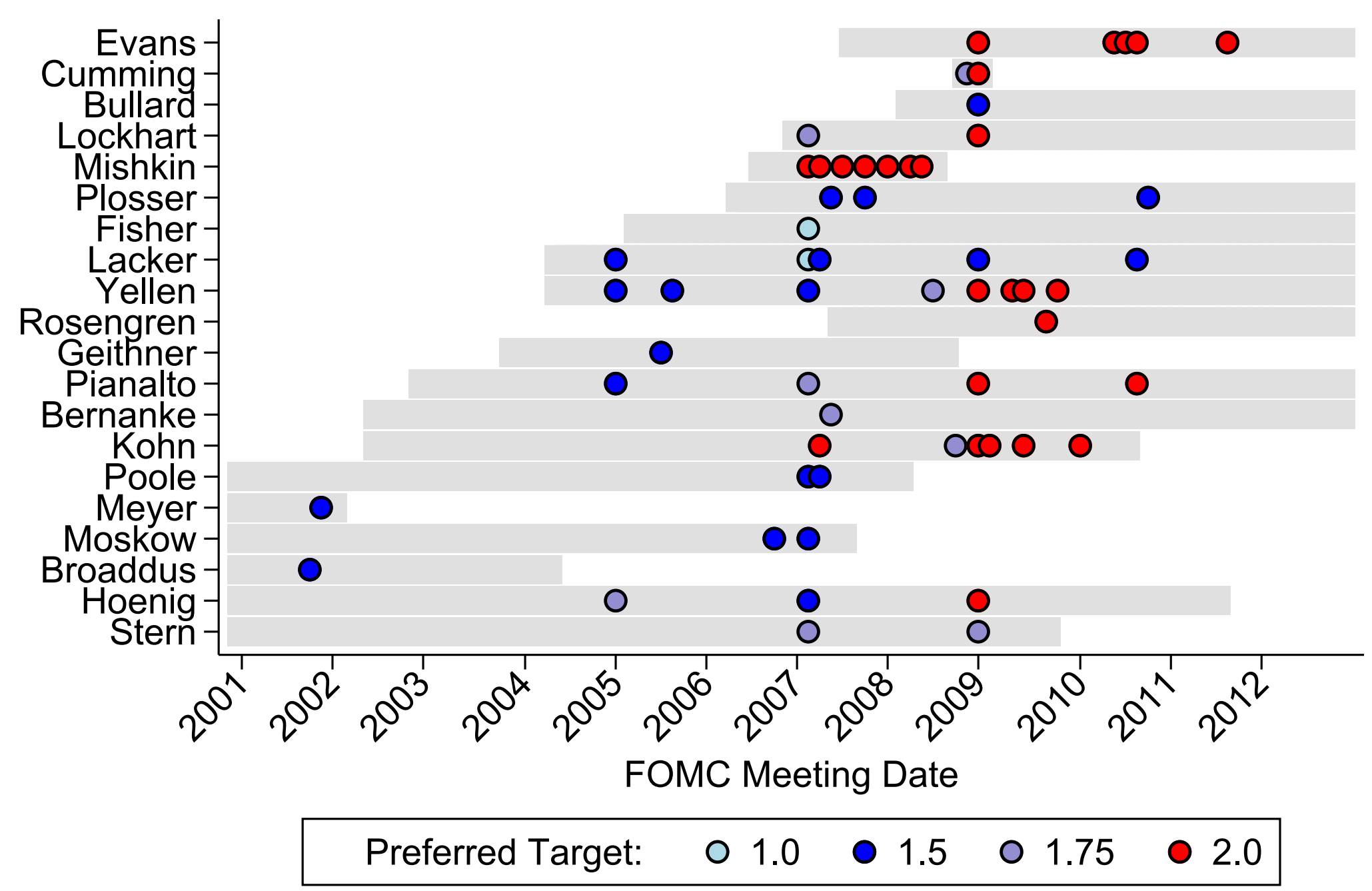

Note: Only speakers with at least one stated preference are shown. Each circle represents a stated inflation target preference from the indicated speaker (y-axis) at the indicated FOMC meeting (x-axis). Gray shading indicates speaker's FOMC tenure. 


\section{Online Appendix — Not For Publication}

\section{A A Simple Theoretical Framework}

\section{A.1 Relating Loss Function to Optimal Interest Rate Rule}

Here we present a simple three-equation New Keynesian model that conveys the role of the loss function in determining interest rate policy and illustrates the difficulty of identifying the structural parameters of the loss function from estimates of the interest rate rule alone. The key elements of this framework consist of a central bank loss function in terms of inflation and real economic activity (for example, the unemployment gap), the "Phillips Curve" relating inflation to real economic activity, and the "IS" curve relating real economic activity to the real interest rate chosen by the central bank.

The central bank seeks to minimize the sum of current and expected future per-period losses:

$$
\mathcal{L}=\sum_{\tau=0}^{\infty} L_{\tau}
$$

where 7 is referred to as the central bank's loss criterion. Suppose the central bank's (per-period or contemporaneous) loss function is given by:

$$
L_{\tau}=\frac{1}{2}\left(\tilde{\pi}_{\tau}^{2}+\phi x_{\tau}^{2}\right) .
$$

The central bank at time 0 chooses the real interest rate, $r_{0}$, to minimize its lifetime loss function:

$$
\mathcal{L}=\sum_{\tau=0}^{2} L_{\tau},
$$

More accurately, $r_{0}$ is the interest rate gap relative to the neutral interest rate, $r^{*}$. In the 3-period version of the model, with the double-lag structure described in Section 2 , at time 0 the central bank can only affect $x_{1}, x_{2}$, and $\pi_{2}$ with its interest rate choice, $r_{0}$; it has no effect on $x_{0}, \pi_{0}$, or $\pi_{1}$, which are predetermined. $x_{1}$ and $x_{2}$ are determined by the IS curve:

$$
x_{1}=\rho x_{0}-a r_{0}, x_{2}=\rho^{2} x_{0}-(1+\rho) a r_{0}
$$

where $\rho$ represents the degree of persistence in real activity. $\tilde{\pi}_{2}$ is determined by the 
Phillips curve (PC):

$$
\tilde{\pi}_{2}=\psi \tilde{\pi}_{1}+\gamma x_{1}=\psi^{2} \tilde{\pi}_{0}+(\psi+\rho) \gamma x_{0}-\gamma a r_{0}
$$

where $\psi$ represents the degree of inflation persistence and we have substituted in the IS equation for $x_{1}$.

The first-order condition for the central banks interest rate choice is:

$$
\frac{\delta \mathcal{L}}{\delta r_{0}}=\frac{\delta \tilde{\pi}_{2}}{\delta r_{0}} \tilde{\pi}_{2}+\phi \frac{\delta x_{1}}{\delta r_{0}} x_{1}+\phi \frac{\delta x_{2}}{\delta r_{0}} x_{2}=0
$$

Taking these derivatives and solving for $r_{0}$ yields the following loss-minimizing interest rate rule chosen in period 0 :

$$
r_{0}=B \tilde{\pi}_{0}+C x_{0}
$$

where $B, C$, and $D$ are complex functions of the structural parameters of the loss function, $\mathrm{PC}$, and IS curve:

$$
\begin{gathered}
B=\frac{\gamma \psi^{2}}{a\left(\gamma^{2}+\phi+\phi(1+\rho)^{2}\right)}, \\
C=\frac{\gamma^{2}(\psi+\rho)+\phi \rho\left(1+\rho+\rho^{2}\right)}{a\left(\gamma^{2}+\phi+\phi(1+\rho)^{2}\right)},
\end{gathered}
$$

This rule demonstrates three key results. First, even if the central bank was a pure inflation targeter $(\phi=0)$, the optimal interest rate would still react to real activity $(x)$ because real activity signals future inflation via the Phillips curve (so long as the PC is not flat - i.e., $\gamma \neq 0$ ). Thus, observing that the central bank tends to raise rates when $x$ is high and lower rates when $x$ is low says very little about whether and how $x$ enters the central bank's loss function. Second, even in the pure inflation targeting case, the coefficient on the inflation gap in the interest rate rule is a combination of multiple structural parameters, making it impossible to back out the structural parameters of the loss function without an exact knowledge of PC and IS curves. Adding real activity to the loss function - quadratically, linearly, or both - only exacerbates the problem.

\section{A.2 How Persistence in GB Forecasts Affects Interpretation of Loss Function Coefficients}

In Section 2 of the main text, we argued that the tone expressed by the FOMC in their meetings, minutes, and speeches proxies for their short-run loss as opposed to their lifetime 
loss, which is the sum of short-run loss and the present discounted value of expected future loss. Of course, if the FOMC believes long-run objectives can be fully achieved via monetary policy, the expected future losses are zero, in which case the short-run loss and lifetime loss are equivalent.

We interpret short-run as the interval of time within which inflation and real economic activity are unaffected by the current interest rate choice of the central bank. More specifically, the short-run is defined by the lag length of the IS curve, the monetary transmission mechanism. For instance, real activity (such as the unemployment gap and GDP growth) is generally thought to respond to interest rates with a lag of around 1 to 2 years. Thus, the short-run loss could be considered to be the sum of $L_{t}$ and $L_{t+l}$, where $l$ is less than the lag length of the IS curve. With the general per-period loss discussed in Section 2, this would translate into a short-run loss of:

$$
\mathcal{L}_{t}=\tilde{\pi}_{t}^{2}+\phi x_{t}^{2}-\lambda x_{t}+\tilde{\pi}_{t+l}^{2}+\phi x_{t+l}^{2}
$$

As discussed in Section 4, we use Greenbook short-run forecasts of macroeconomic variables to measure the FOMC perceptions of the time $t$ variables. Unfortunately, the Greenbook does not provide constant-interest-rate (CIR) forecasts which would to the time $t+l$ variables. Of course, if the near-term forecasts and the longer-term unobserved CIR forecasts are uncorrelated, the coefficients above can be estimated without need to include the CIR forecasts. If we allow for the possibility that the short-run forecast are correlated with the unobserved longer-run CIR forecasts due to the auto-correlation of these macroeconomic variables, the interpretation of the estimated coefficients changes as we detail below. Importantly, we also show below that the estimated inflation target is unaffected by the degree of persistence in inflation (or real activity).

To see these points, suppose that $\tilde{\pi}$ and $x$ are each auto-correlated:

$$
\begin{aligned}
\tilde{\pi}_{t+l} & =\psi \tilde{\pi}_{t}+\gamma x_{t} \\
x_{t+l} & =\rho x_{t} .
\end{aligned}
$$

Note that the equation for $\tilde{\pi}_{t+l}$ allows for possibility that real activity in period $\mathrm{t}$ can affect inflation within the lag length $l$.

Substituting these expressions into (16) yields the following:

$$
\begin{aligned}
\mathcal{L}_{t} & =\tilde{\pi}_{t}^{2}+\phi x_{t}^{2}+\psi^{2} \tilde{\pi}_{t}^{2}+2 \psi \gamma \tilde{\pi}_{t} x_{t}+\gamma^{2} x_{t}^{2}+\phi \rho^{2} x_{t}^{2} \\
& =\left(1+\psi^{2}\right) \tilde{\pi}_{t}^{2}+\left(\phi\left(1+\rho^{2}\right)+\gamma^{2}\right) x_{t}^{2}+2 \psi \gamma \tilde{\pi}_{t} x_{t}
\end{aligned}
$$


As in Section 4, if we assume that FOMC's expressed negativity proxies for their short-run loss, $N_{t}=\delta \mathcal{L}_{t}$, then we obtain an estimating equation (ignoring speaker fixed effects and the error term for exposition) of the form in equation (3):

$$
\begin{aligned}
N_{t} & =\hat{\delta} \tilde{\pi}_{t}^{2}+\hat{\omega} x_{t}^{2}+\hat{\alpha} \tilde{\pi}_{t} x_{t} \\
& =\hat{\delta} \pi_{t}^{2}+\hat{\theta} \pi_{t}+\hat{\omega} x_{t}^{2}+\hat{\alpha} \tilde{\pi}_{t} x_{t}
\end{aligned}
$$

where

$$
\begin{aligned}
\hat{\delta} & =\delta\left(1+\psi^{2}\right) \\
\hat{\theta} & =-2 \hat{\delta} \pi^{*} \\
\hat{\omega} & =\delta\left(\phi\left(1+\rho^{2}\right)+\gamma^{2}\right)=\omega+\omega \rho^{2}+\gamma^{2} \\
\hat{\alpha} & =2 \psi \gamma
\end{aligned}
$$

One can compare these coefficient expressions to their analogs in equation (4) to see how allowing persistence affects the interpretation of our regression coefficients. The coefficient on inflation squared, $\hat{\delta}$, includes the the current-period component, $\delta$, plus the FOMC member's view of how the inflation shock will persist in the short-run, $\delta \psi^{2}$. As in Section 4, the implied inflation target can still be estimated by -2 times the ratio of the coefficient on inflation squared to the coefficient on inflation. In other words, the degree of persistence in inflation (and/or real activity) has no effect on the estimated inflation target.

The coefficient on the squared term of real activity, $\hat{\omega}$, includes the current-period component, $\omega$, plus the FOMC's view of how the real activity shock will persist in the short-run $\omega \rho^{2}$. In addition, $\hat{\omega}$ includes a third term, $\gamma^{2}$, which captures the effect of real activity on future inflation via the Phillips curve. Thus, $\hat{\omega}$ measures the net effect of changes in $x^{2}$ on loss, net of its effects on future inflation.

Lastly, we note that, with persistence, there is an additional interaction term at the end of equation (17) that was not part of our baseline estimating equation. The coefficient on the interaction term, $2 \psi \gamma$, is the product of two fractions and therefore likely to be close to zero. Nonetheless, we tried including this term as a control in our main specifications and the coefficient was small and statistically insignificant. 


\section{B Example of Scored Text}

Below we provide a sample of text from the transcript of the January 28-29, 2008 FOMC meeting. Terms that are scored as negative or positive according to the Loughran and McDonald (2011) dictionaries are shown in green while the negative terms shown in red. We also italicize the instances of term preceded by "not." Our sentiment scoring algorithm does not count negative or positive terms that are preceded by "not."

...

CHAIRMAN BERNANKE. If it is okay with everybody, we can start the economic goaround at this point. President Poole, you are up.

MR. POOLE. Thank you, Mr. Chairman. I am not sure how I got to be first here, but I guess I was being unusually agreeable when Debbie asked me. [Laughter] The general tenor of comments that I hear from our directors and people around the Eighth Federal Reserve District - these are the community bankers and smaller firms-is that things are slow but not disastrously slow. The comments that I hear from a series of phone calls to much larger national companies are decidedly more pessimistic, with one exception that I will talk about in a moment. My contact at a large national trucking firm says that they are in a 20 -month recession in transportation. They are cutting their capacity, cutting the number of trucks, and I think the numbers on their cap-ex illustrate the situation: for 2006, $\$ 410$ million; for 2007, $\$ 336$ million; and their plan for 2008 is $\$ 200$ million. That is down a little more than 50 percent in two years, so they are really cutting back. I also called friends at UPS and FedEx, and generally things are not a whole lot different but a little weaker than they have been. Neither firm has any particular issues with labor supply. Domestic express business is flat, and customers are switching to the lower-priced services instead of overnight delivery at the end of the afternoon, shifting to ground services, and that sort of thing. On international business, U.S.-outbound volume for FedEx is up 6 percent. That would be consistent with the export increases that we have seen. Reports are that Asia is a bit slower but is still growing very rapidly. Asia to the United States is up 80 percent, 20 percent to Europe and Latin America. The freight market is dead - that is the way my contact put it - down 5 percent year over year. That is consistent with my trucking industry contact - and pretty much the same with UPS. My contact with the fast food industry - the quick-serve restaurant, or QSR, business says the demand there is definitely weak. They are coming in roughly flat, I guess, or actually down so far this year. Prices are up because of the increase in food costs. The casual dining industry is in worse shape than the fast food industry.

My contact also follows retail in general pretty closely and finds that retail business in 
general is weak. That is consistent with a lot of the reports that we have been receiving. A major exception is in the IT area - software. I have contact with a large software company, and the contact noted that, as announced, Microsoft had a fantastic quarter. The earnings were up sharply. PC hardware sales are growing at a rate of 11 to 13 percent expected in the first half of this year, so we see strong growth in the PC market. Consumer demand is stronger than business demand. Both, however, are pretty strong. The international business is doing better, in part because the industry is having some success in reducing the amount of software piracy. The biggest problem is finding software engineers. This particular company is running 8 percent behind its hiring forecast and cannot find software engineers. Positive for us old guys; some of the retirees are coming back to write code. [Laughter] Thank you. That is all I have.

\section{Technical Details On Estimating Time-Varying In- flation Target}

The estimation of the optimal time-varying $\pi_{t}^{*}$ over the extended sample, 1986m1$2013 \mathrm{~m} 12$, is performed under two assumptions:

- $\pi_{t}^{*}$ is assumed constant over an "constant-target period" defined as $t \in(s, 2013 \mathrm{~m} 12]$.

- $\pi_{t}^{*}$ is assumed a quadratic polynomial "time-varying-target period" defined as $t \in$ $[1986 \mathrm{~m} 1, s]$.

The optimization takes the following path:

1. For a given $s$,

- Find optimal $\hat{\alpha}_{0}^{s}$ assuming $\pi_{t}^{*, s}=\alpha_{0}^{s}$, over sample period $t \in(s, 2013 \mathrm{~m} 12]$.

- Given $\hat{\alpha}_{0}^{s}$, find optimal $\hat{\alpha}_{2}^{s}$ and $\hat{\alpha}_{2}^{s}$, assuming $\pi_{t}^{*, s}=\hat{\alpha}_{0}^{s}+\alpha_{1}^{s}(s-t)+\alpha_{2}^{s}(s-t)^{2}$, over sample period $t \in[1986 \mathrm{~m} 1, s]$

2. Given $\hat{\pi}_{t}^{*, s}=\hat{\alpha}_{0}^{s}+\hat{\alpha}_{1}^{s}(s-t)+\hat{\alpha}_{2}^{s}(s-t)^{2}$, perform grid search over $\hat{\pi}_{t}^{*, s}$ across $s \in$ [1993m1, 2006m1] to find optimal $\hat{\pi}_{t}^{*}$.

\section{Constant-target period estimation}

For a given $\alpha_{0}^{s}$ and $t=s$, the regression:

$$
N_{i t}=\delta^{s}\left|\pi_{t}-\alpha_{0}^{s}\right|+\mathbf{X}_{t} \Lambda+\varepsilon_{i t}
$$


is run over the sample period $t \in(s, 2013 \mathrm{~m} 12]$.

A grid search is performed over $\alpha_{0}^{s}$ with step size 0.01 , whereby $\hat{\alpha}_{0}^{s}$ is the value $\alpha_{0}^{s} \in[0,4]$ that produces the largest $R^{2}$.

\section{Time-varying-target period estimation}

First, to speed up the optimization routine, we find the window, $\left[\alpha_{1, L}^{s}, \alpha_{1, H}^{s}\right]$, where slope parameter, $\alpha_{1}^{s}$ likely resides. We do so by assuming $\pi_{t}^{*}$ is linear in the time-varyingtarget period.

Let $L I N_{t}^{s}=\hat{\alpha}_{0}^{s}+\alpha_{1}^{s}(s-t)$, where $\hat{\alpha}_{0}^{s}$ was found from (17). For a given $\alpha_{1}^{s}$ and a given $t=s$, the regression:

$$
N_{i t}=\delta^{s}\left|\pi_{t}-L I N_{t}^{s}\right|+\mathbf{X}_{t} \Lambda+\varepsilon_{i t}^{s}
$$

is run over the sample period $t \in[1986 \mathrm{~m} 1, s]$. A grid search is performed over $\alpha_{1}^{s}$ with step size 0.001 , whereby $\hat{\alpha}_{1}^{s}$ is the value $\alpha_{1}^{s} \in[-1,1]$ that produces the largest $R^{2}$. The step size and window size is shrunk by a factor of 10 if the optimal $\hat{\alpha}_{1}^{s}$ is zero. This is repeated until a nonzero $\hat{\alpha}_{1}^{s}$ is found. The likely window $\left[\alpha_{1, L}^{s}, \alpha_{1, H}^{s}\right]$ is assumed to be $\hat{\alpha}_{1}^{s} \pm 10 \hat{\alpha}_{1}^{s}$, with step size $d^{s}=\left(\alpha_{1, H}^{s}-\alpha_{1, L}^{s}\right) / 100$

Next, we perform a joint grid search over $\alpha_{1}^{s}$ and $\alpha_{2}^{s}$ assuming $\pi_{t}^{*, s}$ can be approximated by a quadratic polynomial in the time-varying-target period. Let $Q U A D_{t}^{s}=\hat{\alpha}_{0}^{s}+\alpha_{1}^{s}(s-$ $t)+\alpha_{2}^{s}(s-t)^{2}$, where $\hat{\alpha}_{0}^{s}$ was found from (17). For a given $\alpha_{1}^{s}, \alpha_{2}^{s}$, and $t=s$ the regression:

$$
N_{i t}=\delta^{s}\left|\pi_{t}-Q U A D_{t}^{s}\right|+\mathbf{X}_{t} \Lambda+\varepsilon_{i t}^{s}
$$

is run over the sample period $t \in[1986 \mathrm{~m} 1, s]$. A joint grid search is performed over $\alpha_{1}^{s}$ and $\alpha_{2}^{s}$ with step sizes $d^{s}$ and 0.00001 , and grid intervals $\left[\alpha_{1, L}^{s}, \alpha_{1, H}^{s}\right]$ and [-0.0001, 0.0001], respectively, that produces the largest $R^{2}$. This produces $\widehat{Q U A D}_{t}^{s}=\hat{\alpha}_{0}^{s}+\hat{\alpha}_{1}^{s}(s-t)+$ $\hat{\alpha}_{2}^{s}(s-t)^{2}$.

\section{Full-period estimation}

Finally, the optimal $s$ is found. For a given $\widehat{Q U A D}_{t}^{s}$ the regression:

$$
L_{i t}=\gamma^{p r e}\left|\pi_{t}-\widehat{Q U A D}_{t}^{s}\right| * \mathbb{1}(t \leq s)+\gamma^{\text {post }}\left|\pi_{t}-\widehat{Q U A D}_{t}^{s}\right| * \mathbb{1}(t>s)+\mathbf{X}_{t} \Lambda+\varepsilon_{i t}^{s}
$$

is run over the sample period $t \in[1986 \mathrm{~m} 1,2013 \mathrm{~m} 12]$. Here we allow for different parameters, $\gamma_{1}$ and $\gamma_{2}$, in the constant-target and time-varying-target periods. A grid search is performed over $s$ over the entire sample that produces the largest $R^{2}$. To speed to optimization, an exhaustive grid search is first performed over 12 month intervals. The search is than narrowed to 4 , and then 1 month intervals until the optimal $\hat{\pi}_{t}^{*}=\widehat{Q U A D}_{t}$ 
is found. The results are shown in Figures 5 (without controls) and 6 (with controls).

\section{Selected statements from FOMC meetings}

\section{D.1 Statements of Inflation Target Preference in FOMC Meet- ings}

Below are the quotes we found in the FOMC meeting transcripts over the 2000 to 2013 period in which an FOMC participant explicitly stated a preference for a specific numerical inflation target. If the speaker provides a separate preferred target for PCE inflation and CPI inflation, we take the one for PCE inflation. The target preferences are plotted by speaker and over time in Figure 7 and discussed in Section 5 of the paper.

Nov. 6, 2001

Broaddus: 1.5

Of course, the core PCE inflation rate, which is the measure I think most of us now focus on, is currently about $1 \frac{1}{2}$ percent. I think that's pretty close to the inflation target we should be aiming for at this stage, for the reasons I just noted.

Dec. 11, 2001

Meyer: 1.5

The Committee does not have an explicit long-run inflation objective, so I do the exercise in terms of my own long-run objective for inflation, which is $1 \frac{1}{2}$ percent for the PCE core inflation rate.

Feb. 2, 2005

Hoenig: 1.75

Given its general acceptance by the public, I would choose CPI inflation because it's better known. And I would have an objective somewhere in the range of 1 to 2 percent or $1 \frac{1}{2}$ to $2 \frac{1}{2}$ percent.

Lacker: 1.5

I agree with the recommendation that the objective should be a consumer price indexeither the CPI with a 2 percent midpoint or the PCE price index with a $1 \frac{1}{2}$ percent midpoint.

Yellen: 1.5

Taking measurement bias between the two indexes into account, my preference would now be for a long-run inflation objective of $1 \frac{1}{2}$ percent for core PCE inflation.

Pianalto: 1.5 
My price stability objective is for price expectations to be consistent with the PCE index increasing at an average rate of $1 \frac{1}{2}$ percent per year, which I expect to achieve by having the PCE index itself increasing at that average rate over periods of five to ten years.

Aug. 9, 2005

Geithner: 1.5

However, even this relatively modest path leaves us some margin above the $1 \frac{1}{2}$ percent pace for the core PCE that we believe should be our objective over time.

\section{Sept. 20, 2005}

Yellen: 1.5

Core PCE prices have risen at a $1 \frac{1}{2}$ percent rate over the six months through July, right in the middle of my preferred range, and core CPI inflation has also been well behaved.

\section{Oct. 25, 2006}

Moskow: 1.5

My preference is for core inflation to be $1 \frac{1}{2}$ percent, in the center of that zone.

\section{Mar. 21, 2007}

Poole: 1.5

I think that there's a lot to be said for stating that our inflation objective is $1 \frac{1}{2}$ percent, plus or minus $\frac{1}{2}$.

Fisher:

I would argue for a 1 percent target based on the CPI-if you put a gun to my head, which I hope you don't-over a longer time frame.

Lacker: 1

Taking all of this on board, I believe 1 percent would be our best choice for a numerical inflation objective.

Mishkin: 2

The actual number is less important so long as it is a reasonable number, consistent with the Greenspan definition of price stability-that is, it's sort of like pornography; you know it when you see it. A number of 2 is certainly consistent with that.

Hoenig: 1.5

Now, I would prefer a point goal of 2 percent for the core CPI and $1 \frac{1}{2}$ percent for the core PCE, and I would specify a flexible time horizon.

Stern: 1.75

I think a little less than 2 percent is fully consistent with an objective of low, stable inflation, which is what we're really talking about here. Moreover, the fact that it doesn't have a bottom to the range means that, if we get lucky or if there's an opportunity to bring 
inflation down below 2 percent, we could take advantage of that, and that would be all to the good. I have some concerns with a range or a target that focuses on $1 \frac{1}{2}$ or something even lower....

Lockhart: 1.75

Regarding exact numbers, I've not settled on a specific number, but I would think that something in the range of $1 \frac{1}{2}$ to 2 percent, depending upon the index that's chosen, is a reasonable guide to policy and compatible with the dual mandate.

Pianalto: 1.75

If the majority of the Committee prefers the PCE, I would choose a midpoint of $1 \frac{3}{4}$ percent.

Yellen: 1.5

I remain comfortable with the goal that I enunciated some time ago-a long-run inflation objective of $1 \frac{1}{2}$ percent for the core PCE inflation rate.

Moskow: 1.5

I've talked publicly about a comfort zone of 1 to 2 percent core PCE....

\section{May 9, 2007}

Mishkin: 2

My view of where the number should be is that I lean toward 2 percent because I do think the transition costs are important, although I am concerned about the issue that President Lacker mentioned.

Lacker: 1.5

Under what, in my judgment, would be an appropriate monetary policy, we use the Chairman's July testimony to announce that the FOMC's objective is for PCE inflation to average $1 \frac{1}{2}$ percent and that the Committee intends to reduce inflation to that level within two years.

Kohn: 2

I did this in the context of what I would have as an interim inflation target of 2 percent. I think 2 percent is achievable without significant output loss.

Poole: 1.5

I think that we ought to continue with a comfort zone of 1 to 2, and we ought to think about the inflation target as being $1 \frac{1}{2}$ plus or minus a half.

\section{June 28, 2007}

\section{Plosser: 1.5}

In any event, the bottom line for my forecast is that I anticipate that the economy will grow just below trend of 3 percent in 2008 and at trend of 3 percent in 2009, and we achieve an inflation goal of 1.5 percent by the end of the period. Of course, this forecast is 
based on my desired inflation objective, which may not be representative of other members of the Committee.

\section{Bernanke: 1.75}

I simply take note of the fact that the latest projections show the central tendency of the Committee's inflation objectives to be 1.5 to 2 percent on the core PCE deflator. I actually-and I'm speaking entirely for myself-would be not at all displeased if that became known as the Federal Reserve's comfort zone or informal definition of price stability.

Aug. 7, 2007

Mishkin: 2 $I$ believe that a 2 percent goal is reasonable for reasons that I have discussed before.

Oct. 31, 2007

Mishkin: 2

People know that I am a 2 percent kind of guy, and I know good people here who are $1 \frac{1}{2}$ percent kinds of guys.

Plosser: 1.5

Core PCE inflation remains slightly below 2 percent next year and moderates toward my goal of $1 \frac{1}{2}$ percent by 2010 .

Jan. 30, 2008

Mishkin: 2

The key here is that I think that inflation expectations are grounded-in fact, are grounded at a level that is consistent with my inflation objective, around 2 percent on PCE, which might be different from others' views, but that's where I am right now.

\section{Apr. 30, 2008}

Mishkin: 2

About where I think inflation is going to be-I have been a 2 percent guy for a long time. I am not changing that.

\section{June 25, 2008}

Mishkin: 2

I'm a 2 percent kind of guy on PCE, and I'm still a 2 percent guy-that even though headline inflation is very elevated, we're going to see over the forecast period that inflation will come back down to around the 2 percent level both on the headline and on the core.

\section{Aug. 5, 2008}

Yellen: 1.75

Given my preference for an inflation target of around $1 \frac{3}{4}$ percent and equal welfare weights on the inflation and unemployment gaps, I view the Greenbook policy path and forecast as a roughly optimal trajectory to the attainment of our goals.

Oct. 29, 2008 
Kohn: 1.75

In my forecast for inflation from next year on, inflation was at or below the $1 \frac{1}{2}$ to 2 percent rate $I$ would like to see as a steady state consistent with avoiding the zero bound when adverse shocks hit.

Dec. 16, 2008

Cumming: 1.75

So more fundamentally we need to communicate what we want to accomplish, and that importantly involves our commitment to price stability, as many have said here in the sense of keeping prices in the medium term rising in line with our $1 \frac{1}{2}$ to 2 percent preference, and our commitment to a resumption of sustainable economic activity.

\section{Jan. 16, 2009 (FOMC conference call)}

Bullard: 1.5

I would suggest 1.5 percent as the target.

Lacker: 1.5

About these other questions, a single number to me seems obviously preferable. Total PCE and $1 \frac{1}{2}$ percent would be my choices.

Stern: 1.75

I have long favored something like the European Central Bank target of 2 percent or a little under. That gives us some room on the downside.

Yellen: 2

All in all I have concluded that a long-term numerical inflation objective of 2 percent for the PCE price index would be preferable.

Evans: 2

On the particular numbers, I would favor using the total PCE index at 2 percent. That seems to be more likely to avoid zero lower bound issues.

Pianalto: 2

But in light of our recent experience, I am now leaning toward an objective for total PCE inflation of 2 percent to provide a larger buffer against zero lower bound events.

Hoenig: 2

I would prefer overall CPI but certainly can live with PCE as we have been doing at this time, with an explicit statement that we are targeting the midpoint of 2 percent.

Kohn: 2

On the specific points, I would go for a point rather than a range. I would go for something around 2 percent on the PCE index.

Lockhart: 2

On balance, I favor a point forecast of 2 percent, a round number. 
Cumming: 2

I believe it would be very helpful under the current circumstances to adopt an explicit numerical objective for medium-term inflation of 2 percent for PCE inflation, given the real risk of deflation and the likelihood that deflation fears will become an important part of the public's concerns about the steep global downturn that we are now in.

Jan. 28, 2009

Kohn: 2

With that slack, inflation continues to drop, and even with long-run inflation expectations well anchored, I had total and core PCE in the 1 to $1 \frac{1}{4}$ percent range in 2010-11, well below my objective of 2 percent.

\section{Apr. 29, 2009}

Yellen: 2

I expect at best a gradual recovery starting late this year, with core inflation remaining below my preferred 2 percent rate for the next few years.

\section{June 24, 2009}

Yellen: 2

I expect core inflation to drift lower over the next few years, falling below the 2 percent rate that seems best to me.

Kohn: 2

So, on balance, I see persistent output gaps and inflation falling below my 2 percent objective over the next few years.

\section{Sept. 23, 2009}

Rosengren: 2

Thus, like the Greenbook, I expect that lower labor costs and the substantial slack in the economy will continue to generate disinflation, and, thus, over the next two years, we will likely be moving further below my inflation target of 2 percent.

Nov. 4, 2009

Yellen: 2

It is because I expect resource utilization-namely, unemployment-to remain far above the NAIRU for a long time, for core inflation to be below my preferred 2 percent objective, and inflation expectations to remain anchored that my own policy expectations accord with the assumptions in the Greenbook and the constrained optimal policy path in the Bluebook.

Jan. 29, 2010

Kohn: 2

Continued large slack keeps inflation subdued, well below my 2 percent objective for the next three years, on the assumptions that commodity prices rise in line with futures markets and that longer-term inflation expectations remain anchored. 
June 23, 2010

Evans: 2

Because inflation is projected to underrun my 2 percent inflation goal over the medium term, according to FOMC central tendencies, it's difficult for me to imagine altering our current accommodative policy stance over the next six months or so, and certainly not in a material fashion.

Aug. 10, 2010

Evans: 2

Nevertheless, by my reckoning, with the Tealbook's core PCE inflation projection of 1 percent in 2012, we're failing by a full percentage point; that is, I have 2 percent as my price stability goal.

Sept. 21, 2010

Lacker: 1.5

Inflation remains pretty steady at 1.5 percent overall on a year-over-year basis. That lines up with my own inflation objective.

Pianalto: 2

Although these are encouraging signs, at this point inflation expectations are still well below my longer-run objective of 2 percent.

Evans: 2

If markets understand our explicit commitment to exit this policy, future inflation expectations will converge to our ultimate price stability objective, which I put at 2 percent.

Nov. 3, 2010

Plosser: 1.5

Inflation is now running between 1 and $1 \frac{1}{2}$ percent measured year over year, which is very near my inflation objective.

Sept. 21, 2011

Evans: 2

After reviewing the analyses, I continue to feel that a reasonable and aggressive set of triggers, if it was a decision today, would be 7 percent for unemployment and 3 percent for medium-term inflation. With an inflation objective of 2 percent, I think that 3 percent inflation is a reasonable statement of symmetric preferences around our objective.

\section{D.2 Statements about damange to central bank credibility from missing inflation target}

Below are the quotes we found in the FOMC meeting transcripts over the 2000 to 2011 period in which an FOMC participant inferred a damage to central bank credibility to missing the inflation target.

May 4, 2004 
Poole: And once the indexed bond starts to move, the information, just like the September futures reading, will represent the market's changing view about how the Committee is going to react in the future. Once it starts to move-if it moves to the upside-I think it will mean that we are beginning to lose credibility.

Sept. 20, 2005

Ferguson: If we were to pause today, in my judgment we clearly would risk allowing the pass-through from headline inflation to core inflation to become embedded in inflation expectations, making it difficult to regain control over the inflation process and losing some of our hard-won credibility.

Mar. 27-28, 2006

Bernanke: Like most of you, I am not at all alarmist about inflation. I think the worst that is likely to happen would be 20 or 30 basis points over the next year. But even that amount is a little disconcerting for me. I think it is very important for us to maintain our credibility on inflation and it would be somewhat expensive to bring that additional inflation back down.

May 10, 2006

Moskow: For me, having our inflation forecasts consistently run at or above the top end of my comfort zone is a problem. Market participants will ratchet up their views of the zone, and our credibility is then going to suffer.

June 28-29, 2006

Guynn: Yet if we continue to espouse a target range of 1 to 2 percent and do not behave in a way that seems to move us decisively in that direction, then I think we run the risk of a substantial loss of policy credibility.

June 28-29, 2006

Geithner: But even with that, those exercises imply a view about inflation persistence that says we're going to be above 1.5 percent for a very, very long time. That situation, as I said, does create some risk that people will read the persistence of inflation as implying that we have higher inflation tolerance than we do or it may make us vulnerable to some further gradual erosion in credibility.

Sept. 20, 2006

Plosser: My main concern remains the outlook for inflation and the risk it poses for our credibility....I think we must be concerned that our credibility and the consequences of allowing inflation to remain above our comfort zone for so long are at question....My concern, however, is that the longer we tolerate inflation above our comfort zone, the more risk we have that those expectations will become unhinged.

\section{Sept. 20, 2006}

Bernanke: However, I hear very clearly a definite unhappiness with the level of core inflation and with the amount of time that is projected to return it to a level of less than 2 percent. The principal concern is that our credibility will be damaged if inflation remains 
too high for too long.

Jan. 31, 2007

Bies: If we don't demonstrate our ability to control the inflationary pace, we're going to lose that credibility whether or not we have a forecast.

Mar. 20-21, 2007

Stern: I have some concerns with a range or a target that focuses on $1 \frac{1}{2}$ or something even lower because I question how credible it is.

\section{D.3 Statements about the welfare cost of missing inflation target}

Below are the quotes we found in the FOMC meeting transcripts over the 2000 to 2011 period in which an FOMC participant inferred a welfare cost to missing the inflation target.

Oct. 25, 2006

Poole: Generally, the way that the simulations go, the inflation expectations term grinds away over time, and only the creation of a period of slack and lower inflation gradually changes expectations. If we can wind down inflation expectations discretely through this method, it produces a gain in welfare for the country that I believe we should not lightly pass by, and so I would like to do it sooner rather than later.

Mar. 20-21, 2007

Yellen: I agree with Governor Mishkin that we have to take transition costs into account. It's a question of weighing the gains from being at a better number against the transition costs, and I thought about that tradeoff when I decided on $1 \frac{1}{2}$. I know we're not there, and I guess I decided that the tradeoff was worth making. 


\section{D.4 Statements about raising rates to maintain credibility}

Below are the quotes we found in the FOMC meeting transcripts over the 2000 to 2011 period in which an FOMC participant inferred that raising interest rates was appropriate to keep inflation below 2 percent in order to maintain credibility.

Aug. 10, 2004

Geithner: If monetary policy were not to continue to adjust toward a more neutral position, then we would face the risk that the elevation in near-term inflation expectations would feed through to a higher rate of underlying inflation.

Nov. 1, 2005

Santomero: Where we've gotten into trouble during the earlier energy price shocks is when we've let inflation expectations get away from us... Nonetheless, in my view, inflation pressures remain elevated. So the prudent course of action today is to continue to gradually move rates up nearer to the range of the equilibrium real rate.

Jan. 31, 2006

Moskow: And in that event, we'd be looking at a forecast for core inflation that was stuck above 2 percent. I think this would be a problem. With inflation remaining at such rates, we could begin to lose credibility if markets mistakenly inferred that our comfort zone had drifted higher. When we stop raising rates, we ought to be reasonably confident that policy is restrictive enough to bring inflation back toward the center of our comfort zone, which I believe is $1 \frac{1}{2}$ percent.

\section{E Public Speeches By FOMC Participants}

Speeches provide another textual source of data on the preferences of FOMC members, albeit one that could reflect additional considerations. In particular, central bankers may speak less candidly in their public speeches, both out of concern about revealing nonpublic information regarding likely future policy actions (or views of other members) and about expressing views that may be unpopular with the public or current politicians. For instance, FOMC members may be hesitant to express too little concern about unemployment relative to inflation for fear of sounding insensitive to the plight of the jobless. In addition, members may seek to use their speeches not just to express their own monetary policy views but also to influence the expectations of the public with regard to inflation and/or the future policy path. 
We collected speeches of FOMC members - governors of the Federal Reserve Board and the presidents of the twelve regional Federal Reserve banks - from a number of sources. Governor speeches from 1996 to 2017 in digital format were kindly provided by Michael McMahon 59 The majority of bank president speeches were gathered directly from each bank. All banks provide recent speeches on their websites 60 Some banks only have very recent speeches on their website. In some cases, we were able to obtain early-year speeches from FRASER ${ }^{61}$. Remaining speeches not available on banks' websites or FRASER were obtained in response to email or phone requests to bank libraries. Speeches' text was generally in PDF or HTML format, which we converted to text files. We were able to obtain all bank president speeches from January 1998 to present. Our full data set consists of roughly 3,500 speeches, with 2,200 within the 2000-2013 sample period.

With these caveats about candidness and strategic communications in mind, we repeat the same loss function estimations as above using the negativity scores for speeches. Note that we have a comprehensive data set of speeches from 1998 through 2017, though we present results here based on the 2000-2011 sample period to facilitate comparisons with the results based on the transcripts. The results are shown in Appendix Table G2. Consistent with the results for transcripts and minutes, the speech results point to an implied $\hat{\pi}^{*}$ around 2.1-2.3, though it is imprecisely estimated. The large degree of noise around the estimates of the inflation target shows that the tone from speeches may be less useful for identifying the inflation target than the tone from the transcripts or the minutes.

\section{F Separating observations into hawkish and dovish}

Here we describe how we split speaker-meeting observations into hawkish and dovish categories in Section 5.2 of the paper. We follow the lexical hawkish/dovish sentiment scoring approach of Malmendier et al. (2020) and Apel and Blix Grimadi (2014). The method involves a 2-step lexical procedure:

1. Identify all sentences (which are tagged by speaker-meeting) containing one of the following goal terms: "inflation," "cyclical position," "growth," "price," "wages," "oil price," "development", "employment","unemployment"

2. Parse these sentences into 5-grams (5-word sequences/phrases) centered on the goal term. Generate counts of 5-grams - centered on the goal term (to avoid double

\footnotetext{
${ }^{59} \mathrm{~A}$ few additional speeches were obtained from the Board of Governors website.

${ }^{60}$ Links to each bank's speech webpage can be found here: https://www.chicagofed.org/ publications/speeches/index.

${ }^{61}$ See https : //fraser.stlouisfed.org/series/3761
} 
counting) - with the following combinations:

- Hawkish = ["inflation" OR "cyclical position" OR "growth" OR "price" OR "wages" OR "oil price" OR "development" OR "employment"] AND ["increase" OR "fast" OR "strong" OR "high"]

- Hawkish = ["unemployment"] AND ["decrease" OR "slow" OR "weak" OR "low"]

- Dovish = ["inflation" OR "cyclical position" OR "growth" OR "price" OR "wages" OR "oil price" OR "development" OR "employment"] AND ["decrease" OR "slow" OR "weak" OR "low"]

- Dovish = ["unemployment"] AND ["increase" OR "fast" OR "strong" OR "high"] 


\section{G APPENDIX TABLES AND FIGURES}

Table G1: Estimated V-shaped loss function with unknown $\pi^{*}$

FOMC Meetings: 2000 - 2011

Alternative Sentiment Measures

\begin{tabular}{|c|c|c|c|c|c|c|}
\hline & $\begin{array}{c}(1) \\
\text { LM-Neg, Symmetric }\end{array}$ & $\begin{array}{c}(2) \\
\text { LM-pos, Symmetric }\end{array}$ & $\begin{array}{c}(3) \\
\text { Vader, Symmetric }\end{array}$ & $\begin{array}{c}(4) \\
\text { LM-Neg, Asymmetric }\end{array}$ & $\begin{array}{c}(5) \\
\text { LM-pos, Asymmetric }\end{array}$ & $\begin{array}{c}(6) \\
\text { Vader, Asymmetric }\end{array}$ \\
\hline$\left|\pi_{t}-\pi^{*}\right|, \mathrm{GB}$ & $\begin{array}{c}0.358^{* * *} \\
(0.124)\end{array}$ & $\begin{array}{c}-0.265^{* * *} \\
(0.0637)\end{array}$ & $\begin{array}{l}0.0163^{* * *} \\
(0.00410)\end{array}$ & & & \\
\hline$\left(\pi_{t}>\pi^{*}\right)=0 \times\left(\pi_{t}-\pi^{*}\right), \mathrm{GB}$ & & & & $\begin{array}{c}-0.629^{* * *} \\
(0.150)\end{array}$ & $\begin{array}{c}0.170 \\
(0.106)\end{array}$ & $\begin{array}{c}-0.0193^{* * *} \\
(0.00513)\end{array}$ \\
\hline$\left(\pi_{t}>\pi^{*}\right)=1 \times\left(\pi_{t}-\pi^{*}\right), \mathrm{GB}$ & & & & $\begin{array}{c}0.130 \\
(0.130)\end{array}$ & $\begin{array}{c}-0.276^{* * *} \\
(0.0682)\end{array}$ & $\begin{array}{l}0.0142^{* * *} \\
(0.00504)\end{array}$ \\
\hline$\left(u_{t}-u_{t}^{*}\right), \mathrm{GB}$ & $\begin{array}{c}0.0560 \\
(0.0672)\end{array}$ & $\begin{array}{c}0.0483 \\
(0.0480)\end{array}$ & $\begin{array}{c}0.00188 \\
(0.00234)\end{array}$ & $\begin{array}{c}0.0246 \\
(0.0745)\end{array}$ & $\begin{array}{c}0.0412 \\
(0.0548)\end{array}$ & $\begin{array}{l}0.000703 \\
(0.00283)\end{array}$ \\
\hline$\left(u_{t}-u_{t}^{*}\right)^{2}, \mathrm{~GB}$ & $\begin{array}{l}-0.0115 \\
(0.0116)\end{array}$ & $\begin{array}{l}-0.0169^{*} \\
(0.00873)\end{array}$ & $\begin{array}{l}-0.000622 \\
(0.000393)\end{array}$ & $\begin{array}{r}-0.00971 \\
(0.0117)\end{array}$ & $\begin{array}{l}-0.0163^{*} \\
(0.00906)\end{array}$ & $\begin{array}{l}-0.000488 \\
(0.000432)\end{array}$ \\
\hline$\Delta y_{t}, \mathrm{~GB}$ & $\begin{array}{c}-0.0142 \\
(0.0230)\end{array}$ & $\begin{array}{l}0.0184^{*} \\
(0.0104)\end{array}$ & $\begin{array}{c}0.000412 \\
(0.000815)\end{array}$ & $\begin{array}{l}-0.0166 \\
(0.0225)\end{array}$ & $\begin{array}{l}0.0184^{*} \\
(0.0104)\end{array}$ & $\begin{array}{c}0.000386 \\
(0.000825)\end{array}$ \\
\hline$\Delta y_{t}^{2}, \mathrm{~GB}$ & $\begin{array}{c}-0.0363^{* * *} \\
(0.00496)\end{array}$ & $\begin{array}{l}-0.00295 \\
(0.00207)\end{array}$ & $\begin{array}{c}-0.00110^{* * *} \\
(0.000152)\end{array}$ & $\begin{array}{c}-0.0374^{* * *} \\
(0.00528)\end{array}$ & $\begin{array}{l}-0.00309 \\
(0.00222)\end{array}$ & $\begin{array}{c}-0.00114^{* * *} \\
(0.000172)\end{array}$ \\
\hline S\&P Return, 3m & $\begin{array}{c}-1.606^{* * *} \\
(0.471)\end{array}$ & $\begin{array}{c}0.507^{*} \\
(0.287)\end{array}$ & $\begin{array}{c}-0.0398^{* *} \\
(0.0169)\end{array}$ & $\begin{array}{c}-1.659^{* * *} \\
(0.443)\end{array}$ & $\begin{array}{l}0.498^{*} \\
(0.286)\end{array}$ & $\begin{array}{c}-0.0435^{* *} \\
(0.0172)\end{array}$ \\
\hline Shiller PE Ratio & $\begin{array}{l}0.0235^{* * *} \\
(0.00801)\end{array}$ & $\begin{array}{c}0.00205 \\
(0.00599)\end{array}$ & $\begin{array}{l}0.0000274 \\
(0.000358)\end{array}$ & $\begin{array}{c}0.0194^{* *} \\
(0.00810)\end{array}$ & $\begin{array}{c}0.00134 \\
(0.00630)\end{array}$ & $\begin{array}{l}-0.0000335 \\
(0.000377)\end{array}$ \\
\hline VIX Uncertainty & $\begin{array}{c}0.00683 \\
(0.00497)\end{array}$ & $\begin{array}{l}-0.00158 \\
(0.00297)\end{array}$ & $\begin{array}{c}0.000364 \\
(0.000226)\end{array}$ & $\begin{array}{c}0.00599 \\
(0.00485)\end{array}$ & $\begin{array}{l}-0.00144 \\
(0.00298)\end{array}$ & $\begin{array}{c}0.000343 \\
(0.000222)\end{array}$ \\
\hline Short-Term Yield Volatility & $\begin{array}{l}0.0358 \\
(0.219)\end{array}$ & $\begin{array}{l}-0.192^{* *} \\
(0.0962)\end{array}$ & $\begin{array}{l}-0.00146 \\
(0.00851)\end{array}$ & $\begin{array}{l}0.0671 \\
(0.219)\end{array}$ & $\begin{array}{l}-0.197^{* *} \\
(0.0960)\end{array}$ & $\begin{array}{l}-0.000807 \\
(0.00850)\end{array}$ \\
\hline Observations & 1676 & 1676 & 1676 & 1676 & 1676 & 1676 \\
\hline Adjusted $R^{2}$ & 0.231 & 0.067 & 0.140 & 0.234 & 0.067 & 0.140 \\
\hline Type & meeting & meeting & meeting & meeting & meeting & meeting \\
\hline Sample & $2000 \mathrm{~m} 1-2011 \mathrm{~m} 12$ & 2000m1-2011m12 & $2000 \mathrm{~m} 1-2011 \mathrm{~m} 12$ & $2000 \mathrm{~m} 1-2011 \mathrm{~m} 12$ & 2000m1-2011m12 & 2000m1-2011m12 \\
\hline Symmetry p-val & 0. & 0. & 0. & 0.001 & 0.395 & 0.397 \\
\hline$\hat{\pi^{*}}$ & 1.8 & 1.31 & 1.7 & 1.55 & 1.35 & 1.7 \\
\hline SE & $(0.35)$ & $(0.12)$ & $(0.14)$ & $(0.3)$ & $(0.2)$ & $(0.25)$ \\
\hline $95 \%$ C.I. & {$[1.11,2.49]$} & {$[1.07,1.55]$} & {$[1.43,1.97]$} & {$[.96,2.14]$} & {$[.96,1.74]$} & {$[1.21,2.19]$} \\
\hline
\end{tabular}

The variables y and $\mathrm{y}^{*}$ denote $\log$ GDP and log potential GDP, respectively.
Standard errors (in parentheses) are robust to heteroskedasticity and two-way clustering by sample-month and speaker.

Regressions include speaker fixed effects.

${ }^{*} p<0.10,{ }^{* *} p<0.05,{ }^{* * *} p<0.01$ 
Table G2: Estimated V-shaped Loss Function

FOMC Speeches: 2000 - 2011

\begin{tabular}{|c|c|c|c|c|}
\hline & $\begin{array}{c}(1) \\
\text { Symmetric V }\end{array}$ & $\begin{array}{c}(2) \\
\text { Symmetric V }\end{array}$ & $\begin{array}{c}(3) \\
\text { Asymmetric V }\end{array}$ & $\begin{array}{c}(4) \\
\text { Asymmetric } \mathrm{V}\end{array}$ \\
\hline$\left|\pi_{t}-\pi^{*}\right|, \mathrm{GB}$ & $\begin{array}{c}0.463^{* * *} \\
(0.124)\end{array}$ & $\begin{array}{c}0.127 \\
(0.0981)\end{array}$ & & \\
\hline$\left(\pi_{t}>\pi^{*}\right)=0 \times\left(\pi_{t}-\pi^{*}\right), \mathrm{GB}$ & & & $\begin{array}{c}-0.467^{* * *} \\
(0.124)\end{array}$ & $\begin{array}{r}-0.0918 \\
(0.120)\end{array}$ \\
\hline$\left(\pi_{t}>\pi^{*}\right)=1 \times\left(\pi_{t}-\pi^{*}\right), \mathrm{GB}$ & & & $\begin{array}{c}0.547 \\
(0.370)\end{array}$ & $\begin{array}{c}0.563^{*} \\
(0.336)\end{array}$ \\
\hline$\left(u_{t}-u_{t}^{*}\right), \mathrm{GB}$ & & $\begin{array}{c}0.0455 \\
(0.0931)\end{array}$ & & $\begin{array}{c}0.0596 \\
(0.0986)\end{array}$ \\
\hline$\left(u_{t}-u_{t}^{*}\right)^{2}, \mathrm{~GB}$ & & $\begin{array}{c}0.0270^{*} \\
(0.0159)\end{array}$ & & $\begin{array}{c}0.0256 \\
(0.0159)\end{array}$ \\
\hline$\Delta y_{t}, \mathrm{~GB}$ & & $\begin{array}{c}-0.0923^{* * *} \\
(0.0242)\end{array}$ & & $\begin{array}{c}-0.0932^{* * *} \\
(0.0233)\end{array}$ \\
\hline$\Delta y_{t}^{2}, \mathrm{~GB}$ & & $\begin{array}{c}0.00524 \\
(0.00642)\end{array}$ & & $\begin{array}{c}0.00640 \\
(0.00675)\end{array}$ \\
\hline S\&P Return, 3m & & $\begin{array}{c}0.181 \\
(0.613)\end{array}$ & & $\begin{array}{c}0.302 \\
(0.680)\end{array}$ \\
\hline Shiller PE Ratio & & $\begin{array}{l}-0.0179 \\
(0.0120)\end{array}$ & & $\begin{array}{l}-0.0171 \\
(0.0119)\end{array}$ \\
\hline VIX Uncertainty & & $\begin{array}{c}0.00307 \\
(0.00512)\end{array}$ & & $\begin{array}{c}0.00366 \\
(0.00535)\end{array}$ \\
\hline Short-Term Yield Volatility & & $\begin{array}{c}1.104^{* * *} \\
(0.383)\end{array}$ & & $\begin{array}{c}1.121^{* * *} \\
(0.380)\end{array}$ \\
\hline Observations & 1888 & 1888 & 1888 & 1888 \\
\hline Adjusted $R^{2}$ & -0.000 & 0.080 & -0.001 & 0.080 \\
\hline Type & speech & speech & speech & speech \\
\hline Sample & $2000 \mathrm{~m} 1-2011 \mathrm{~m} 12$ & 2000m1-2011m12 & 2000m1-2011m12 & 2000m1-2011m12 \\
\hline Symmetry p-val & 0. & 0. & 0.814 & 0.245 \\
\hline$\hat{\pi^{*}}$ & 2.15 & 2.15 & 2.15 & 2.3 \\
\hline $\mathrm{SE}$ & $(0.2)$ & $(0.61)$ & $(0.16)$ & $(0.54)$ \\
\hline 95\% C.I. & {$[1.76,2.54]$} & {$[.95,3.35]$} & {$[1.84,2.46]$} & {$[1.24,3.36]$} \\
\hline
\end{tabular}

The variables y and $\mathrm{y}^{*}$ denote $\log$ GDP and $\log$ potential GDP, respectively.

Standard errors (in parentheses) are robust to heteroskedasticity and two-way clustering by sample-month and speaker. Regressions include speaker fixed effects.

${ }^{*} p<0.10,{ }^{* *} p<0.05,{ }^{* * *} p<0.01$ 
Table G3: Estimated V-shaped Loss Function Core CPI inflation instead of core PCE inflation

FOMC Meetings: 2000 - 2011

\begin{tabular}{|c|c|c|c|c|}
\hline & $\begin{array}{c}1) \\
\text { Symmetric V }\end{array}$ & $\begin{array}{c}(2) \\
\text { Symmetric V }\end{array}$ & $\begin{array}{c}(3) \\
\text { Asymmetric V }\end{array}$ & $\begin{array}{c}(4) \\
\text { Asymmetric V }\end{array}$ \\
\hline$\left|\pi_{t}-\pi^{*}\right|, \mathrm{GB}$ & $\begin{array}{c}0.613^{* * *} \\
(0.128)\end{array}$ & $\begin{array}{l}0.370^{* * *} \\
(0.0912)\end{array}$ & & \\
\hline$\left(\pi_{t}>\pi^{*}\right)=0 \times\left(\pi_{t}-\pi^{*}\right), \mathrm{GB}$ & & & $\begin{array}{c}-0.403^{* *} \\
(0.192)\end{array}$ & $\begin{array}{c}-0.368^{* * *} \\
(0.101)\end{array}$ \\
\hline$\left(\pi_{t}>\pi^{*}\right)=1 \times\left(\pi_{t}-\pi^{*}\right), \mathrm{GB}$ & & & $\begin{array}{c}0.644^{* * *} \\
(0.134)\end{array}$ & $\begin{array}{c}0.374^{*} \\
(0.201)\end{array}$ \\
\hline$\left(u_{t}-u_{t}^{*}\right), \mathrm{GB}$ & & $\begin{array}{l}-0.0750 \\
(0.0850)\end{array}$ & & $\begin{array}{l}-0.0739 \\
(0.0928)\end{array}$ \\
\hline$\left(u_{t}-u_{t}^{*}\right)^{2}, \mathrm{~GB}$ & & $\begin{array}{c}0.00856 \\
(0.0134)\end{array}$ & & $\begin{array}{c}0.00844 \\
(0.0137)\end{array}$ \\
\hline$\Delta y_{t}, \mathrm{~GB}$ & & $\begin{array}{l}-0.0229 \\
(0.0299)\end{array}$ & & $\begin{array}{l}-0.0229 \\
(0.0299)\end{array}$ \\
\hline$\Delta y_{t}^{2}, \mathrm{~GB}$ & & $\begin{array}{c}-0.0398^{* * *} \\
(0.00687)\end{array}$ & & $\begin{array}{c}-0.0397^{* * *} \\
(0.00771)\end{array}$ \\
\hline S\&P Return, 3m & & $\begin{array}{c}-2.306^{\text {*** }} \\
(0.614)\end{array}$ & & $\begin{array}{c}-2.300^{* * *} \\
(0.592)\end{array}$ \\
\hline Shiller PE Ratio & & $\begin{array}{c}0.00887 \\
(0.0117)\end{array}$ & & $\begin{array}{l}0.00888 \\
(0.0117)\end{array}$ \\
\hline VIX Uncertainty & & $\begin{array}{c}0.00794 \\
(0.00602)\end{array}$ & & $\begin{array}{c}0.00796 \\
(0.00584)\end{array}$ \\
\hline Short-Term Yield Volatility & & $\begin{array}{c}0.260 \\
(0.248)\end{array}$ & & $\begin{array}{c}0.260 \\
(0.247)\end{array}$ \\
\hline Observations & 1676 & 1676 & 1676 & 1676 \\
\hline Adjusted $R^{2}$ & 0.038 & 0.225 & 0.039 & 0.224 \\
\hline Type & meeting & meeting & meeting & meeting \\
\hline Sample & 2000m1-2011m12 & $2000 \mathrm{~m} 1-2011 \mathrm{~m} 12$ & 2000m1-2011m12 & $2000 \mathrm{~m} 1-2011 \mathrm{~m} 12$ \\
\hline Speaker & ChairGovPres & ChairGovPres & ChairGovPres & ChairGovPres \\
\hline Symmetry p-val & 0. & 0. & 0.23 & 0.979 \\
\hline$\hat{\pi}^{*}$ & 1.54 & 2.05 & 1.6 & 2.05 \\
\hline $\mathrm{SE}$ & $(0.2)$ & $(0.23)$ & $(0.22)$ & $(0.14)$ \\
\hline 95\% C.I. & {$[1.15,1.93]$} & {$[1.6,2.5]$} & {$[1.17,2.03]$} & {$[1.78,2.32]$} \\
\hline
\end{tabular}

The variables y and $\mathrm{y}^{*}$ denote $\log$ GDP and log potential GDP, respectively.

Standard errors (in parentheses) are robust to heteroskedasticity and two-way clustering by sample-month and speaker. Regressions include speaker fixed effects.

${ }^{*} p<0.10,{ }^{* *} p<0.05,{ }^{* * *} p<0.01$ 
Table G4: Interest Rate Smoothing Controls: Symmetric V FOMC Meetings: $2000-2011$

\begin{tabular}{|c|c|c|c|c|}
\hline & (1) & $(2)$ & $(3)$ & $(4)$ \\
\hline$\left|\pi_{t}-\pi^{*}\right|, \mathrm{GB}$ & $\begin{array}{c}0.490^{* * *} \\
(0.133)\end{array}$ & $\begin{array}{c}0.489^{* * *} \\
(0.132)\end{array}$ & $\begin{array}{c}0.493^{* * *} \\
(0.134)\end{array}$ & $\begin{array}{c}0.495^{* * *} \\
(0.133)\end{array}$ \\
\hline$\left(u_{t}-u_{t}^{*}\right), \mathrm{GB}$ & $\begin{array}{c}0.0316 \\
(0.0762)\end{array}$ & $\begin{array}{c}0.0226 \\
(0.0764)\end{array}$ & $\begin{array}{l}0.0326 \\
(0.0765)\end{array}$ & $\begin{array}{c}0.0182 \\
(0.0767)\end{array}$ \\
\hline$\left(u_{t}-u_{t}^{*}\right)^{2}, \mathrm{~GB}$ & $\begin{array}{c}0.000402 \\
(0.0126)\end{array}$ & $\begin{array}{l}0.00326 \\
(0.0127)\end{array}$ & $\begin{array}{c}-0.000199 \\
(0.0127)\end{array}$ & $\begin{array}{l}0.00351 \\
(0.0128)\end{array}$ \\
\hline$\Delta y_{t}, \mathrm{~GB}$ & $\begin{array}{l}-0.0346 \\
(0.0253)\end{array}$ & $\begin{array}{l}-0.0323 \\
(0.0265)\end{array}$ & $\begin{array}{l}-0.0352 \\
(0.0252)\end{array}$ & $\begin{array}{l}-0.0325 \\
(0.0265)\end{array}$ \\
\hline$\Delta y_{t}^{2}, \mathrm{~GB}$ & $\begin{array}{l}-0.0337^{* * *} \\
(0.00592)\end{array}$ & $\begin{array}{r}-0.0331^{* * *} \\
(0.00597)\end{array}$ & $\begin{array}{r}-0.0338^{* * *} \\
(0.00596)\end{array}$ & $\begin{array}{r}-0.0334^{* * *} \\
(0.00601)\end{array}$ \\
\hline S\&P Return, 3m & $\begin{array}{c}-2.206^{* * *} \\
(0.577)\end{array}$ & $\begin{array}{c}-2.104^{* * *} \\
(0.606)\end{array}$ & $\begin{array}{c}-2.219^{* * *} \\
(0.581)\end{array}$ & $\begin{array}{c}-2.116^{* * *} \\
(0.608)\end{array}$ \\
\hline Shiller PE Ratio & $\begin{array}{l}0.0222^{* *} \\
(0.0103)\end{array}$ & $\begin{array}{l}0.0206^{*} \\
(0.0106)\end{array}$ & $\begin{array}{l}0.0224^{* *} \\
(0.0103)\end{array}$ & $\begin{array}{l}0.0206^{*} \\
(0.0106)\end{array}$ \\
\hline VIX Uncertainty & $\begin{array}{c}0.00783 \\
(0.00584)\end{array}$ & $\begin{array}{c}0.00768 \\
(0.00616)\end{array}$ & $\begin{array}{c}0.00798 \\
(0.00582)\end{array}$ & $\begin{array}{c}0.00782 \\
(0.00618)\end{array}$ \\
\hline Short-Term Yield Volatility, 3m Treas. & & $\begin{array}{c}0.249 \\
(0.240)\end{array}$ & & $\begin{array}{c}0.286 \\
(0.240)\end{array}$ \\
\hline$(\Delta \text { Fed Futures, } 3 \mathrm{~m})^{2}$ & & & $\begin{array}{c}-0.0242^{*} \\
(0.0131)\end{array}$ & $\begin{array}{r}-0.0290^{* * *} \\
(0.00988)\end{array}$ \\
\hline Observations & 1676 & 1676 & 1676 & 1676 \\
\hline Adjusted $R^{2}$ & 0.228 & 0.229 & 0.228 & 0.229 \\
\hline Type & meeting & meeting & meeting & meeting \\
\hline Sample & $2000 \mathrm{~m} 1-2011 \mathrm{~m} 12$ & $2000 \mathrm{~m} 1-2011 \mathrm{~m} 12$ & $2000 \mathrm{~m} 1-2011 \mathrm{~m} 12$ & $2000 \mathrm{~m} 1-2011 \mathrm{~m} 12$ \\
\hline$\hat{\pi}^{*}$ & 1.55 & 1.55 & 1.55 & 1.56 \\
\hline $\mathrm{SE}$ & $(0.16)$ & $(0.2)$ & $(0.16)$ & $(0.13)$ \\
\hline $95 \%$ C.I. & {$[1.24,1.86]$} & {$[1.16,1.94]$} & {$[1.24,1.86]$} & {$[1.31,1.81]$} \\
\hline
\end{tabular}

The variables y and $\mathrm{y}^{*}$ denote $\log$ GDP and $\log$ potential GDP, respectively.

Standard errors (in parentheses) are robust to heteroskedasticity and two-way clustering by sample-month and speaker.

Regressions include speaker fixed effects.

${ }^{*} p<0.10,{ }^{* *} p<0.05,{ }^{* * *} p<0.01$ 
Table G5: Interest Rate Smoothing Controls: Asymmetric V FOMC Meetings: $2000-2011$

\begin{tabular}{|c|c|c|c|c|}
\hline & $(1)$ & 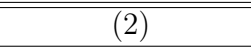 & $(3)$ & $(4)$ \\
\hline$\left(\pi_{t}>\pi^{*}\right)=0 \times\left(\pi_{t}-\pi^{*}\right), \mathrm{GB}$ & $\begin{array}{c}-1.026^{* * *} \\
(0.211)\end{array}$ & $\begin{array}{c}-1.033^{* * *} \\
(0.212)\end{array}$ & $\begin{array}{c}-1.030^{* * *} \\
(0.211)\end{array}$ & $\begin{array}{c}-1.040^{* * *} \\
(0.212)\end{array}$ \\
\hline$\left(\pi_{t}>\pi^{*}\right)=1 \times\left(\pi_{t}-\pi^{*}\right), \mathrm{GB}$ & $\begin{array}{l}0.340^{* *} \\
(0.135)\end{array}$ & $\begin{array}{l}0.329^{* *} \\
(0.135)\end{array}$ & $\begin{array}{l}0.340^{* *} \\
(0.135)\end{array}$ & $\begin{array}{l}0.328^{* *} \\
(0.135)\end{array}$ \\
\hline$\left(u_{t}-u_{t}^{*}\right), \mathrm{GB}$ & $\begin{array}{l}0.00717 \\
(0.0826)\end{array}$ & $\begin{array}{r}-0.00553 \\
(0.0847)\end{array}$ & $\begin{array}{l}0.00736 \\
(0.0828)\end{array}$ & $\begin{array}{r}-0.00720 \\
(0.0847)\end{array}$ \\
\hline$\left(u_{t}-u_{t}^{*}\right)^{2}, \mathrm{~GB}$ & $\begin{array}{l}0.00102 \\
(0.0125)\end{array}$ & $\begin{array}{l}0.00413 \\
(0.0128)\end{array}$ & $\begin{array}{c}0.000528 \\
(0.0126)\end{array}$ & $\begin{array}{l}0.00401 \\
(0.0129)\end{array}$ \\
\hline$\Delta y_{t}, \mathrm{~GB}$ & $\begin{array}{l}-0.0404^{*} \\
(0.0242)\end{array}$ & $\begin{array}{l}-0.0384 \\
(0.0252)\end{array}$ & $\begin{array}{l}-0.0409^{*} \\
(0.0241)\end{array}$ & $\begin{array}{l}-0.0387 \\
(0.0252)\end{array}$ \\
\hline$\Delta y_{t}^{2}, \mathrm{~GB}$ & $\begin{array}{r}-0.0335^{* * *} \\
(0.00648)\end{array}$ & $\begin{array}{r}-0.0332^{* * *} \\
(0.00646)\end{array}$ & $\begin{array}{r}-0.0336^{* * *} \\
(0.00653)\end{array}$ & $\begin{array}{r}-0.0334^{* * *} \\
(0.00651)\end{array}$ \\
\hline S\&P Return, 3m & $\begin{array}{c}-2.202^{* * *} \\
(0.604)\end{array}$ & $\begin{array}{c}-2.126^{* * *} \\
(0.628)\end{array}$ & $\begin{array}{c}-2.216^{* * *} \\
(0.610)\end{array}$ & $\begin{array}{l}-2.132^{* * *} \\
(0.631)\end{array}$ \\
\hline Shiller PE Ratio & $\begin{array}{c}0.0185^{*} \\
(0.00989)\end{array}$ & $\begin{array}{c}0.0168 \\
(0.0104)\end{array}$ & $\begin{array}{c}0.0186^{*} \\
(0.00990)\end{array}$ & $\begin{array}{c}0.0167 \\
(0.0104)\end{array}$ \\
\hline VIX Uncertainty & $\begin{array}{c}0.00808 \\
(0.00610)\end{array}$ & $\begin{array}{c}0.00784 \\
(0.00634)\end{array}$ & $\begin{array}{c}0.00819 \\
(0.00609)\end{array}$ & $\begin{array}{c}0.00794 \\
(0.00637)\end{array}$ \\
\hline Short-Term Yield Volatility, 3m Treas. & & $\begin{array}{c}0.226 \\
(0.246)\end{array}$ & & $\begin{array}{c}0.259 \\
(0.246)\end{array}$ \\
\hline$(\Delta \text { Fed Futures, } 3 \mathrm{~m})^{2}$ & & & $\begin{array}{c}-0.0229^{*} \\
(0.0132)\end{array}$ & $\begin{array}{c}-0.0273^{* * *} \\
(0.0104)\end{array}$ \\
\hline Observations & 1676 & 1676 & 1676 & 1676 \\
\hline Adjusted $R^{2}$ & 0.230 & 0.230 & 0.230 & 0.230 \\
\hline Type & meeting & meeting & meeting & meeting \\
\hline Sample & 2000m1-2011m12 & $2000 \mathrm{~m} 1-2011 \mathrm{~m} 12$ & $2000 \mathrm{~m} 1-2011 \mathrm{~m} 12$ & $2000 \mathrm{~m} 1-2011 \mathrm{~m} 12$ \\
\hline Symmetry p-val & 0.002 & 0.002 & 0.002 & 0.001 \\
\hline$\hat{\pi^{*}}$ & 1.35 & 1.35 & 1.35 & 1.35 \\
\hline $\mathrm{SE}$ & $(0.18)$ & $(0.17)$ & $(0.2)$ & $(0.21)$ \\
\hline $95 \%$ C.I. & {$[1,1.7]$} & {$[1.02,1.68]$} & {$[.96,1.74]$} & {$[.94,1.76]$} \\
\hline
\end{tabular}

The variables y and $\mathrm{y}^{*}$ denote $\log$ GDP and $\log$ potential GDP, respectively.

Standard errors (in parentheses) are robust to heteroskedasticity and two-way clustering by sample-month and speaker.

Regressions include speaker fixed effects.

${ }^{*} p<0.10,{ }^{* *} p<0.05,{ }^{* * *} p<0.01$ 
Table G6: Squared Financial Variables, SPF Dispersion, and Lagged Dependent Variable Controls: Symmetric V

FOMC Meetings: $2000-2011$

\begin{tabular}{|c|c|c|c|c|c|}
\hline & $(1)$ & $(2)$ & (3) & (4) & $(5)$ \\
\hline$\left|\pi_{t}-\pi^{*}\right|, \mathrm{GB}$ & $\begin{array}{c}0.489^{* * *} \\
(0.132)\end{array}$ & $\begin{array}{c}0.506^{* * *} \\
(0.137)\end{array}$ & $\begin{array}{c}0.628^{* * *} \\
(0.135)\end{array}$ & $\begin{array}{c}0.452^{* * *} \\
(0.125)\end{array}$ & $\begin{array}{c}0.577^{* * *} \\
(0.135)\end{array}$ \\
\hline$\left(u_{t}-u_{t}^{*}\right), \mathrm{GB}$ & $\begin{array}{c}0.0226 \\
(0.0764)\end{array}$ & $\begin{array}{c}-0.0807 \\
(0.0859)\end{array}$ & $\begin{array}{c}0.117 \\
(0.0936)\end{array}$ & $\begin{array}{l}-0.00439 \\
(0.0729)\end{array}$ & $\begin{array}{c}0.00778 \\
(0.0859)\end{array}$ \\
\hline$\left(u_{t}-u_{t}^{*}\right)^{2}, \mathrm{~GB}$ & $\begin{array}{c}0.00326 \\
(0.0127)\end{array}$ & $\begin{array}{c}0.0198 \\
(0.0151)\end{array}$ & $\begin{array}{l}0.000561 \\
(0.0122)\end{array}$ & $\begin{array}{l}0.00852 \\
(0.0121)\end{array}$ & $\begin{array}{c}0.0229 \\
(0.0142)\end{array}$ \\
\hline$\Delta y_{t}, \mathrm{~GB}$ & $\begin{array}{l}-0.0323 \\
(0.0265)\end{array}$ & $\begin{array}{l}-0.0308 \\
(0.0269)\end{array}$ & $\begin{array}{c}-0.0992^{* * *} \\
(0.0332)\end{array}$ & $\begin{array}{l}-0.0152 \\
(0.0259)\end{array}$ & $\begin{array}{c}-0.0883^{* *} \\
(0.0391)\end{array}$ \\
\hline$\Delta y_{t}^{2}, \mathrm{~GB}$ & $\begin{array}{c}-0.0331^{* * *} \\
(0.00597)\end{array}$ & $\begin{array}{c}-0.0277^{* * *} \\
(0.00568)\end{array}$ & $\begin{array}{c}-0.0293^{* * *} \\
(0.00597)\end{array}$ & $\begin{array}{c}-0.0296^{* * *} \\
(0.00622)\end{array}$ & $\begin{array}{c}-0.0213^{* * *} \\
(0.00746)\end{array}$ \\
\hline S\&P Return, $3 \mathrm{~m}$ & $\begin{array}{c}-2.104^{* * *} \\
(0.606)\end{array}$ & $\begin{array}{c}-1.783^{* * *} \\
(0.635)\end{array}$ & $\begin{array}{c}-2.211^{* * *} \\
(0.578)\end{array}$ & $\begin{array}{c}-2.250^{* * *} \\
(0.581)\end{array}$ & $\begin{array}{c}-2.138^{* * *} \\
(0.593)\end{array}$ \\
\hline Shiller PE Ratio & $\begin{array}{c}0.0206^{*} \\
(0.0106)\end{array}$ & $\begin{array}{c}0.0609 \\
(0.0577)\end{array}$ & $\begin{array}{c}0.0332^{* * *} \\
(0.0116)\end{array}$ & $\begin{array}{c}0.0177^{*} \\
(0.00988)\end{array}$ & $\begin{array}{c}0.102^{*} \\
(0.0596)\end{array}$ \\
\hline VIX Uncertainty & $\begin{array}{c}0.00768 \\
(0.00616)\end{array}$ & $\begin{array}{c}0.0447^{* * *} \\
(0.0157)\end{array}$ & $\begin{array}{c}0.00667 \\
(0.00557)\end{array}$ & $\begin{array}{c}0.00582 \\
(0.00555)\end{array}$ & $\begin{array}{c}0.0309^{*} \\
(0.0163)\end{array}$ \\
\hline Short-Term Yield Volatility, 3m Treas. & $\begin{array}{c}0.249 \\
(0.240)\end{array}$ & $\begin{array}{c}0.674 \\
(0.864)\end{array}$ & $\begin{array}{c}0.265 \\
(0.262)\end{array}$ & $\begin{array}{c}0.102 \\
(0.236)\end{array}$ & $\begin{array}{c}0.129 \\
(0.802)\end{array}$ \\
\hline$(\mathrm{S} \& \mathrm{P} \text { Return, } 3 \mathrm{~m})^{2}$ & & $\begin{array}{c}2.179 \\
(3.502)\end{array}$ & & & $\begin{array}{l}-1.318 \\
(4.564)\end{array}$ \\
\hline$(\text { Shiller PE Ratio) })^{2}$ & & $\begin{array}{c}-0.000843 \\
(0.000939)\end{array}$ & & & $\begin{array}{c}-0.00125 \\
(0.000931)\end{array}$ \\
\hline (VIX Uncertainty) $^{2}$ & & $\begin{array}{c}-0.000517^{* * *} \\
(0.000175)\end{array}$ & & & $\begin{array}{c}-0.000322 \\
(0.000207)\end{array}$ \\
\hline$(\text { Short-Term Yield Volatility, } 3 \mathrm{~m} \text { Treas. })^{2}$ & & $\begin{array}{c}-0.571 \\
(1.073)\end{array}$ & & & $\begin{array}{l}0.0276 \\
(1.003)\end{array}$ \\
\hline$\pi_{t}$, SPF Nowcast Dispersion & & & $\begin{array}{l}-0.109^{* *} \\
(0.0431)\end{array}$ & & $\begin{array}{c}-0.0364 \\
(0.0603)\end{array}$ \\
\hline$\pi_{t}$, SPF 4q-ahead Dispersion & & & $\begin{array}{l}0.363^{* *} \\
(0.177)\end{array}$ & & $\begin{array}{l}0.397^{* *} \\
(0.194)\end{array}$ \\
\hline$\Delta y_{t}$, SPF Nowcast Dispersion & & & $\begin{array}{c}-0.156^{*} \\
(0.0918)\end{array}$ & & $\begin{array}{c}-0.149 \\
(0.0988)\end{array}$ \\
\hline$\Delta y_{t}$, SPF $4 q$-ahead Dispersion & & & $\begin{array}{l}-0.166 \\
(0.275)\end{array}$ & & $\begin{array}{l}-0.145 \\
(0.263)\end{array}$ \\
\hline$u_{t}$, SPF Nowcast Dispersion & & & $\begin{array}{c}0.199 \\
(0.495)\end{array}$ & & $\begin{array}{c}0.122 \\
(0.487)\end{array}$ \\
\hline$u_{t}$, SPF 4q-ahead Dispersion & & & $\begin{array}{c}-0.800^{* *} \\
(0.337)\end{array}$ & & $\begin{array}{c}-0.799^{* *} \\
(0.350)\end{array}$ \\
\hline$N_{i, t-1}$ & & & & $\begin{array}{l}0.152^{* * *} \\
(0.0281)\end{array}$ & $\begin{array}{l}0.144^{* * *} \\
(0.0276)\end{array}$ \\
\hline Observations & 1676 & 1676 & 1676 & 1658 & 1658 \\
\hline Adjusted $R^{2}$ & 0.229 & 0.235 & 0.247 & 0.245 & 0.263 \\
\hline Type & meeting & meeting & meeting & meeting & meeting \\
\hline Sample & $2000 \mathrm{~m} 1-2011 \mathrm{~m} 12$ & $2000 \mathrm{~m} 1-2011 \mathrm{~m} 12$ & $2000 \mathrm{~m} 1-2011 \mathrm{~m} 12$ & $2000 \mathrm{~m} 1-2011 \mathrm{~m} 12$ & $2000 \mathrm{~m} 1-2011 \mathrm{~m} 12$ \\
\hline$\hat{\pi}^{*}$ & 1.55 & 1.55 & 1.55 & 1.57 & 1.58 \\
\hline $\mathrm{SE}$ & $(0.2)$ & $(0.18)$ & $(0.15)$ & $(0.18)$ & $(0.19)$ \\
\hline $95 \%$ C.I. & {$[1.16,1.94]$} & {$[1.2,1.9]$} & {$[1.26,1.84]$} & {$[1.22,1.92]$} & {$[1.21,1.95]$} \\
\hline
\end{tabular}

The variables y and $\mathrm{y}^{*}$ denote $\log$ GDP and $\log$ potential GDP, respectively.

Standard errors (in parentheses) are robust to heteroskedasticity and two-way clustering by sample-month and speaker.

Regressions include speaker fixed effects.

${ }^{*} p<0.10,{ }^{* *} p<0.05,{ }^{* * *} p<0.01$ 
Table G7: Squared Financial Variables, SPF Dispersion, and Lagged Dependent Variable Controls: Asymmetric V

FOMC Meetings: $2000-2011$

\begin{tabular}{|c|c|c|c|c|c|}
\hline$\left(\pi_{t}>\pi^{*}\right)=0 \times\left(\pi_{t}-\pi^{*}\right), \mathrm{GB}$ & $\begin{array}{c}(1) \\
-1.033^{* * * *} \\
(0.212)\end{array}$ & $\begin{array}{c}(2) \\
-1.046^{* * *} \\
(0.222)\end{array}$ & $\begin{array}{c}(3) \\
-0.382^{*} \\
(0.203)\end{array}$ & $\begin{array}{c}(4) \\
-0.949^{\text {*** }} \\
(0.208)\end{array}$ & $\begin{array}{c}(5) \\
-0.387^{* *} \\
(0.191)\end{array}$ \\
\hline$\left(\pi_{t}>\pi^{*}\right)=1 \times\left(\pi_{t}-\pi^{*}\right), \mathrm{GB}$ & $\begin{array}{l}0.329^{* *} \\
(0.135)\end{array}$ & $\begin{array}{c}0.373^{* * *} \\
(0.135)\end{array}$ & $\begin{array}{c}0.826^{* * *} \\
(0.189)\end{array}$ & $\begin{array}{l}0.290^{* *} \\
(0.122)\end{array}$ & $\begin{array}{c}0.780^{* * *} \\
(0.176)\end{array}$ \\
\hline$\left(u_{t}-u_{t}^{*}\right), \mathrm{GB}$ & $\begin{array}{l}-0.00553 \\
(0.0847)\end{array}$ & $\begin{array}{l}-0.0900 \\
(0.0982)\end{array}$ & $\begin{array}{c}0.152 \\
(0.0939)\end{array}$ & $\begin{array}{l}-0.0272 \\
(0.0842)\end{array}$ & $\begin{array}{c}0.0359 \\
(0.0868)\end{array}$ \\
\hline$\left(u_{t}-u_{t}^{*}\right)^{2}, \mathrm{~GB}$ & $\begin{array}{l}0.00413 \\
(0.0128)\end{array}$ & $\begin{array}{c}0.0164 \\
(0.0159)\end{array}$ & $\begin{array}{l}0.0000444 \\
(0.0116)\end{array}$ & $\begin{array}{l}0.00888 \\
(0.0126)\end{array}$ & $\begin{array}{l}0.0250^{*} \\
(0.0145)\end{array}$ \\
\hline$\Delta y_{t}, \mathrm{~GB}$ & $\begin{array}{l}-0.0384 \\
(0.0252)\end{array}$ & $\begin{array}{l}-0.0333 \\
(0.0257)\end{array}$ & $\begin{array}{c}-0.107^{* * *} \\
(0.0345)\end{array}$ & $\begin{array}{l}-0.0214 \\
(0.0244)\end{array}$ & $\begin{array}{l}-0.102^{* *} \\
(0.0401)\end{array}$ \\
\hline$\Delta y_{t}^{2}, \mathrm{~GB}$ & $\begin{array}{c}-0.0332^{* * *} \\
(0.00646)\end{array}$ & $\begin{array}{c}-0.0278^{* * *} \\
(0.00595)\end{array}$ & $\begin{array}{c}-0.0278^{* * *} \\
(0.00666)\end{array}$ & $\begin{array}{c}-0.0296^{* * * *} \\
(0.00661)\end{array}$ & $\begin{array}{c}-0.0191^{* *} \\
(0.00780)\end{array}$ \\
\hline S\&P Return, $3 \mathrm{~m}$ & $\begin{array}{c}-2.126^{* * * *} \\
(0.628)\end{array}$ & $\begin{array}{c}-1.776^{* * *} \\
(0.648)\end{array}$ & $\begin{array}{c}-2.127^{* * *} \\
(0.563)\end{array}$ & $\begin{array}{c}-2.265^{* * *} \\
(0.598)\end{array}$ & $\begin{array}{c}-2.055^{* * * *} \\
(0.528)\end{array}$ \\
\hline Shiller PE Ratio & $\begin{array}{c}0.0168 \\
(0.0104)\end{array}$ & $\begin{array}{c}0.0440 \\
(0.0548)\end{array}$ & $\begin{array}{c}0.0394 * * * \\
(0.0117)\end{array}$ & $\begin{array}{c}0.0142 \\
(0.00981)\end{array}$ & $\begin{array}{l}0.125^{* *} \\
(0.0594)\end{array}$ \\
\hline VIX Uncertainty & $\begin{array}{c}0.00784 \\
(0.00634)\end{array}$ & $\begin{array}{c}0.0467^{* * *} \\
(0.0157)\end{array}$ & $\begin{array}{c}0.00817 \\
(0.00526)\end{array}$ & $\begin{array}{c}0.00588 \\
(0.00572)\end{array}$ & $\begin{array}{l}0.0310^{*} \\
(0.0161)\end{array}$ \\
\hline Short-Term Yield Volatility, 3m Treas. & $\begin{array}{c}0.226 \\
(0.246)\end{array}$ & $\begin{array}{c}0.524 \\
(0.866)\end{array}$ & $\begin{array}{c}0.293 \\
(0.265)\end{array}$ & $\begin{array}{l}0.0819 \\
(0.244)\end{array}$ & $\begin{array}{c}0.153 \\
(0.758)\end{array}$ \\
\hline$(\mathrm{S} \& \mathrm{P} \text { Return, } 3 \mathrm{~m})^{2}$ & & $\begin{array}{c}2.691 \\
(3.590)\end{array}$ & & & $\begin{array}{l}-1.632 \\
(4.446)\end{array}$ \\
\hline$(\text { Shiller PE Ratio })^{2}$ & & $\begin{array}{c}-0.000621 \\
(0.000902)\end{array}$ & & & $\begin{array}{c}-0.00153^{*} \\
(0.000923)\end{array}$ \\
\hline (VIX Uncertainty) $^{2}$ & & $\begin{array}{c}-0.000557^{* * *} \\
(0.000177)\end{array}$ & & & $\begin{array}{c}-0.000290 \\
(0.000208)\end{array}$ \\
\hline$(\text { Short-Term Yield Volatility, 3m Treas. })^{2}$ & & $\begin{array}{c}-0.378 \\
(1.075)\end{array}$ & & & $\begin{array}{c}-0.00211 \\
(0.950)\end{array}$ \\
\hline$\pi_{t}$, SPF Nowcast Dispersion & & & $\begin{array}{c}-0.119^{* * * *} \\
(0.0460)\end{array}$ & & $\begin{array}{c}-0.0475 \\
(0.0627)\end{array}$ \\
\hline$\pi_{t}$, SPF 4q-ahead Dispersion & & & $\begin{array}{l}0.355^{* *} \\
(0.165)\end{array}$ & & $\begin{array}{l}0.401^{* *} \\
(0.183)\end{array}$ \\
\hline$\Delta y_{t}, \mathrm{SPF}$ Nowcast Dispersion & & & $\begin{array}{c}-0.179^{*} \\
(0.0928)\end{array}$ & & $\begin{array}{c}-0.160 \\
(0.0993)\end{array}$ \\
\hline$\Delta y_{t}$, SPF $4 \mathrm{q}$-ahead Dispersion & & & $\begin{array}{l}-0.255 \\
(0.284)\end{array}$ & & $\begin{array}{l}-0.232 \\
(0.258)\end{array}$ \\
\hline$u_{t}$, SPF Nowcast Dispersion & & & $\begin{array}{c}0.267 \\
(0.515)\end{array}$ & & $\begin{array}{c}0.133 \\
(0.504)\end{array}$ \\
\hline$u_{t}$, SPF 4q-ahead Dispersion & & & $\begin{array}{c}-0.887^{* * *} \\
(0.334)\end{array}$ & & $\begin{array}{c}-0.906^{* * *} \\
(0.351)\end{array}$ \\
\hline$N_{i, t-1}$ & & & & $\begin{array}{l}0.150^{* * *} \\
(0.0278)\end{array}$ & $\begin{array}{l}0.144^{* * *} \\
(0.0273)\end{array}$ \\
\hline Observations & 1676 & 1676 & 1676 & 1658 & 1658 \\
\hline Adjusted $R^{2}$ & 0.230 & 0.237 & 0.247 & 0.245 & 0.264 \\
\hline Type & meeting & meeting & meeting & meeting & meeting \\
\hline Sample & $2000 \mathrm{~m} 1-2011 \mathrm{~m} 12$ & $2000 \mathrm{~m} 1-2011 \mathrm{~m} 12$ & $2000 \mathrm{~m} 1-2011 \mathrm{~m} 12$ & $2000 \mathrm{~m} 1-2011 \mathrm{~m} 12$ & $2000 \mathrm{~m} 1-2011 \mathrm{~m} 12$ \\
\hline Symmetry p-val & 0.002 & 0.003 & 0.06 & 0.003 & 0.052 \\
\hline$\hat{\pi^{*}}$ & 1.35 & 1.35 & 1.7 & 1.35 & 1.73 \\
\hline SE & $(0.17)$ & $(0.19)$ & $(0.25)$ & $(0.24)$ & $(0.35)$ \\
\hline $95 \%$ C.I. & {$[1.02,1.68]$} & {$[.98,1.72]$} & {$[1.21,2.19]$} & {$[.88,1.82]$} & {$[1.04,2.42]$} \\
\hline
\end{tabular}


Table G8: Lagged Inflation and Inflation Expectation Controls: Symmetric V

FOMC Meetings: $2000-2011$

\begin{tabular}{|c|c|c|c|c|c|c|}
\hline$\left|\pi_{t}-\pi^{*}\right|, \mathrm{GB}$ & $\begin{array}{c}(1) \\
0.489^{* * *} \\
(0.132)\end{array}$ & $\begin{array}{c}(2) \\
0.468^{* * *} \\
(0.138)\end{array}$ & $\begin{array}{c}(3) \\
0.458^{* * *} \\
(0.140)\end{array}$ & $\begin{array}{c}(4) \\
0.532^{* * *} \\
(0.139)\end{array}$ & $\begin{array}{c}(5) \\
0.508^{* * *} \\
(0.144)\end{array}$ & $\begin{array}{c}(6) \\
0.496^{* * *} \\
(0.150)\end{array}$ \\
\hline$\left(u_{t}-u_{t}^{*}\right), \mathrm{GB}$ & $\begin{array}{c}0.0226 \\
(0.0764)\end{array}$ & $\begin{array}{l}-0.0393 \\
(0.0728)\end{array}$ & $\begin{array}{c}-0.229^{* *} \\
(0.106)\end{array}$ & $\begin{array}{l}-0.0548 \\
(0.0863)\end{array}$ & $\begin{array}{c}-0.113 \\
(0.0832)\end{array}$ & $\begin{array}{c}-0.248^{* *} \\
(0.109)\end{array}$ \\
\hline$\left(u_{t}-u_{t}^{*}\right)^{2}, \mathrm{~GB}$ & $\begin{array}{l}0.00326 \\
(0.0127)\end{array}$ & $\begin{array}{c}0.0117 \\
(0.0116)\end{array}$ & $\begin{array}{l}0.0408^{* *} \\
(0.0165)\end{array}$ & $\begin{array}{c}0.0213 \\
(0.0162)\end{array}$ & $\begin{array}{l}0.0293^{*} \\
(0.0153)\end{array}$ & $\begin{array}{c}0.0485^{* * *} \\
(0.0180)\end{array}$ \\
\hline$\Delta y_{t}, \mathrm{~GB}$ & $\begin{array}{l}-0.0323 \\
(0.0265)\end{array}$ & $\begin{array}{l}-0.0243 \\
(0.0257)\end{array}$ & $\begin{array}{l}-0.0388 \\
(0.0248)\end{array}$ & $\begin{array}{l}-0.0385 \\
(0.0273)\end{array}$ & $\begin{array}{l}-0.0306 \\
(0.0266)\end{array}$ & $\begin{array}{l}-0.0423^{*} \\
(0.0256)\end{array}$ \\
\hline$\Delta y_{t}^{2}, \mathrm{~GB}$ & $\begin{array}{c}-0.0331^{* * *} \\
(0.00597)\end{array}$ & $\begin{array}{c}-0.0349^{* * *} \\
(0.00608)\end{array}$ & $\begin{array}{r}-0.0378^{* * *} \\
(0.00617)\end{array}$ & $\begin{array}{r}-0.0373^{* * *} \\
(0.00559)\end{array}$ & $\begin{array}{r}-0.0389^{* * *} \\
(0.00557)\end{array}$ & $\begin{array}{c}-0.0402^{* * *} \\
(0.00582)\end{array}$ \\
\hline S\&P Return, 3m & $\begin{array}{c}-2.104^{* * *} \\
(0.606)\end{array}$ & $\begin{array}{c}-2.163^{* * *} \\
(0.614)\end{array}$ & $\begin{array}{c}-2.174^{* * *} \\
(0.620)\end{array}$ & $\begin{array}{c}-2.234^{* * *} \\
(0.587)\end{array}$ & $\begin{array}{c}-2.282^{* * *} \\
(0.595)\end{array}$ & $\begin{array}{c}-2.264^{* * *} \\
(0.600)\end{array}$ \\
\hline Shiller PE Ratio & $\begin{array}{l}0.0206^{*} \\
(0.0106)\end{array}$ & $\begin{array}{c}0.0156 \\
(0.00994)\end{array}$ & $\begin{array}{l}-0.00399 \\
(0.0110)\end{array}$ & $\begin{array}{l}0.0205^{* *} \\
(0.0104)\end{array}$ & $\begin{array}{c}0.0155 \\
(0.00986)\end{array}$ & $\begin{array}{c}-0.000256 \\
(0.0115)\end{array}$ \\
\hline VIX Uncertainty & $\begin{array}{c}0.00768 \\
(0.00616)\end{array}$ & $\begin{array}{c}0.00945 \\
(0.00612)\end{array}$ & $\begin{array}{c}0.0112^{*} \\
(0.00602)\end{array}$ & $\begin{array}{c}0.00811 \\
(0.00652)\end{array}$ & $\begin{array}{c}0.00991 \\
(0.00644)\end{array}$ & $\begin{array}{c}0.0109^{*} \\
(0.00634)\end{array}$ \\
\hline Short-Term Yield Volatility, 3m Treas. & $\begin{array}{c}0.249 \\
(0.240)\end{array}$ & $\begin{array}{c}0.244 \\
(0.243)\end{array}$ & $\begin{array}{c}0.259 \\
(0.241)\end{array}$ & $\begin{array}{c}0.236 \\
(0.237)\end{array}$ & $\begin{array}{c}0.230 \\
(0.240)\end{array}$ & $\begin{array}{c}0.249 \\
(0.237)\end{array}$ \\
\hline$\pi_{t-1}, \mathrm{~GB}$ & & $\begin{array}{l}-0.0838 \\
(0.0518)\end{array}$ & & & $\begin{array}{c}-0.0848^{*} \\
(0.0506)\end{array}$ & \\
\hline $\bar{\pi}_{t-1, t-4}, \mathrm{~GB}$ & & & $\begin{array}{c}-0.380^{* *} \\
(0.157)\end{array}$ & & & $\begin{array}{c}-0.320^{*} \\
(0.168)\end{array}$ \\
\hline Inflation Expectations, 10-year ahead & & & & $\begin{array}{l}0.510^{*} \\
(0.263)\end{array}$ & $\begin{array}{l}0.512^{* *} \\
(0.259)\end{array}$ & $\begin{array}{c}0.375 \\
(0.277)\end{array}$ \\
\hline $\begin{array}{l}\text { Observations } \\
\text { Adjusted } R^{2}\end{array}$ & $\begin{array}{c}1676 \\
0.229\end{array}$ & $\begin{array}{l}1676 \\
0.231\end{array}$ & $\begin{array}{l}1676 \\
0.235\end{array}$ & $\begin{array}{l}1676 \\
0.233\end{array}$ & $\begin{array}{l}1676 \\
0.235\end{array}$ & $\begin{array}{l}1676 \\
0.237\end{array}$ \\
\hline Type & meeting & meeting & meeting & meeting & meeting & meeting \\
\hline Sample & $2000 \mathrm{~m} 1-2011 \mathrm{~m} 12$ & 2000m1-2011m12 & 2000m1-2011m12 & 2000m1-2011m12 & $2000 \mathrm{~m} 1-2011 \mathrm{~m} 12$ & $2000 \mathrm{~m} 1-2011 \mathrm{~m} 12$ \\
\hline$\hat{\pi}^{*}$ & 1.55 & 1.55 & 1.56 & 1.56 & 1.55 & 1.57 \\
\hline SE & $(0.2)$ & $(0.18)$ & $(0.19)$ & $(0.14)$ & $(0.16)$ & $(0.23)$ \\
\hline $95 \%$ C.I. & {$[1.16,1.94]$} & {$[1.2,1.9]$} & {$[1.19,1.93]$} & {$[1.29,1.83]$} & {$[1.24,1.86]$} & {$[1.12,2.02]$} \\
\hline
\end{tabular}


Table G9: Lagged Inflation and Inflation Expectation Controls: Asymmetric V

FOMC Meetings: $2000-2011$

\begin{tabular}{|c|c|c|c|c|c|c|}
\hline$\left(\pi_{t}>\pi^{*}\right)=0 \times\left(\pi_{t}-\pi^{*}\right), \mathrm{GB}$ & $\begin{array}{c}(1) \\
-1.033^{* * *} \\
(0.212)\end{array}$ & $\begin{array}{c} \\
-0.567^{* * *} \\
(0.193)\end{array}$ & $\begin{array}{c}(3) \\
-0.580^{* * *} \\
(0.182)\end{array}$ & $\begin{array}{c}(4) \\
-0.742^{* * *} \\
(0.199)\end{array}$ & $\begin{array}{c} \\
-0.668^{* * *} \\
(0.218)\end{array}$ & $\begin{array}{c}(6) \\
-0.667^{* * *} \\
(0.213)\end{array}$ \\
\hline$\left(\pi_{t}>\pi^{*}\right)=1 \times\left(\pi_{t}-\pi^{*}\right), \mathrm{GB}$ & $\begin{array}{l}0.329^{* *} \\
(0.135)\end{array}$ & $\begin{array}{c}0.435^{* * *} \\
(0.156)\end{array}$ & $\begin{array}{l}0.412^{* *} \\
(0.163)\end{array}$ & $\begin{array}{c}0.458^{* * *} \\
(0.155)\end{array}$ & $\begin{array}{c}0.458^{* * *} \\
(0.156)\end{array}$ & $\begin{array}{c}0.434^{* * *} \\
(0.164)\end{array}$ \\
\hline$\left(u_{t}-u_{t}^{*}\right), \mathrm{GB}$ & $\begin{array}{l}-0.00553 \\
(0.0847)\end{array}$ & $\begin{array}{l}-0.0599 \\
(0.0821)\end{array}$ & $\begin{array}{c}-0.252^{* *} \\
(0.114)\end{array}$ & $\begin{array}{c}-0.112 \\
(0.0967)\end{array}$ & $\begin{array}{c}-0.151 \\
(0.0963)\end{array}$ & $\begin{array}{c}-0.279^{* *} \\
(0.118)\end{array}$ \\
\hline$\left(u_{t}-u_{t}^{*}\right)^{2}, \mathrm{~GB}$ & $\begin{array}{l}0.00413 \\
(0.0128)\end{array}$ & $\begin{array}{c}0.0137 \\
(0.0122)\end{array}$ & $\begin{array}{l}0.0429^{* *} \\
(0.0171)\end{array}$ & $\begin{array}{l}0.0279^{*} \\
(0.0166)\end{array}$ & $\begin{array}{l}0.0336^{* *} \\
(0.0162)\end{array}$ & $\begin{array}{c}0.0516^{* * *} \\
(0.0187)\end{array}$ \\
\hline$\Delta y_{t}, \mathrm{~GB}$ & $\begin{array}{l}-0.0384 \\
(0.0252)\end{array}$ & $\begin{array}{l}-0.0251 \\
(0.0253)\end{array}$ & $\begin{array}{l}-0.0389 \\
(0.0243)\end{array}$ & $\begin{array}{l}-0.0395 \\
(0.0266)\end{array}$ & $\begin{array}{l}-0.0323 \\
(0.0261)\end{array}$ & $\begin{array}{l}-0.0430^{*} \\
(0.0249)\end{array}$ \\
\hline$\Delta y_{t}^{2}, \mathrm{~GB}$ & $\begin{array}{c}-0.0332^{* * *} \\
(0.00646)\end{array}$ & $\begin{array}{c}-0.0357^{* * *} \\
(0.00656)\end{array}$ & $\begin{array}{c}-0.0388^{* * *} \\
(0.00669)\end{array}$ & $\begin{array}{r}-0.0396^{* * *} \\
(0.00636)\end{array}$ & $\begin{array}{c}-0.0405^{* * *} \\
(0.00630)\end{array}$ & $\begin{array}{c}-0.0417^{* * *} \\
(0.00647)\end{array}$ \\
\hline S\&P Return, 3m & $\begin{array}{l}-2.126^{* * *} \\
(0.628)\end{array}$ & $\begin{array}{l}-2.227^{* * *} \\
(0.607)\end{array}$ & $\begin{array}{l}-2.250^{* * *} \\
(0.611)\end{array}$ & $\begin{array}{l}-2.381^{* * *} \\
(0.569)\end{array}$ & $\begin{array}{l}-2.392^{* * *} \\
(0.583)\end{array}$ & $\begin{array}{l}-2.370^{* * *} \\
(0.586)\end{array}$ \\
\hline Shiller PE Ratio & $\begin{array}{c}0.0168 \\
(0.0104)\end{array}$ & $\begin{array}{c}0.0147 \\
(0.00996)\end{array}$ & $\begin{array}{l}-0.00508 \\
(0.0111)\end{array}$ & $\begin{array}{l}0.0177^{*} \\
(0.0103)\end{array}$ & $\begin{array}{c}0.0140 \\
(0.00990)\end{array}$ & $\begin{array}{l}-0.00126 \\
(0.0115)\end{array}$ \\
\hline VIX Uncertainty & $\begin{array}{c}0.00784 \\
(0.00634)\end{array}$ & $\begin{array}{c}0.00903 \\
(0.00603)\end{array}$ & $\begin{array}{c}0.0108^{*} \\
(0.00589)\end{array}$ & $\begin{array}{c}0.00756 \\
(0.00639)\end{array}$ & $\begin{array}{c}0.00927 \\
(0.00637)\end{array}$ & $\begin{array}{c}0.0103^{*} \\
(0.00625)\end{array}$ \\
\hline Short-Term Yield Volatility, 3m Treas. & $\begin{array}{c}0.226 \\
(0.246)\end{array}$ & $\begin{array}{c}0.261 \\
(0.246)\end{array}$ & $\begin{array}{c}0.277 \\
(0.243)\end{array}$ & $\begin{array}{c}0.268 \\
(0.238)\end{array}$ & $\begin{array}{c}0.255 \\
(0.241)\end{array}$ & $\begin{array}{c}0.272 \\
(0.238)\end{array}$ \\
\hline$\pi_{t-1}, \mathrm{~GB}$ & & $\begin{array}{c}-0.0771 \\
(0.0528)\end{array}$ & & & $\begin{array}{c}-0.0741 \\
(0.0506)\end{array}$ & \\
\hline $\bar{\pi}_{t-1, t-4}, \mathrm{~GB}$ & & & $\begin{array}{c}-0.372^{* *} \\
(0.158)\end{array}$ & & & $\begin{array}{c}-0.302^{*} \\
(0.169)\end{array}$ \\
\hline Inflation Expectations, 10-year ahead & & & & $\begin{array}{l}0.553^{* *} \\
(0.265)\end{array}$ & $\begin{array}{l}0.545^{* *} \\
(0.265)\end{array}$ & $\begin{array}{c}0.417 \\
(0.281)\end{array}$ \\
\hline Observations & 1676 & 1676 & 1676 & 1676 & 1676 & 1676 \\
\hline Adjusted $R^{2}$ & 0.230 & 0.231 & 0.235 & 0.234 & 0.235 & 0.237 \\
\hline Type & meeting & meeting & meeting & meeting & meeting & meeting \\
\hline Sample & $2000 \mathrm{~m} 1-2011 \mathrm{~m} 12$ & 2000m1-2011m12 & 2000m1-2011m12 & $2000 \mathrm{~m} 1-2011 \mathrm{~m} 12$ & $2000 \mathrm{~m} 1-2011 \mathrm{~m} 12$ & $2000 \mathrm{~m} 1-2011 \mathrm{~m} 12$ \\
\hline Symmetry p-val & 0.002 & 0.536 & 0.429 & 0.194 & 0.35 & 0.297 \\
\hline$\hat{\pi}^{*}$ & 1.35 & 1.55 & 1.55 & 1.55 & 1.55 & 1.55 \\
\hline & $(0.17)$ & $(0.2)$ & $(0.31)$ & $(0.17)$ & $(0.21)$ & $(0.3)$ \\
\hline $95 \%$ C.I. & {$[1.02,1.68]$} & {$[1.16,1.94]$} & {$[.94,2.16]$} & {$[1.22,1.88]$} & {$[1.14,1.96]$} & {$[.96,2.14]$} \\
\hline
\end{tabular}


Table G10: Estimated Loss Function Based on FOMC Minutes Allowing For Asymmetry

\begin{tabular}{|c|c|c|c|c|}
\hline & $\begin{array}{c}(1) \\
2000-2011 \\
\end{array}$ & $\begin{array}{c}(2) \\
2000-2011 \\
\end{array}$ & $\begin{array}{c}(3) \\
2012-2019 \\
\end{array}$ & $\begin{array}{c}(4) \\
2012-2019 \\
\end{array}$ \\
\hline$\left|\pi_{t}-\pi^{*}\right|$ & & & & \\
\hline$\left(\pi_{t}>\pi^{*}\right)=0 \times\left(\pi_{t}-\pi^{*}\right)$ & $\begin{array}{l}-0.298 \\
(0.356)\end{array}$ & $\begin{array}{l}-0.403 \\
(0.253)\end{array}$ & $\begin{array}{l}-0.205 \\
(0.128)\end{array}$ & $\begin{array}{c}-0.292^{* *} \\
(0.140)\end{array}$ \\
\hline$\left(\pi_{t}>\pi^{*}\right)=1 \times\left(\pi_{t}-\pi^{*}\right)$ & $\begin{array}{c}0.789^{* * *} \\
(0.275)\end{array}$ & $\begin{array}{l}0.436^{* *} \\
(0.206)\end{array}$ & $\begin{array}{l}33.00^{* * *} \\
(4.348)\end{array}$ & $\begin{array}{c}8.428^{* * *} \\
(2.232)\end{array}$ \\
\hline$\left(u_{t}-u_{t}^{*}\right)$ & & $\begin{array}{c}0.167 \\
(0.138)\end{array}$ & & $\begin{array}{c}-0.505^{* * *} \\
(0.114)\end{array}$ \\
\hline$\left(u_{t}-u_{t}^{*}\right)^{2}$ & & $\begin{array}{l}-0.0235 \\
(0.0213)\end{array}$ & & $\begin{array}{l}0.0713^{*} \\
(0.0378)\end{array}$ \\
\hline$\Delta y_{t}$ & & $\begin{array}{c}-0.198^{* * *} \\
(0.0319)\end{array}$ & & $\begin{array}{l}-0.261 \\
(0.474)\end{array}$ \\
\hline$\Delta y_{t}^{2}$ & & $\begin{array}{r}-0.0332^{* * *} \\
(0.00630)\end{array}$ & & $\begin{array}{c}0.0229 \\
(0.0835)\end{array}$ \\
\hline S\&P Return, 3m & & $\begin{array}{l}-1.025 \\
(0.704)\end{array}$ & & $\begin{array}{l}-0.674 \\
(1.070)\end{array}$ \\
\hline Shiller PE Ratio & & $\begin{array}{l}0.0352^{* *} \\
(0.0145)\end{array}$ & & $\begin{array}{c}-0.134^{* * *} \\
(0.0295)\end{array}$ \\
\hline VIX Uncertainty & & $\begin{array}{c}0.0112 \\
(0.00759)\end{array}$ & & $\begin{array}{l}-0.0126 \\
(0.0144)\end{array}$ \\
\hline Short-Term Yield Volatility & & $\begin{array}{l}0.0353 \\
(0.407)\end{array}$ & & $\begin{array}{c}0.313 \\
(0.585)\end{array}$ \\
\hline Constant & $\begin{array}{c}0.679^{* * *} \\
(0.137)\end{array}$ & $\begin{array}{c}0.284 \\
(0.458)\end{array}$ & $\begin{array}{l}0.365^{* * *} \\
(0.0988)\end{array}$ & $\begin{array}{c}4.697^{* * *} \\
(0.688)\end{array}$ \\
\hline Observations & 95 & 95 & 64 & 64 \\
\hline Adjusted $R^{2}$ & 0.086 & 0.762 & 0.057 & 0.374 \\
\hline Type & minutes & minutes & minutes & minutes \\
\hline Sample & $2000 \mathrm{~m} 1-2011 \mathrm{~m} 12$ & $2000 \mathrm{~m} 1-2011 \mathrm{~m} 12$ & $2012 \mathrm{~m} 1-2019 \mathrm{~m} 12$ & $2012 \mathrm{~m} 1-2019 \mathrm{~m} 12$ \\
\hline Symmetry p-val & 0.099 & 0.909 & 00 & 00 \\
\hline$\hat{\pi^{*}}$ & 1.54 & 1.55 & 2.31 & 2.27 \\
\hline $\mathrm{SE}$ & $(0.29)$ & $(0.38)$ & $(0.24)$ & $(0.23)$ \\
\hline 95\% C.I. & {$[.97,2.15]$} & {$[1.21,2.5]$} & {$[1.88,2.32]$} & {$[1.7,2.29]$} \\
\hline
\end{tabular}

Because Greenbook forecasts are unavailable past 2015m12 we use IHS Markit/Macroeconomic Advisers forecasts for $2016 \mathrm{~m} 1$ onward. Standard errors (in parentheses) are robust to heteroskedasticity.

${ }^{*} p<0.10,{ }^{* *} p<0.05,{ }^{* * *} p<0.01$ 


\section{Table G11: Top 50 Trigrams and Bigrams from LM Dictionary}

\begin{tabular}{|c|c|c|c|c|c|}
\hline Bigrams with LM word & Count & Removed & Trigrams with LM word & Count & Removed \\
\hline price stability & 2334 & $\mathrm{X}$ & labor force participation & 429 & $\mathrm{X}$ \\
\hline question whether & 1185 & & current account deficit & 328 & $\mathrm{X}$ \\
\hline great deal & 1039 & & improvement labor market & 280 & \\
\hline labor force & 1017 & $\mathrm{X}$ & basis point cut & 182 & \\
\hline financial stability & 889 & $\mathrm{X}$ & decline unemployment rate & 175 & \\
\hline pretty good & 785 & & toward price stability & 150 & \\
\hline think good & 742 & & late last year & 150 & $\mathrm{X}$ \\
\hline without objection & 696 & & force participation rate & 147 & $\mathrm{X}$ \\
\hline good news & 651 & & greater reserve restraint & 142 & \\
\hline good deal & 610 & & tightening monetary policy & 136 & \\
\hline ask question & 535 & & consistent price stability & 126 & \\
\hline coffee break & 510 & $\mathrm{X}$ & price stability sustainable & 123 & \\
\hline downward pressure & 470 & & decline interest rates & 122 & \\
\hline answer question & 442 & & stability sustainable economic & 119 & \\
\hline much better & 433 & & question whether & 115 & \\
\hline force participation & 431 & $\mathrm{X}$ & tightening financial conditions & 110 & \\
\hline would argue & 412 & & discount rate cut & 107 & \\
\hline slower growth & 408 & & put downward pressure & 107 & \\
\hline slow growth & 391 & & foster price stability & 106 & \\
\hline one question & 384 & & price level stability & 106 & $\mathrm{X}$ \\
\hline financial crisis & 381 & & may ask question & 105 & \\
\hline improvement labor & 372 & & easing monetary policy & 104 & \\
\hline would better & 353 & & happy answer questions & 102 & \\
\hline tax cut & 348 & & progress toward price & 97 & \\
\hline would good & 345 & & price stability promote & 96 & \\
\hline good idea & 343 & & substantial improvement labor & 95 & \\
\hline second question & 342 & & commitment price stability & 93 & $\mathrm{X}$ \\
\hline account deficit & 331 & $\mathrm{X}$ & don think good & 92 & \\
\hline think question & 325 & & think would mistake & 92 & \\
\hline downward revision & 315 & & happy take questions & 91 & \\
\hline strong growth & 308 & & stability promote sustainable & 90 & \\
\hline progress toward & 298 & & without objection approved & 89 & \\
\hline think better & 298 & & cut funds rate & 88 & \\
\hline could easily & 287 & & one could argue & 88 & \\
\hline bad news & 275 & & effective federal funds & 88 & $\mathrm{X}$ \\
\hline question would & 266 & & claims unemployment insurance & 87 & $\mathrm{X}$ \\
\hline first question & 264 & & improvement labor markets & 83 & \\
\hline substantial improvement & 263 & & think would good & 83 & \\
\hline productivity gains & 261 & & exceptionally low levels & 83 & \\
\hline strength economy & 256 & & initial claims unemployment & 83 & $\mathrm{X}$ \\
\hline policy tightening & 254 & & think good idea & 81 & \\
\hline two questions & 253 & & downward pressure inflation & 80 & \\
\hline quantitative easing & 249 & $\mathrm{X}$ & objectives price stability & 80 & $\mathrm{X}$ \\
\hline best way & 245 & & labor force growth & 79 & \\
\hline economic weakness & 240 & & definition price stability & 77 & $\mathrm{X}$ \\
\hline remains strong & 240 & & let ask question & 77 & \\
\hline rate cut & 240 & & great deal uncertainty & 76 & \\
\hline get better & 239 & & good morning everyone & 76 & \\
\hline initial claims & 239 & $\mathrm{X}$ & lagged reserve accounting & 74 & \\
\hline
\end{tabular}

Notes: Bigrams and trigrams flagged as "removed" were considered neutral in the filtered LM dictionary, labeled as "Adjusted LM" - results reported in column (7) of Table 4. 
Table G12: Factual phrases in the LM Dictionary

\begin{tabular}{l|l} 
Economic Variables & Directional LM Words \\
\hline inflation & cease(d)(s)(ing) \\
price & curtail(s)(ed)(ing)(ment)(ments) \\
product & cut \\
unemployment & declin(d)(s)(ing) \\
employment & diminish(ed)(s)(ing) \\
gdp & disappear(ed)(ing)(ance)(ances) \\
output & ease(ing) \\
wage & hat(ed) \\
stock & loss(es) \\
retail & lag(s)(ged)(ging) \\
consumption & low \\
profit & negative(ly)(s) \\
pce & persist(s)(ed)(ence)(ent)(ing) \\
cpi & slow(ed)(er)(est)(ing)(ly) \\
volatility & advance(s)(ing) \\
deflation & attain(s)(ed)(ing)(ment)(ments) \\
payroll & gain(s)(ed)(ing) \\
wealth & great(er)(est)(ly) \\
nairu & positive(ly) \\
revenue & surpass(es)(ed) \\
growth & tighten(ing) \\
tax & \\
rate(s) & \\
policy & \\
job(s) & \\
monetary & \\
interest & \\
dollar & \\
funds &
\end{tabular}


Table G13: Cross-correlation table

\begin{tabular}{lcccccccc}
\hline \hline \multicolumn{1}{c}{ Variables } & All Text & Baseline & $\begin{array}{c}\text { Inflation } \\
\text { Text }\end{array}$ & $\begin{array}{c}\text { Slack } \\
\text { Text }\end{array}$ & $\begin{array}{c}\text { Opinion } \\
\text { Text }\end{array}$ & $\begin{array}{c}\text { Adjusted } \\
\text { LM }\end{array}$ & $\begin{array}{c}\text { No Fact } \\
\text { Phrases }\end{array}$ & Vader \\
\hline All Text & 1.000 & & & & & & & \\
Baseline & 0.999 & 1.000 & & & & & & \\
Inflation Text & 0.953 & 0.953 & 1.000 & & & & & \\
Slack Text & 0.921 & 0.920 & 0.942 & 1.000 & & & & \\
Opinion Tex & 0.870 & 0.870 & 0.765 & 0.749 & 1.000 & & & \\
Adjusted LM & 0.973 & 0.973 & 0.929 & 0.890 & 0.881 & 1.000 & & \\
No Fact Phrases & 0.967 & 0.968 & 0.918 & 0.880 & 0.899 & 0.983 & 1.000 & \\
Vader & 0.605 & 0.605 & 0.528 & 0.494 & 0.539 & 0.580 & 0.571 & 1.000 \\
\hline \hline
\end{tabular}


Figure G1: Public Communications

(a) Minutes of FOMC Meetings

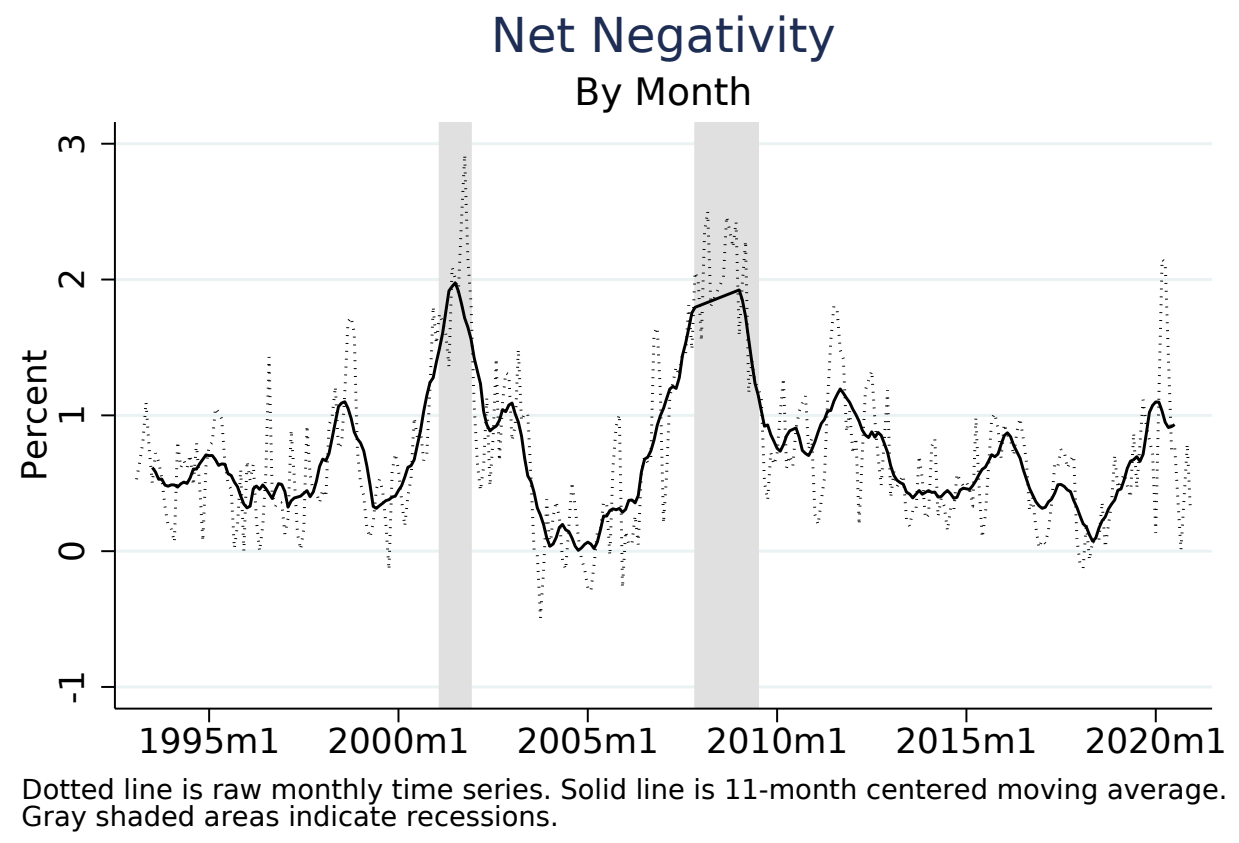

(b) Public Speeches of FOMC Members

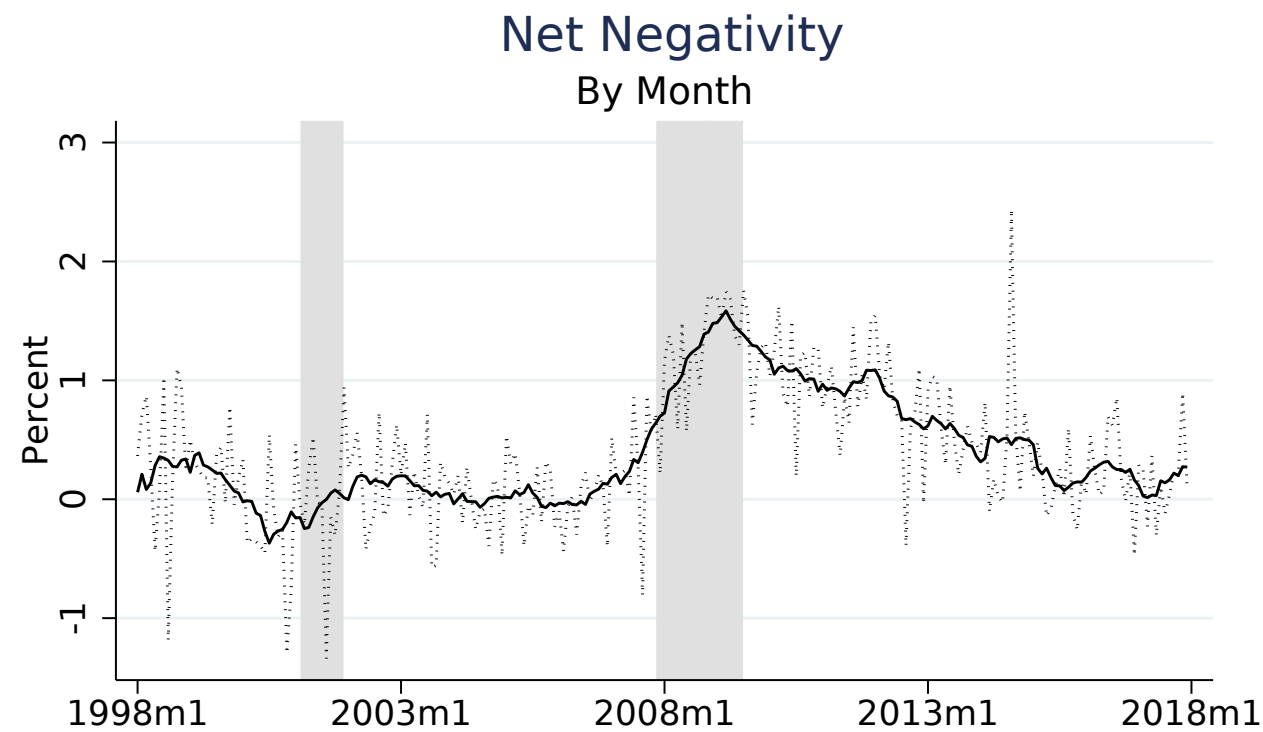

Dotted line plots coefficients on time dummies from regression with speaker fixed effects. Solid line is 11-month centered moving average.

Gray shaded areas indicate recessions. 
Figure G2: Transcripts of FOMC Meetings

(a) Baseline, Econ-Filtered Text

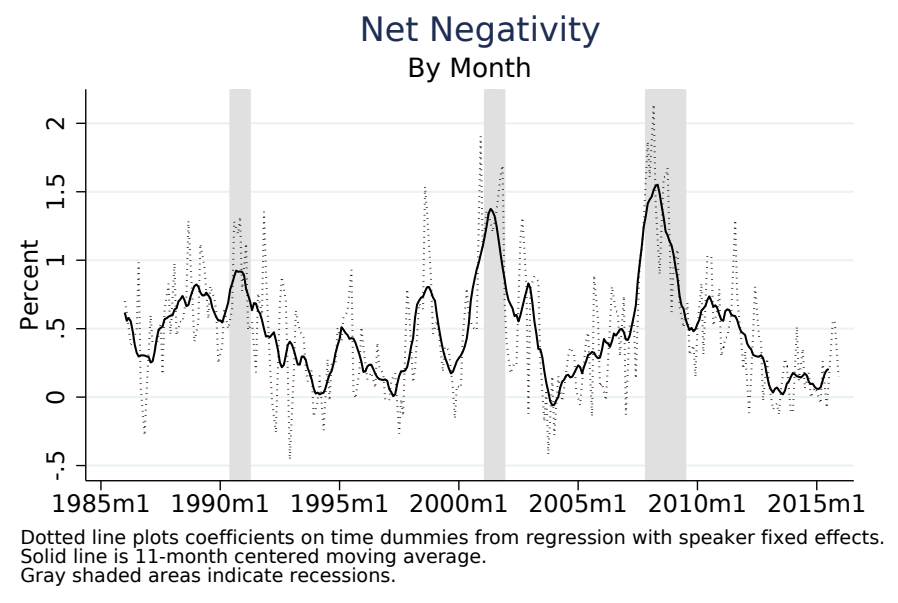

(c) Inflation-Filtered Text

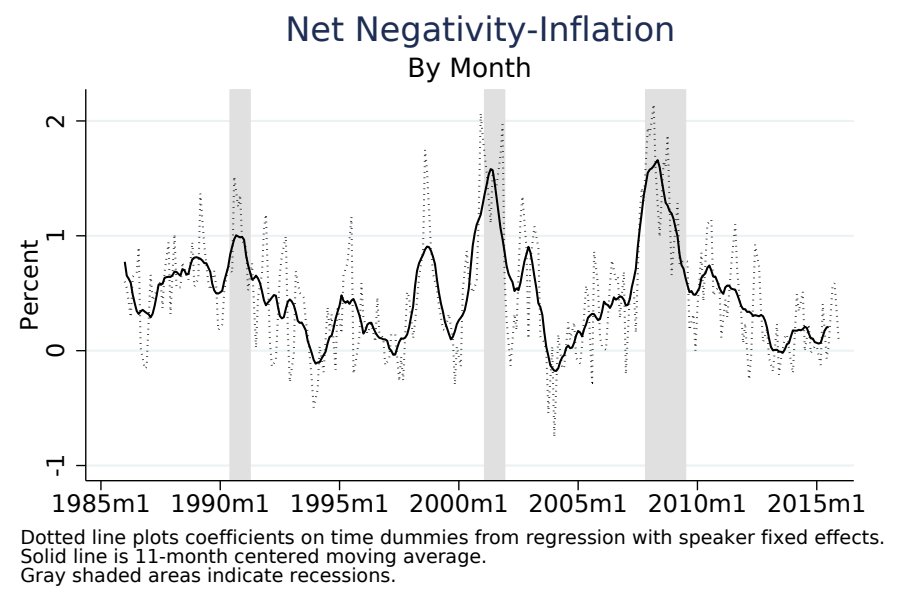

(b) All Text

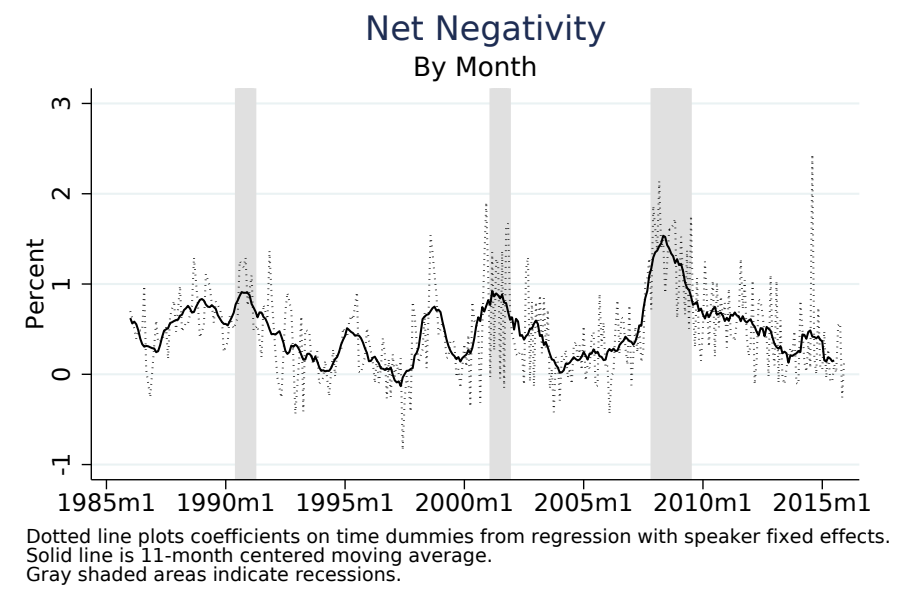

(d) Slack-Filtered Text

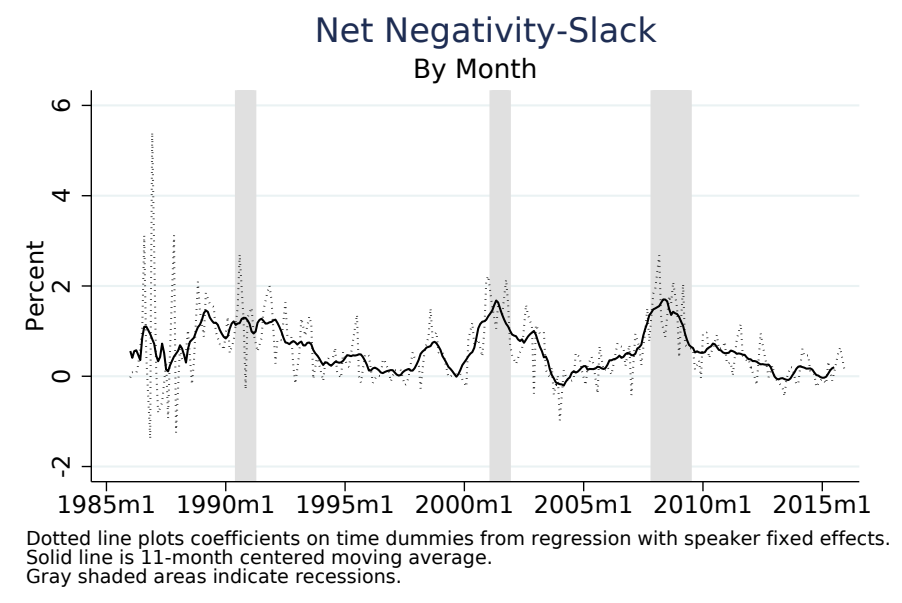


Figure G3: Near-Term Inflation Forecasts Since 2000

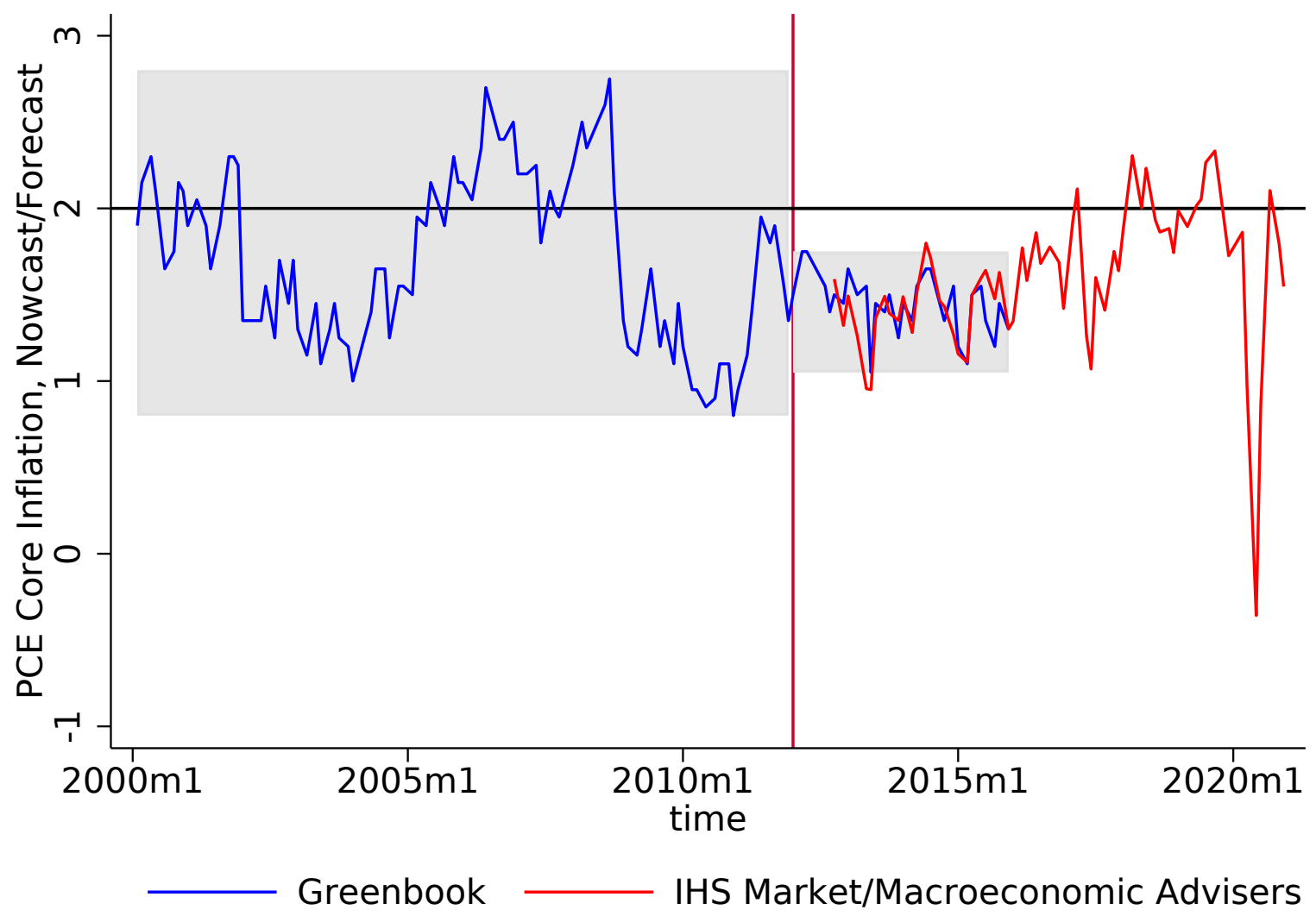

Notes: Gray shaded areas indicate the ranges of Greenbook inflation forecasts over the 2000-2011 and 2012-2015 periods. 